\title{
EVALUATION OF NOISE ANALYSIS \\ FOR THE ENRICO FERMI REACTOR
}

\author{
M. L. Barch \\ A. E. Klickman
}

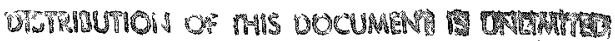




\section{DISCLAIMER}

This report was prepared as an account of work sponsored by an agency of the United States Government. Neither the United States Government nor any agency Thereof, nor any of their employees, makes any warranty, express or implied, or assumes any legal liability or responsibility for the accuracy, completeness, or usefulness of any information, apparatus, product, or process disclosed, or represents that its use would not infringe privately owned rights. Reference herein to any specific commercial product, process, or service by trade name, trademark, manufacturer, or otherwise does not necessarily constitute or imply its endorsement, recommendation, or favoring by the United States Government or any agency thereof. The views and opinions of authors expressed herein do not necessarily state or reflect those of the United States Government or any agency thereof. 


\section{DISCLAIMER}

Portions of this document may be illegible in electronic image products. Images are produced from the best available original document. 
. 


\section{FOREWORD}

This report is one of a series of reports on the low-power (up to $1 \mathrm{Mwt}$ ) and high-power (up to $200 \mathrm{Mwt}$ ) nuclear testing of the Enrico Fermi reactor. The Nuclear Test Program is planned, directed, and evaluated by Atomic Power Development Associates, Inc. (APDA). The tests a re conducted by Power Reactor Development Company (PRDC). The reactor proper is owned and operated by PRDC. The steam generators and electrical generation facilities are owned by The Detroit Edison Company (DECo).

The authors gratefully acknowledge the assistance of H. A. Wilber and P. M. Harrigan of Power Reactor Development Company in planning and conducting the nuclear testing of the Enrico Fermi reactor; of Dr. J. A. Thie, consultant, in the initial planning, analysis techniques, and interpretation of results; and of $R$. W. Hyndman of Argonne National Laboratory, Idaho Division, in digitizing the original recordings. 

TABLE OF CONTENTS

$\underline{\text { Page }}$

LIST OF ILLUSTRATIONS ....................... vii

LIST OF TABLES $\ldots \ldots \ldots \ldots \ldots \ldots \ldots \ldots \ldots \ldots \ldots \ldots \ldots \ldots$

SUMMARY $\ldots \ldots \ldots \ldots \ldots \ldots \ldots \ldots \ldots \ldots \ldots \ldots \ldots \ldots \ldots \ldots$

I. INTRODUCTION $\ldots \ldots \ldots \ldots \ldots \ldots \ldots \ldots \ldots \ldots \ldots \ldots \ldots \ldots \ldots \ldots$

II. DESCRIPTION OF THE ENRICO FERMI REACTOR .......... 5

III. GENERAL DISCUSSION OF NOISE ANALYSIS ............ 11

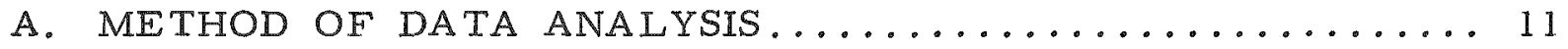

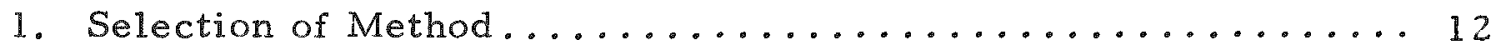

2. Description of Method ....................... 12

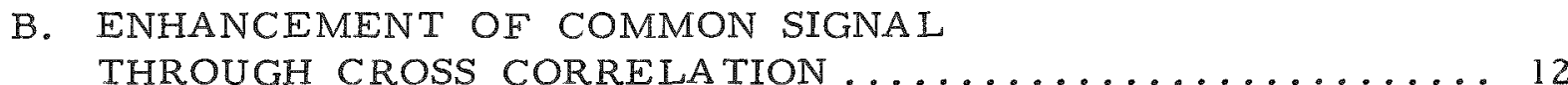

C. USING DATA ANALYSIS RESULTS TO
ATTAIN SYSTEM CHARACTERISTICS ................ 13

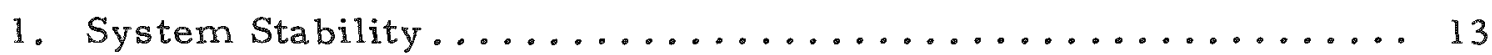

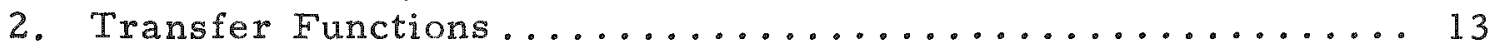

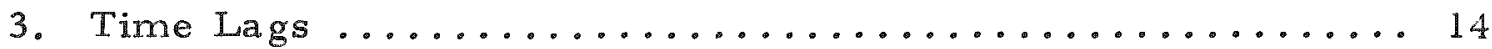

D. EVALUATION OF ACCURACY OF RESULTS ............. 15

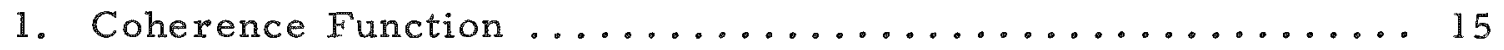

2. Equations for Computation of Errors ............... 15

a. Power Spectral Density Estimates ................. 15

b. Cross Spectral Density Estimates ............... 16

IV. DATA RECORDING AND REDUCTION ................. 17

A. SELECTION OF PARAMETERS .................. 17

B. REACTOR OPERATING CONDITIONS

AND EXPERIMENTAL PROCEDURE................. 17

C. DATA RECORDING......................... 20

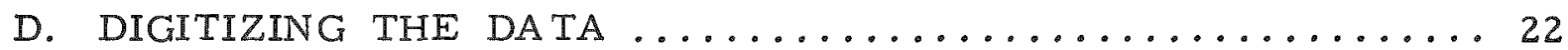

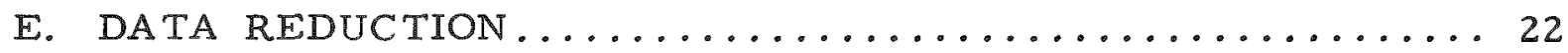

F. NOTES ON QUALITY AND INTERPRETATION OF DATA .... 23

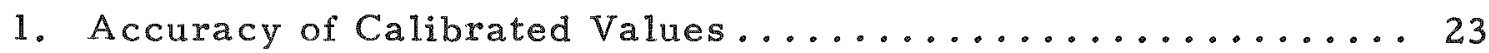

2. Reactor Power Signals........................ 23

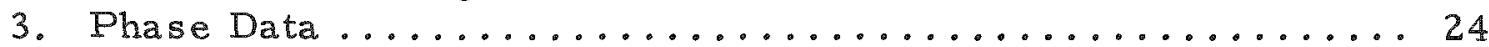

4. Distinction between Terms "Reactor" and "Core" ........ 24 


\section{TABLE OF CONTENTS (Continued)}

$\underline{\text { Page }}$

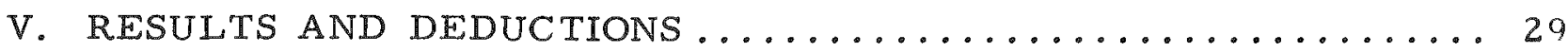

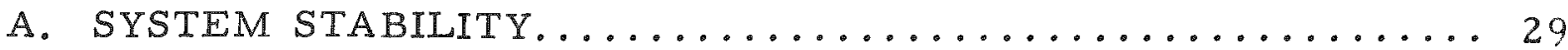

B. POWER SPECTRAL DENSITY FUNCTIONS .............. 29

1. Reactor Power PSD Function ..................... 42

2. PSD Measurements of Outlet Temperature ............ 42

C. TRANSFER FUNCTIONS ...................... 45

1. Flow to Inlet Temperature ................... 45

2. Sodium Flow to Reactor Power ................... 45

3. Inlet Temperature to Reactor Power ................ 51

4. Core Outlet Temperatures to Reactor Outlet Temperature ... 51

a. Computation of Core Outlet Temperature Spectrum ...... 51

b. Core Outlet Temperature to $\mathrm{R}$ sactor Outlet

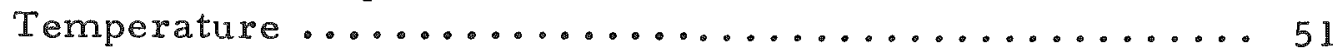

5. Core Outlet Temperature to Plenum Outlet Temperature .... 54

6. Reactor Inlet to Core, Reactor, and Plenum

Outlet Temperatures ........................ 54

7. Reactor Outlet to Plenum Outlet Temperature ........... 57

8. Low Frequency Asymptotic Value of Temperature

Transfer Functions ......................... 57

D. DETERMINATION OF LAGS FROM PHASE CURVES........ 57

E. COHERENCE FUNCTION ....................... 68

F. ESTIMATION OF ERRORS ON XSD FUNCTIONS........... 70

VI. CONCLUSIONS .............................. 73

REFERENCES ............................... 75

APPENDIX A. DERIVATION OF EQUATIONS OF PHASE SHIFTS DUE TO TIME DISPLACEMENT BETWEEN PARAMETERS . . 77

APPENDIX B. DETERMINATION OF CORE OUTLET TEMPERATURE SPECTRUM ....................... 81 


\section{LIST OF ILLUSTRA TIONS}

Figure No.

Title

Page

1 Perspective View of the Enrico Eermi Reactor ........... 6

2 Reactor Cross Section ....................... 7

3 Power Spectral Density of Reactor Power, 56 Mwt Operation ... 25

4 Power Spectral Density of Reactor Power, 88 Mwt Operation ... 26

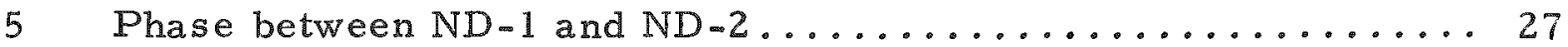

6 Cross Spectral Density and Transfer Function for Loop 3

Sodium Flow and Reactor Power, 0.05 Mwt ........... 30

7 Cross Spectral Density for Reactor Inlet Temperature

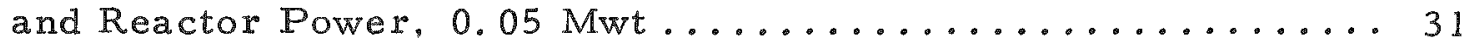

8 Power Spectral Density of Inlet Sodium Flow ........... 32

9 Power Spectral Density of Reactor Inlet Temperature . . . . . . 33

10 Cross Spectral Density for Reactor Inlet Temperature and

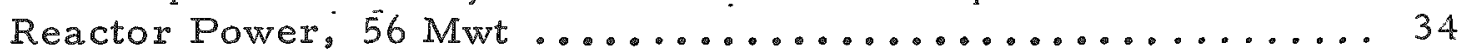

11 Cross Spectral Density for Reactor Outlet Temperature

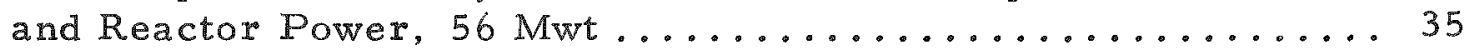

12 Cross Spectral Density for Plenum Outlet Temperature and Reactor Power, $56 \mathrm{Mwt} \ldots \ldots \ldots \ldots \ldots \ldots \ldots \ldots \ldots \ldots . \ldots \ldots$

13 Cross Spectral Density and Transfer Function for Loop 1 Sodium Flow to Reactor Outlet Temperature, $56 \mathrm{Mwt} \ldots . . . . .37$

14 Cross Spectral Density for Reactor Inlet and Outlet

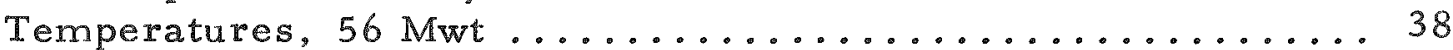

15 Cross Spectral Density for Reactor Inlet Temperature and Reactor Power, $88 \mathrm{Mwt} \ldots \ldots \ldots \ldots \ldots \ldots \ldots \ldots \ldots \ldots \ldots \ldots . \ldots \ldots$

16 Cross Spectral Density for Plenum Outlet Temperature and Reactor Power, $88 \mathrm{Mwt}$ 


\section{LIST OF ILLUSTRATIONS (Continued)}

Figure No.

Title

Page

17 Cross Spectral Density and Transfer Function for Loop 3 Sodium Flow and Plenum Outlet Temperature, $88 \mathrm{Mwt}$...... 41

18 Power Spectral Density of Reactor Power, 0.05 Mwt ...... 43

19 Power Spectral Density of Upper Plenum Temperatures..... 44

20 Cross Spectral Density and Transfer Function for Loop 3 Sodium Flow and Reactor Inlet Temperatures, $0.05 \mathrm{Mwt}$.... 46

21 Cross Spectral Density and Transfer Function for Loop 1 Sodium Flow and Reactor Inlet Temperatures, 56 Mwt ......

22 Cross Spectral Density for Loop 3 Sodium Flow and Reactor Inlet Temperature, $88 \mathrm{Mwt} \ldots \ldots \ldots \ldots \ldots \ldots \ldots \ldots \ldots \ldots$

23 Cross Spectral Density and Transfer Function for Loop 1

Sodium Flow and Reactor Power, $56 \mathrm{Mwt} \ldots \ldots \ldots \ldots \ldots$

24 Cross Spectral Density and Transfer Function for Loop 3

Sodium Flow and Reactor Power, $88 \mathrm{Mwt} \ldots \ldots \ldots \ldots \ldots \ldots$

25 Transfer Function from Reactor Inlet Temperature to

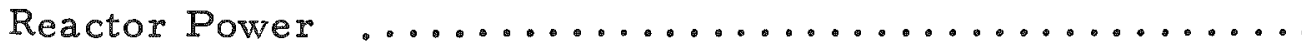

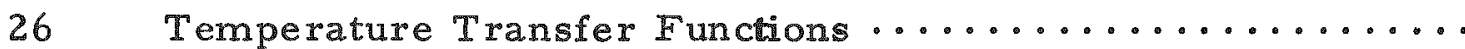

27 Cross Spectral Density for Reactor Inlet and Plenum Outlet

Temperatures, $88 \mathrm{Mwt}$

28 Cross Spectral Density for Reactor Outlet and Plenum Outlet Temperatures, $56 \mathrm{Mwt}$

29 Phase Curves from 0.05 Mwt Cross Spectral Density

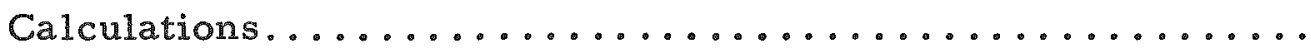

30 Phase Curves from 56 Mwt Cross Spectral Density

Calculations (4 sheets)

31 Phase Curves for 88 Mwt Cross Spectral Density

Calculations ( 3 sheets) 


\section{LIST OF ILLUSTRATIONS (Continued)}

Figure No.

Title

Page

A. 1 Development and Net Phase Shift for Two Transport Lags.... is

A. 2 Study of Phase Function with Two Transport Lags......... 0

\section{LIST OF IAELES}

Table

Title

Page

I Dimensions and Composition of Core and Blanket Regions ...... 8

II Sodium Volume in Various Sections of Primary System ........ 9

III Specifications of Parameters ..................... 18

IV Primary System Conditions .................... 19

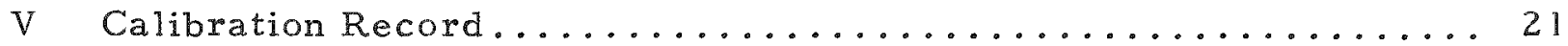

VI Summary of Transfer Functions .................... 53

VII Measured Iime Lags between Parameters............... 67

VIII Coherence Functions ......................... 69

IX Estimation of Errors on XSD Functions $\ldots \ldots \ldots \ldots \ldots \ldots \ldots$ 


\section{SUMMARY}

An evaluation was made of the potential of noise measurement for determining useful information about the Enrico Fermi Atomic Power Reactor (EFAPP). The evaluation was made by reducing and analyzing sample data obtained from the heat-generating half of the primary system at three power levels: $0.05 \mathrm{Mwt}, 56 \mathrm{Mwt}$, and $88 \mathrm{Mwt}$.

The analysis of results covered the following aspects:

- Search for indications of instability

- Examination of power spectral distribution of various signals

- Measurement of the amplitude of the transfer function between various parameters

- Measurement of the time lag between the various parameters

- Measurement of the relative amount of coherent signal between input and output parameters.

The study indicates that through noise analys is meaningful results can be obtained in each of these aspects and points up changes in recording techniques and selection of parameters which could lead to improved accuracy. reliability, and understanding of future work.

that

The most significant specific results from this preliminary study are

- Flow variation is the major contributor to power fluctuation

- The power spectral density of core power is greater under 2-loop (Loops 1 and 2) than 3-loop operation

- Measured transfer functions and time lags support a nonmixing-type flow in the upper plenum with little or no channeling. 


\section{INTRODUCTION}

Inherent in the noise or undulating portion of signals from anv system are characteristics of the system. A field of specialized techniques has been developed to extract the system characteristics from these signals: [hat field is generally classified as noise analysis.

During the spring and summer of 1966 an investigation was made to determine the applicability of noise analysis to the Enrico Fermi Atomic Power Plant. The investigation concentrated on analyzing in depth a small amount of data in order to illustrate the potential of this technique. The investigation was based on data from the heat-generating portion of the primary loop at three power levels: $0.05 \mathrm{Mwt}, 56 \mathrm{Mwt}$, and $88 \mathrm{Mwt}$. Data were recorded on inlet and outlet temperatures, sodium flow in one loop, and reactor power. Data recordings were made on magnetic tape; data processing was performed by a digital computer using an existing program. 


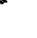




\section{DESCRIPTION OF THE ENRICO FERMI REACTOR}

The Enrico Fermi reactor, with its associated structures, is shown in perspective in Figure 1. The reactor is contained in a stainless steel vessel sealed at the top by a rotating shield plug which supports the control mechanisms, the holddown mechanism, and the fuel handling mechanism; the reactor vessel is contained inside the primary shield tank. The reactor is of the fast breeder type, cooled by sodium and operated at essentially atmospheric pressure. The maximum reactor power with the first core loading (Core A) is $200 \mathrm{Mwt}$.

The core and blanket section consists of square subassemblies arranged to approximate a cylinder about 80 inches in diameter and 70 inches high. The core is contained in the central portion of the subassemblies and approximates a right cylinder 31 inches in diameter and 31 inches high. It is axially and radially surrounded by breeder blankets. The fuel consists of zirconium-clad pins containing $U-10 \mathrm{w} / 0$ Mo alloy with the uranium enriched to $25.6 \mathrm{w} / 0 \mathrm{U}-235$. A core section of a subassembly is made up of 140 fuel pins containing a total of 4.75 kilograms of $U-235$. The blanket is depleted $U-3$ w/o Mo alloy. More specific information is given in Table I.

The reactor cross section, shown in Figure 2 , indicates the placement of individual components within the reactor vessel. The central 149 lattice positions are occupied by core and inner radial blanket subassemblies, the neutron source, and the 10 control and safety rod channels. All these positions are cooled with upward flowing sodium which is fed by the 14 -inch lines from the three primary pumps through the high-pressure plenum.

The lattice positions surrounding the inner radial blanket comprise the outer radial blanket area and form an annlar region whose top and bottom are at the same elevation as the top and bottom of the inner radial blanket. Surrounding the outer radial blanket are lattice positions for the stainless steel subassemblies used to provide thermal and neutron shielding. The outer radial blanket and shielding lattice positions are cooled with sodium flowing upward from the low pressure plenum, which is fed through 6-inch lines from the three primary sodium pumps. This sodium mixes in the upper plenum with the sodium from the core. From the upper plenum the sodium flows to three intermediate heat exchangers and thence to the suction side of the primary pumps.

The reactor is controlled by two control rods and seven safety rods using electromechanical drives mounted to the rotating plug. The rods are of the poison type, containing boron carbide enriched in boron-10. Of the two control rods, one is for regulating purposes and the other for shimming. The seven safety rods are used only to provide shutdown reactivity and are held 


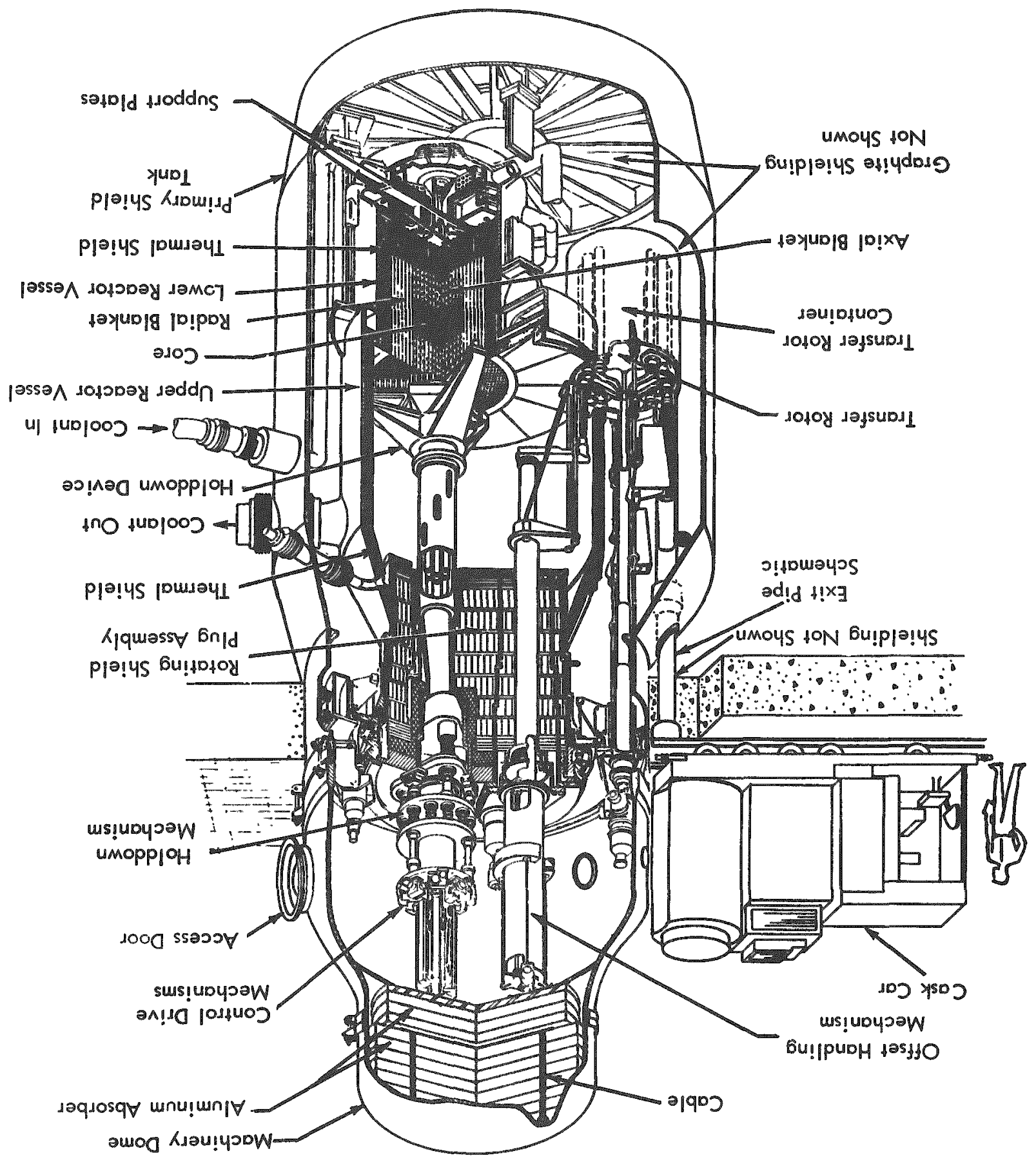




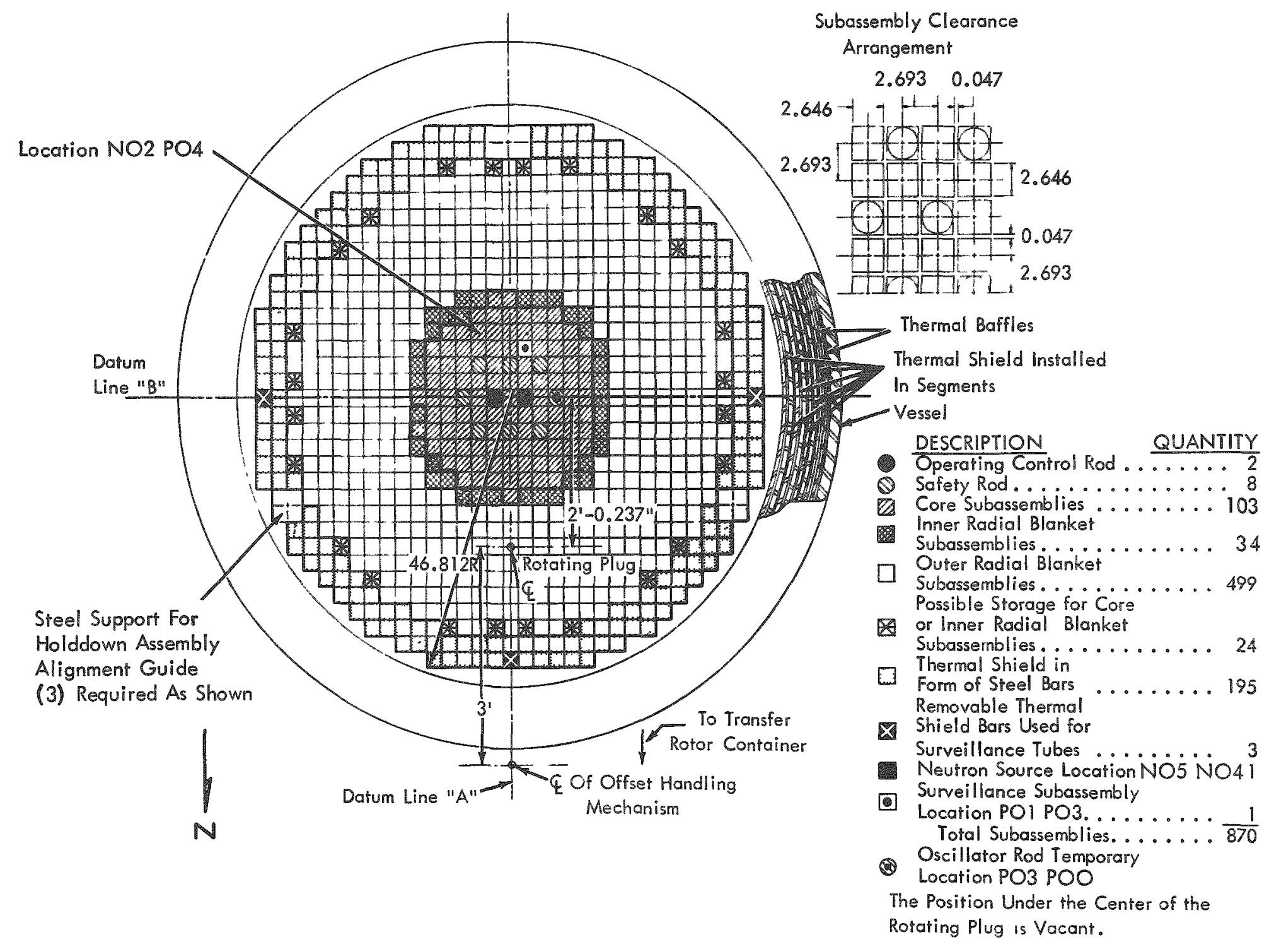

FIG. 2 REACTOR CROSS SECTION 


\section{TABLE I - DIMENSIONS AND COMPOSITION OF}

CORE AND BLANKET REGIONS

Subassembly

Cross section

Outside dimension, ${ }^{a}$ in.

Wall thickness (stainless steel), in.

Space between subassemblies, in.

Number of subassemblies or sections $b$

Fuel Element

Shape

Cladding material

OD of cladding, in.

Thickness of cladding, in.

Uranium diameter, in.

Uranium length, in.

Pitch (square), in.

Pins or rods per subassembly

\begin{tabular}{|c|c|c|}
\hline Core Section & $\begin{array}{l}\text { Axial } \\
\text { Blanket } \\
\text { Section } \\
\end{array}$ & $\begin{array}{c}\text { Inner and Outer } \\
\text { Radial Blanket } \\
\text { Section } \\
\end{array}$ \\
\hline Square & Square & Square \\
\hline 2.646 & 2.646 & 2.646 \\
\hline 0.096 & 0.096 & 0.096 \\
\hline 0.047 & 0.047 & 0.047 \\
\hline 103 & $206^{c}$ & 533 \\
\hline
\end{tabular}

Fuel Section

Composition, v/o

Uranium

Molybdenum

Zirconium

Stainless Steel

Sodium

Heat transfer surface, $f t^{2}$

Uranium alloy composition

U-235 enrichment, w/o

$\begin{array}{rcc}27.3 & 25.6 & 40.0 \\ 5.5 & 1.4 & 2.3 \\ 4.6 & - & - \\ 17.4 & 16.5 & 18.6 \\ 45.2 & 56.5 & 39.1 \\ 1545 & 455^{\mathrm{C}} & 7923 \\ 10 \mathrm{w} / \mathrm{O} \text { Mo U }-3 \mathrm{w} / \mathrm{O} \mathrm{Mo} & \mathrm{U}-3 \mathrm{w} / \mathrm{OMO} \\ 25.6 & 0.35 & 0.35\end{array}$

NOTES

a. Does not include the spacer rods

b. There are 103 core, 34 inner radial blanket, and 499 outer radial blanket subassemblies

c. Total for both axial blanket sections 
just above the axial blanket during operation of the reactor. Upon a scram signal, each safety rod is delatched from its drive and fired into the core with a compressed spring.

In dealing with transport delays caused by a fluid circulating through a system, it is important to know the volume of fluid in the various sections. The sodium volumes pertinent to this study are listed in Table II.

Additional information concerning the reactor design may be found in the Enrico Fermi Hazards Summary Report. 1

TABLE II - SODIUM VOLUME IN VARIOUS SECTIONS OF PRIMARY SYSTEM

\section{Section}

Loop 1 14-Inch Line

Loop 2 14-Inch Line

Loop 314 -Inch Line

Reactor Inlet Plenum

Blanket Inlet Plenum

Reactor

Blanket

Upper Plenum
Volume, $f t^{3}$

59

64

56

158

28

4

6

1143 


\section{GENERAL DISCUSSION OE NOISE ANALYSIS}

The objectives of noise analysis are to ascertain system characteris tics and stability and to determine the transfer function and time lags between various parameters. The technique is based upon analyzing the system's inherent fluctuations rather than inducing a parametric variation. Results and conclusions are based upon the examination of the frequency distribution of the signals; if the frequency distribution of a signal indicates a resonance and if this resonance is a positive function of power level, then a system instability is indicated.

A transfer function between two parameters is the amplitude and phase response of the "driven" parameter to a unit amplitude and zero phase perturbation of the "driver" parameter. In noise analysis, the amplitude at a frequency is the quotient of amplitudes of driven and driver signals at that frequency; the phase is the difference between respective measured phases.

The time lag is the time required for information to travel from one point in the system to another. This time lag should not be confused with time constants. For example, if a unit step in temperature is introduced at one point of a system, the time lag is the time required for the leading edge of the step to reach the down-line point, and the time constant associated with the down-line point is the time required for that point to attain $63 \%$ of its new value after the leading edge of the step reaches it. The time constant will be determined from the amplitude of the transfer function measurement; the time lag manifests itself as additional terms in the phase relationship between the two parameters.

\section{A. METHOD OF DATA ANALYSIS}

\section{Selection of Method}

The most familiar method for determining the frequency distribution of a signal is Fourier analysis; however, the inherent fluctuations of a system are nearly random in nature, so the amount of power contained at any one frequency is nearly zero. Consequently, to obtain meaningful results from a rea sonable amount of data, the signals must be analyzed and averaged over a band of frequencies. This cannot be done by Fourier analysis.

One method for analyzing noise is by passing the signal through a bandpass filter and measuring the power of the filter output. This method is readily carried out on an analog computer. For analysis by a digital computer, the most efficient method is to Fourier-transform the correlation function of 
the signal. All analyses reported here were performed on a digital computer using the latter method.

\section{Description of Method}

A full development of this data reduction method is beyond the scope of this report, but the brief discussion below will define the terms and outline the procedure.

The computation is carried out in two parts: determination of the correlation function and Fourier transformation of the correlation function. The correlation function is most easily described algebraically. Given two sets of data, $A$ and $B$, represented as two series of $N$ discrete, equally timespaced values, the correlation function is:

$$
\begin{aligned}
C F(L) & =\frac{1}{N-L} \sum_{n=0}^{N-L} A(n) B(n+L) \text { for } L \geq 0 \\
& =\frac{1}{N+L} \sum_{n=0}^{N+L} A(n-L) B(n) \text { for } L<0
\end{aligned}
$$

where $L$ varies from zero to plus and minus a desired integer value. The accuracy of the Fourier transform depends inversely upon $L / N$; usually $L$ is $5 \%-10 \%$ of $\mathrm{N}$ (the lower value was used throughout this study).

The Fourier transform of the correlation function is the power contained in the product of the two original data sets over a band of frequencies divided by the width of the frequency band. The results are called spectral density estimates or, more simply, spectral densities. Spectral densities are computed for frequencies from $1 /(2 \mathrm{~L} \Delta \mathrm{t})$ to $1 /(2 \Delta \mathrm{t})$ at increments of $1 /(2 \mathrm{~L} \Delta \mathrm{t})$ ( $\Delta t$ is the time between data points). The effective bandwidth is $1 /(\mathrm{L} \Delta \mathrm{t})$.

The analysis can be performed on a single data set by letting $B(n)$ equal $A(n)$. In this case, the correlation function is called autocorrelation and the spectral density estimates are called power spectral densities (PSD's). In contrast, when the analysis is performed on two data sets, the correlation function is called cross correlation and the spectral density estimates are called cross spectral densities (XSD's).

\section{B. ENHANCEMENT OF COMMON SIGNAL THROUGH CROSS CORREIAATION}

In many systems, including nuclear reactors, output parameters are a composite effect from several inputs; e.g. , reactor outlet temperature fluctuations reflect both the inlet temperature fluctuations and flow fluctuations. 
To measure transfer functions by noise analysis in such systems, a means must be found which can separate the output parameter into components so that only the portion which is the response to a particular input parameter is used. If the various input parameters are not interrelated, the output signal can be separated into components by using only the portion it has in common with each input signa1. This is accomplished by the cross-spectral-density technique of data analysis.

In the cross-correlation method of obtaining cross spectral densities, components in common between two signals will increase as the product of their common-signal amplitudes and the square of data length, whereas components not in common will increase as the sum of their amplitudes multiplied by a constant and the data length. (This constant is directly related to the fraction of the total signal which is not related between the two signals.) Thus, the common signals are enhanced by cross correlation.

Quantitatively, it is nearly impossible to estimate when the data length is sufficient that the common signal portion of the cross-correlation analysis exceeds the nonrelated portion by a specified amount; however, the quality of an XSD can be estimated. A special function called coherence has been developed which measures the common signal function between two parameters. Equations have been derived relating accuracy of XSD with coherence. These functions are discussed later in this chapter.

\section{USING DATA ANALYSIS RESULTS TO}

OBTAIN SYST EM CHARACTERISTICS

\section{System Stability}

The search for indications of system instability consists of examining PSD and XSD functions for humps or resonances; however, for a resonance to be a prognostication of an instability, it must increase with power level. Resonances may exist under certain flow conditions and power levels, but if they do not increase with power level they are not indicative of an instability.

If the resonance exists between two measured parameters, it will be seen as a large hump on the XSD between those two parameters. This can be a great aid in selecting possible causes of a resonance.

\section{Transfer Functions}

A reactor system is very tightly coupled, and nearly every signal is a composite of influences from several parameters. Under these conditions, analyzing data by the cross spectral density technique is essential for measuring transfer functions. The transfer function between two signals can be obtained from the cross-spectral-density technique, since the amplutide of a transfer function from $A$ to $B$ is the cross spectral density between them divided 
by the power spectral density of $A .2$ The power spectral density by its very nature has zero phase for all frequencies; thus, the phase of the transfer function is the phase of the cross spectral density function.

\section{Time Lags}

One of the goals of these analyses is the determination of the time lag between the various signals. If data are very clean and highly correlated, the lag corresponds to the displacement of the maximum of the cross-correlation function from zero. However, when high noise levels and low correlations are encountered, as with these data, an alternate method of analyzing the phase function from the Fourier analysis must be used.

If two sets of data are correlated but displaced in time, the phase relationship will contain a term

$$
\text { phase }=2 \pi \text { (time lag) (frequency) }
$$

which, of course, is linear and passes through the origin. The relationship becomes more complicated if two time lags are involved

$$
\text { phase }=2 \pi f T_{1}+\arctan \frac{\sin 2 \pi f\left(T_{2}-T_{1}\right)}{a / b+\cos 2 \pi f\left(T_{2}-T_{1}\right)}
$$

where

$T_{1}$ and $T_{2}$ are the two time lags

$a$ is relative amplitude corresponding to lag $T_{1}$

$\mathrm{b}$ is relative amplitude corresponding to $\operatorname{lag} \mathrm{T}_{2}$

The derivation of these equations and a brief discussion of their interpretation are given in Appendix A. As shown in this appendix, both above expressions have negative signs. However, the convention adopted throughout the remainder of the report is that the phase is measured clockwise from input signal to output signal; thus, phase curves will be in first rather than fourth quadrants, and time lags will be positive slopes on these curves.

When the phase relations hip between two functions is computed, it is possible to determine only that fraction of a cycle the one differs from the other, and it is impossible to calculate how many whole-cycle phase shifts exist in addition. For cases of a time lag between signals, the number of whole cycles is very important. The procedure used for determining the lag between two signals consisted of empirically adding unit circles to segments of the computed phases until the best linear function was found. 


\section{EVALUATION OF ACCURACY OF RESULTS}

Since noise analysis is based upon extracting information from near random fluctuations, the usual equation relating the accuracy of estimates with length of recording apply. This equation states that the standard error of a power spectral density estimate is inversely proportional to the square root of the product of the total recording time and the bandwidth. ${ }^{3}$

The accuracy of a cross spectral density estimate has an additional factor which reflects the success of filtering out the common signal between the two parameters. If each of the two parameters contains no other signal, the accuracy of the $\mathrm{XSD}$ is the same as a corresponding PSD, i. e., $1 /(\mathrm{T} \Delta \mathrm{f})^{1 / 2}$. As the fraction of additional signal increases, the accuracy becomes poorer. Thus, the first step in estimating the accuracy of an XSD must be the determination of the fraction of common signal between the two parameters. A technique has been developed for computing this fraction as a function of frequency. The square of the fraction of common signal is called coherence; the variation of the squared fraction with frequency is called the coherence function.

\section{Coherence Function}

Consider a multiple input system in which $A$ is one of the inputs, $O$ is the total output, and $B$ is the fraction of the output due to $A$. Note that the transfer function from $B$ to $A$ will be the inverse of the transfer function from $A$ to $B$, and thus the product of these two transfer functions should be unity. Using data from noise of a multiple input system, the transfer function from $A$ to $B$ is computed by dividing the XSD between $A$ and $O$ by the PSD of $A$. If $B$ (the portion of the output due to $A$ only) could be directly measured, the transfer function from $B$ to $A$ would be the XSD divided by the PSD of $B$. The product of these two transfer functions will be unity (assuming the XSD between $A$ and $O$ completely filters out the extraneous portion of the output). But if now, instead, the PSD of $O$ is used in place of the PSD of $B$, the product of the two transfer functions will be less than unity; it will be the fraction of common signal power to total power in the output signal. This is the coherence function.

\section{Equations for Computation of Errors}

\section{a. Power Spectra1 Density Estimates}

The standard error of a PSD was previously stated to be $1 /(\mathrm{T} \Delta \mathrm{f})^{1 / 2}$. Reference 4 gives an equivalent expression using quantities from the correlation function:

$$
\sigma=\sqrt{\frac{\text { Number of Lags }}{\text { Total Number of Points }}}
$$




\section{b. Cross Spectral Density Estimates}

Bendat 5 develops the equations for the amplitude and phase errors of transfer function for systems having multiple inputs. These equations for the case of incoherent inputs with 1000 points of data and 95 per cent certainty (which are directly applicable to the APDA date) are

$$
\begin{aligned}
& E^{2}=0.006\left(1-\gamma^{2}(f) \frac{\operatorname{PSD}_{0}(f)}{\operatorname{PSD}_{A}(f)}\right. \\
& \Delta \phi=\sin ^{-1}\left(\frac{E(f)}{T F(f)}\right)
\end{aligned}
$$

where

$$
\begin{aligned}
\gamma^{2}(f) & =\text { coherence function } \\
\mathrm{PSD}_{O} & =\text { PSD of total output } \\
\mathrm{PSD}_{\mathrm{A}} & =\text { PSD of input parameter A } \\
\mathrm{TF}(f) & =\frac{\mathrm{XSD}(\mathrm{f})}{\mathrm{PSD}_{\mathrm{A}}(\mathrm{f})} \\
\mathrm{XSD} & =\mathrm{XSD} \text { between total output signal and input signal A. } \\
\mathrm{E} & =\text { transfer function amplitude error } \\
\Delta \phi & =\text { transfer function phase error }
\end{aligned}
$$

Transformation of the amplitude error equation to a XSD amplitude error equation can be accomplished by taking partial derivatives of the transfer function and approximating the partial derivative with PSD by zero. The expression for fractional error, $\epsilon$, in XSD amplitude then becomes:

$$
\epsilon \quad=\frac{\left(0.006\left(1-\gamma^{2}(f)\right) \operatorname{PSD}(f) \operatorname{PSDA}_{A}(f)\right)^{1 / 2}}{\operatorname{XSD}(f)}
$$




\section{DATA RECORDING AND REDUCTION}

The overall plan was to obtain the sample sets of data by recording the variation of selected parameters during reactor operation, transform these data to a form suitable for digital computer input, reduce the data using the standard technique of Fourier-transforming the autocorrelation and crosscorrelation functions, and examine the results, thereby illustrating both the technique and type and quality of results. This section gives a detailed description of all but the last of these steps.

\section{A. SELECTION OF PARAMETERS}

The study confined itself to the heat generating half of the primary loop. The parameters selected were

1. Sodium flow into the lower high-pressure plenum from one loop

2. Temperature of the lower high-pressure plenum

3. Reactor power

4. Temperature of sodium leaving reactor

5. Temperature of sodium leaving upper plenum.

A detailed description of the sensors for these parameters is given in Table III.

B. REACTOR OPERATING CONDITIONS AND EXPERIMENTAL PROCEDURE

One set of data was obtained for each of the following three power levels:

- $0.05 \mathrm{Mwt}$ with 3 primary loops operating

- 56 Mwtwith 2 primary loops operating

- 88 Mwt with 3 primary loops operating.

The general plant conditions for each of these sets are given in Table IV.

When the signals were connected to the recorders and calibrated the experimental procedure was very straightforward; i.e.,

1. Attain the desired power 
Parameter

1. Flow

$$
\text { FE-201-1 }
$$

FE 201-3

2. Reactor Inlet Temperature TE $110-1$

\section{Reactor Power}

$$
\mathrm{ND}-1
$$

\section{Magnetic Flowmeter}

Magnetic Flowmeter

Iron constantan thermocouple encased in 0.125 -inch OD stainless steel sheath

RSN B-10 lined No. F-774, connected to Keithley Model 415 picoammeter

$$
\text { (3.76 } \left.\times 10^{-13} \mathrm{amps} / \mathrm{watt}\right)
$$

ND -2

4. Core Outlet Temperature TE 115-26

5. Upper Plenum Outlet Temperature TE 201-1

TE $217-1$
RSN B-10 lined No. F-793, connected to operational amplifier

$$
\text { (2. } \left.99 \times 10^{-13} \mathrm{amps} / \mathrm{watt}\right)
$$

\section{Same as TE 110-1}

Response time approximately 1 second

Platinum resistance thermometer feeding bridge circuit with $d-c$ amplifier; response time approximately 6 seconds

Same as TE 110-1. Response time longer than 1 second due to steel well

\section{Location}

In 14 -inch piping on discharge of pump in Loop 1 .

14-inch piping, Loop 3.

Mounted in wall of support plate support very near the support plate.

Located in well approximately 88 inches from core center

Located in well approximately 95 inches from core center.

In holddown finger over fuel element location NO2 PO4 (See Fig. 2).

In 30-inch outlet pipe, Loop 1.

Sheath in direct contact with sodium.

In 30-inch outlet pipe, Loop 1. Inserted in steel well, enabling replacement 
TABLE IV - PRIMARY SYSTEM CONDITIONS

Total Power

Date

Time

Total Recording Time, min

Instrument Readings

Ion Chambers, cpm IR-1

IR-2

IR-3

ND-1, amps

ND-2, amps

Regulating Rod Position, in. withdrawn

Reactor Inlel Temperatures, ${ }^{\circ} \mathrm{F}$

TE 209-1

TE 209-2

TE 209-3

Reactor Outlet Temperatures, ${ }^{\circ} \mathrm{F}$

TE 115-9

TE 115-31

TE 115-33

Upper Plenum Outlet Temperatures, ${ }^{\circ} \mathrm{F}$

TE 217-Loop 1

TE 217-Loop 2

TE 217-Loop 3

Sodium Flow Through 14 Inch Reactor

Inlet Pipes, $10^{6} \mathrm{lb} / \mathrm{hr}$

FE 201-Loop 1

FE 201-Loop 2

FE 201-Loop 3

Sodium Flow Through 6 Inch Blanket

Inlel Pipes, $10^{6} \mathrm{lb} / \mathrm{hr}$

FR 202-Loop 1

FR 202-Loop 2

FR 202-Loop 3

Pump Speed, rpm

Primary Pump

Loop 1

Loop 2

Loop 3

Secondary Pump

Loop 1

Loop 2

Loop 3

* Flow was oscillating between 1.6 and $2.0 \times 10^{6} \mathrm{lb} / \mathrm{hr}$ on $30 \mathrm{~min}$ period due to temperature controller on liquid rheostat.
$5.7 \times 10^{5}$
$5 \times 10^{5}$
$4 \times 10^{5}$
$1.7 \times 10^{-8}$

4.56

521.4

521.8

521.8

521.4

521.3

521.2

524.3

522.2

520.5
$4.7 \times 10^{8}$

$4.2 \times 10^{8}$

$3.8 \times 10^{8}$

$2.1 \times 10^{-5}$

$1.6 \times 10^{-5}$

6.96

540.0

-

737.0

719.5

673.8

651.6

656.3

-

2.4

2.5

$-0.4$

0.26

0.25

0.25

357

370

0

353

350

0

\begin{tabular}{|c|c|c|}
\hline $0.05 \mathrm{Mwt}$ & $56 \mathrm{Mwt}$ & $88 \mathrm{Mwt}$ \\
\hline May 12, 1966 & June 28,1966 & August 1,1966 \\
\hline 1115 & 1600 & 1610 \\
\hline 20 & 60 & 120 \\
\hline
\end{tabular}

$8.2 \times 10^{8}$

$7.2 \times 10^{8}$

$7.8 \times 10^{8}$

$3.3 \times 10^{-5}$

$2.6 \times 10^{-5}$

7.065

535.6

$5 \overline{1} .6$

748.4

675.1

731.0

660.5

657.1

659.4

$\begin{array}{ccc}0 & 353 & 393 \\ 0 & 350 & 370 \\ 347 & 0 & 373\end{array}$


2. Balance plant conditions so that this level is maintained without varying any primary control (plant operation is in manual mode).

3. Hold this condition for the duration of the recording.

This simple procedure is one of the major advantages of noise analysis.

\section{DATA RECORDING}

The data were recorded on a Sanborn thermal recording oscillograph for a "hard" copy and a Sangamo magnetic tape recorder for a copy readily played back for transforming into a form acceptable by a digital computer. The signals were first fed into appropriate Sanborn galvanometer amplifiers and the amplifier output signal was used for tape recordings as well as for driving the galvanometers. However, the Sanborn galvanometer amplifier output is a 75 -volt signal floating on 200 volts and not compatible with the magnetic tape recorder. To reduce the signal and to suppress the large d-c component, the signals from the Sanborn were first fed into fractional-gain, variably-biased operational amplifiers on an analog computer and then were fed to the tape recorder. The tape recorder was operated in $f-m$ mode at $7-1 / 2$ ips. Signals were connected to even-numbered channels.

Maintaining calibration is a major problem when such a chain of equipment is used. The following steps were taken during recording and should be reversible for playback:

1. The Sanborn preamplifier was calibrated in such a manner that zero to full scale on the pen was a known change of parameter level, e.g., $30^{\circ} \mathrm{F}$

2. The gain of the analog computer operational amplifier was known

3. The gain of each tape recording amplifier was set so that a known voltage in (e.g., $10.0 \mathrm{v})$ gave a 0 -db level on its meter

4. To calibrate the playback amplifier, a $0-\mathrm{db}$ recording on every channel was made at the beginning of each set of data.

Table V traces each signal through these steps.

The data as recorded has two features which are not desirable for digital analysis:

- A fair amount of high frequency noise is present (particularly 60 cycle noise) 


\section{TABLE V - CALIBRATION RECORD}

Sanborn Recording

Calibration,

$$
\begin{gathered}
0 \text { to } \\
\text { Channel Full Seale } \\
\hline
\end{gathered}
$$

Parameter
Tape Recording

Calibration, Gain Track $\mathrm{v} / \mathrm{O}-\mathrm{db}$ 0.05 Mwt Data

$\begin{array}{lccccc}\text { FE 201-3 } & 2 & \text { None } & 1 / 3 & 4 & 30 \\ \text { TE 110-1 } & 4 & 50^{\circ} \mathrm{F} & 1 / 3 & 8 & 30 \\ \text { ND-1 } & 3 & 3 \times 10^{-9} \mathrm{~A} & 1 / 3 & 6 & 30 \\ \text { TE 115-26 } & 5 & 50^{\circ} \mathrm{F} & 1 / 3 & 10 & 30\end{array}$

56 Mwt Data

$\begin{array}{lccccc}\text { FE 201-1 } & 4 & \text { None } & 1 / 3 & 12 & 5 \\ \text { TE 110-1 } & 3 & 30^{\circ} \mathrm{F} & 1 / 5 & 6 & 10 \\ \text { ND-1 } & 1 & 1 \times 10^{-6} \mathrm{~A} & 1 / 5 & 2 & 10 \\ \text { ND-2 } & 2 & \text { None } & 1 / 5 & 4 & 10 \\ \text { TE 115-26 } & 5 & 30^{\circ} \mathrm{F} & 1 / 3 & 8 & 5 \\ \text { TE 217-1 } & 6 & 30^{\circ} \mathrm{F} & 1 / 3 & 10 & 5\end{array}$

Tape Playback

Filter Track Gain Bandwidth

$\begin{array}{rrrccccr}3 & 1 & 0.012-1.2 & \text { None } & 1.83 & \text { None } & 1.2 & 2003 \\ 7 & 10 & 0.012-1.2 & 6^{\circ} \mathrm{F} & 1.83 & 0.3 \mathrm{v} /{ }^{\circ} \mathrm{F} & 1.2 & 2001 \\ 5 & 10 & 0.012-1.2 & 0.36 \times 10^{-9} \mathrm{~A} & 1.83 & 5.2 \times 10^{-4} \mathrm{Mw} / \mathrm{v} & 1.2 & 2002 \\ 9 & 10 & 0.012-1.2 & 6^{\circ} \mathrm{F} & 1.83 & 0.3 \mathrm{v} /{ }^{\circ} \mathrm{F} & 1.2 & 2000\end{array}$

Digitizing

\begin{tabular}{ccc} 
& & Sample \\
Volts/ & Overall & Spacing, Deck \\
O-db & Calibration & sec \\
\hline
\end{tabular}

88 Mwt Data

$\begin{array}{lccccccrrrrrrrr}\text { FE 201-3 } & 7 & \text { None } & 1 / 3 & 10 & 10 & 9 & 1 & 0.0012-1.2 & \text { None } & 1.10 & \text { None } & 6.4 & 2017 \\ \text { FE 202-3 } & 5 & \text { None } & 1 / 3 & 12 & 10 & 11 & 10 & 0.0012-1.2 & \text { None } & 1.10 & \text { None } & 6.4 & 2016 \\ \text { TE 110-1 } & 4 & 30^{\circ} \mathrm{F} & 1 / 5 & 6 & 5 & 5 & 10 & 0.0012-1.2 & 1^{\circ} \mathrm{F} & 1.10 & 1.1 \mathrm{v} /{ }^{\circ} \mathrm{F} & 6.4 & 2024 \\ \text { ND-1 } & 1 & 3 \times 10^{-6} \mathrm{~A} & 1 / 5 & 2 & 10 & 1 & 10 & 0.0012-1.2 & 0.2 \times 10^{-6} & 1.10 & 0.48 \mathrm{Mw} / \mathrm{v} & 6.4 & 2025 \\ \text { ND-2 } & 2 & \text { None } & 1 / 5 & 4 & 10 & 3 & 10 & 0.0012-1.2 & \text { None } & 1.10 & \text { None } & 6.4 & 2021 \\ \text { TE 201-1 } & 6 & 50^{\circ} \mathrm{F} & 1 / 3 & 8 & 5 & 7 & 1 & 0.0012-1.2 & 10^{\circ} \mathrm{F} & 1.10 & 0.11 \mathrm{v} / \mathrm{F} & 6.4 & 2020\end{array}$


- Several parameters inevitably had a slow fluctuation from a fraction of a cycle to several cycles during the recording period.

The first of these could lead to eroneous higher-frequency power measurements due to biasing; the second could lead to erroneous low-frequency power measurements.

To eliminate these problems, the data were read from the tape, passed through filters, and rerecorded on unused adjacent channels. The bandwidth of the filter (converted to original real-time units, since the rerecording was done at 60 inches per second (ips)) used for each measurement is listed in Table V. This rerecording was done with a gain of either 1 or 10; the gain of 10 was used on data which originally had a small dynamic range.

\section{DIGITIZING THE DATA}

The digitization of analog recordings requires specialized electronic equipment not available at EFAPP; however, appropriate equipment was made a vailable by the Idaho Division of Argonne National Laboratory.

The digitizing process consisted of playing the tapes into a multiplexing digital voltmeter (DVM) and recording readings (in a binary-coded decimal format, $B C D$ ) on a digital tape recorder. The sampling rates were chosen so that the original recording would be approximately covered in 1100 points. (The computer program used for data reduction was limited to 1000 points per data deck.) The sampling rate was set up on a laboratory-standard oscillator which was calibrated daily to a standard signal transmitted by radio station WWV. Only two channels at a time could be digitized; therefore, a "start" pulse on channel 14 had to be added to trigger the DVM.

The digitizer is capable of \pm 2.0 volts, whereas the original recordings were set up for \pm 1.0 volt at 0 decibels. To use as much of the DVM range as possible, but allowing room for some overshoot, the playback equipment chain into the DVM was set up so that the original 1.0-volt recording digitized at 1.8 volts. This factor is included in Table $V$ for the final overall calibration.

After all the data were converted to $\mathrm{BCD}$ and recorded on magnetic tape, they were fed into a digital computer and placed on cards on a (10F7.3) format. Each channel of data was put on a separate deck of cards serially labeled from 1 to 110 . The identifying number for each deck of cards is also included in Table $\mathrm{V}$.

\section{E. DATA REDUCTION}

Data reduction consisted of autocorrelating and cross - correlating the various sets and Fourier-transforming the correlation functions. The 
digital computer program BMD02T was used for data reduction. * The problems were run on a CDC 3600 computer at Minneapolis, Minnesota.

The Fourier transform of a correlation function is carried out over each half-harmonic of the maximum lag period. The "raw" power estimates are poor, and smoothing must be employed. Several smoothing techniques are available. The technique incorporated into the original program, called "hamming", smooths by combining $23 \%$ of each of the adjacent estimates with $54 \%$ of the computed estimate. Another technique, called "hanning", is very similar but combines $25 \%$ of each of the adjacent estimates with $50 \%$ of the computed estimate.6

One of the peculiar characteristics of many of the correlation functions from these data was the presence of a linear slope. During the course of analyzing results, an investigation showed "hanning" to be far superior to "hamming" in the presence of these linear slopes. The original BMD02T program was subsequently modified.

The BMD02T program also computes the transfer functions; however, it was found that the best technique for determining the transfer functions is to draw smooth curves through plots of the computed power spectra of autocorrelation and cross-correlation functions, read off values from the smooth curves, and take their ratios.

\section{F. NOTES ON QUALITY AND INTERPRETATION OF DATA}

1. Accuracy of Calibrated Values

Due to the long path between original recording and digitizing, the accuracy of the calibration is probably no better than $20 \%$ for individual signals and $30 \%$ for transfer functions. However, many of the transfer functions can be checked (and recalibrated, if desired) by knowing what the low-frequency asymptotic value should be. For instance, transfer functions between two temperatures should approach unity at low frequencies.

\section{Reactor Power Signals}

Both ND-1 and ND-2 signals of reactor power were recorded for the $56 \mathrm{Mwt}$ and $88 \mathrm{Mwt}$ data sets. Whenever convenient, both detectors were used to compute cross spectral densities with other signals; in these cases the cross spectral densities were normalized and averaged.

* BMD02T is one of a group of programs for data handling prepared by the School of Medicine, University of California, Los Angeles. See Reference 7 . 
A cross spectral density was also computed between ND-1 and ND-2 for these two data sets (see Figures 3 and 4). Very little divergence is noted between the XSD and PSD functions. This implies that both detectors are truly indicating core power over the frequency band of measurements with very little interference from extraneous noise sources.

The phase functions from these data are shown in Figure 5 . The phase beteen ND-1 and ND-2 for the 56-Mwt data indicates very clearly a 4. 4-sec displacement between these two signals. Such a displacement is, of course, impossible and must be attributed to a bad start pulse on the tape during digitizing. It appears that the bad start occurred in the ND-2 digitization run. TE 110-1 was also digitized on this run. In dealing with these data, corrections have been applied for the $4.4-\mathrm{sec}$ offset. The phase between ND-1 and ND-2 for the 88-Mwt data shows no displacement, as should be the case.

\section{Phase Data}

The phase measurements from the XSD functions were quite rough; no information could be obtained on the phase associated with transfer function measurements. However, linear trends indicative of time lags could be seen in many phase functions.

The accidental shift of the highly correlated data above gives an excellent example of the linearity of the phase curve for a lag between two signals.

\section{Distinction Between Terms "Reactor" and "Core"}

During the course of analysis, the need developed to distinguish between temperature in the main power-producing portion of the reactor and temperatures at the reactor blanket inlet and outlet extremities. To make this distinction, the parameters concerned only with the main power-producing portion are identified with the term "core" and those concerned with the inlet or outlet extremeties are identified with the term "reactor". Thus, core and reactor inlet temperatures are separate entities, as are core and reactor outlet temperatures. 


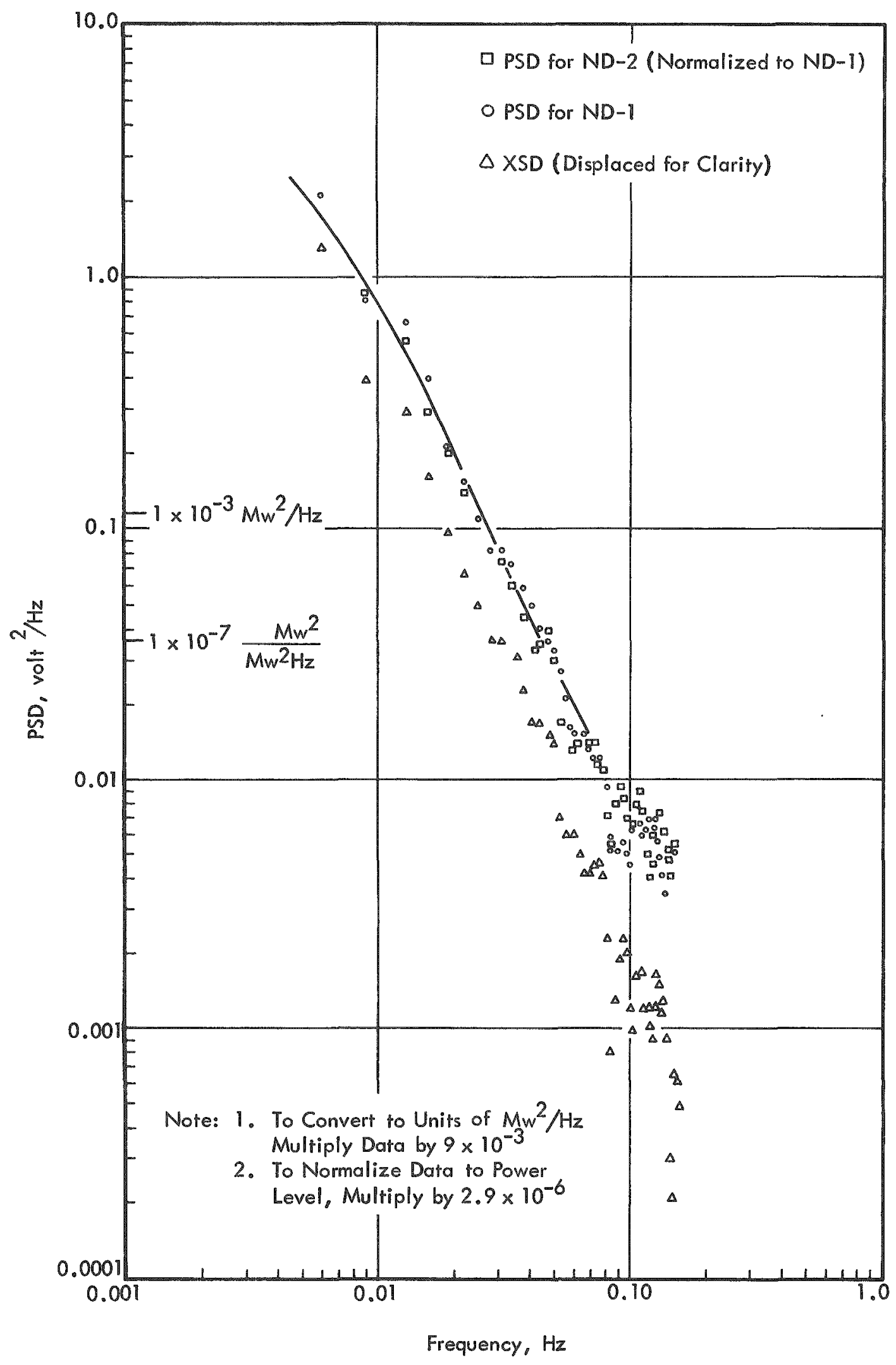

FIG. 3 POWER SPECTRAL DENSITY OF REACTOR POWER, 56 MWt 


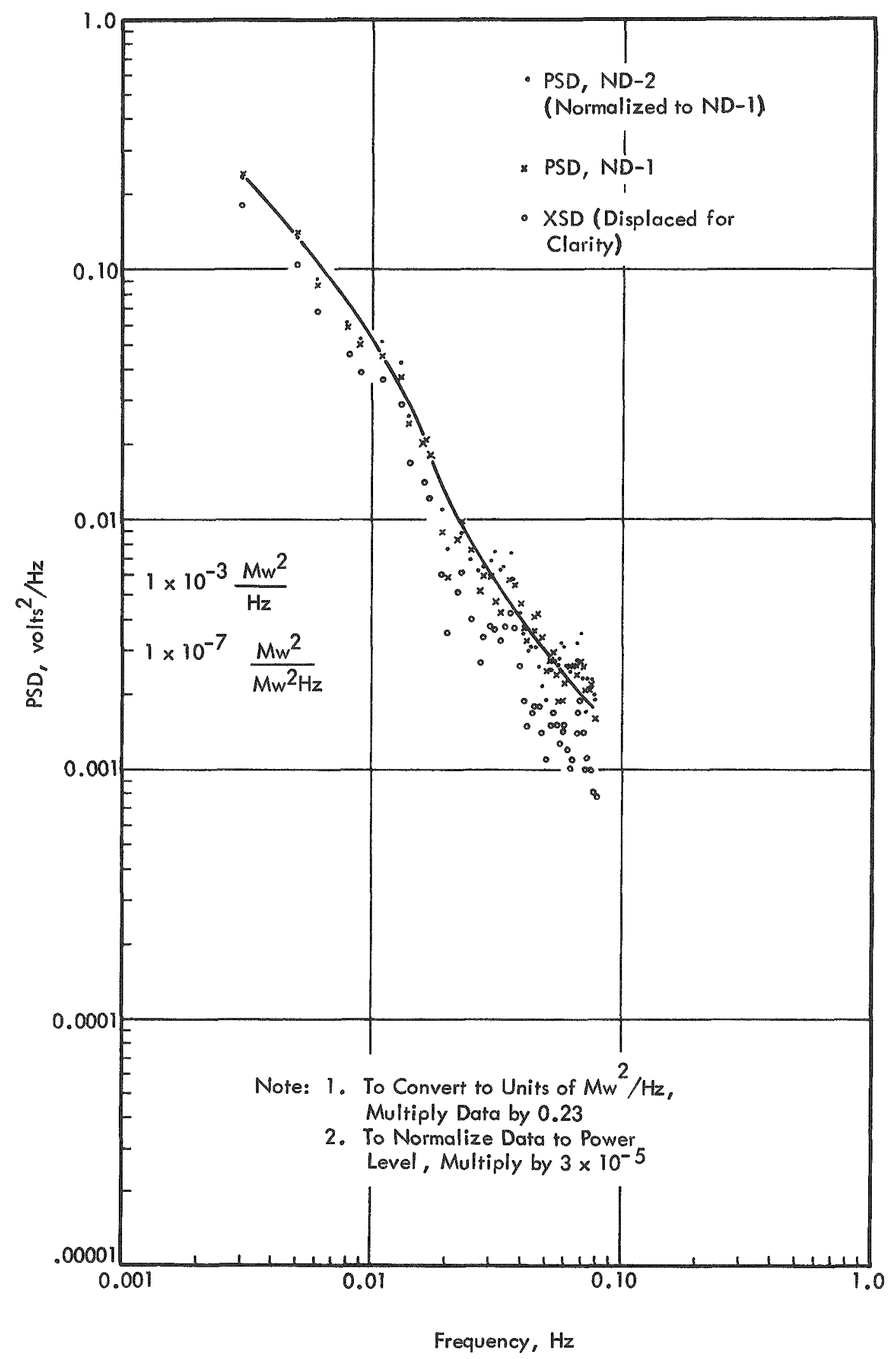

FIG. 4 POWER SPECTRAL DENSITY OF REACTOR POWER, 88 MWH 

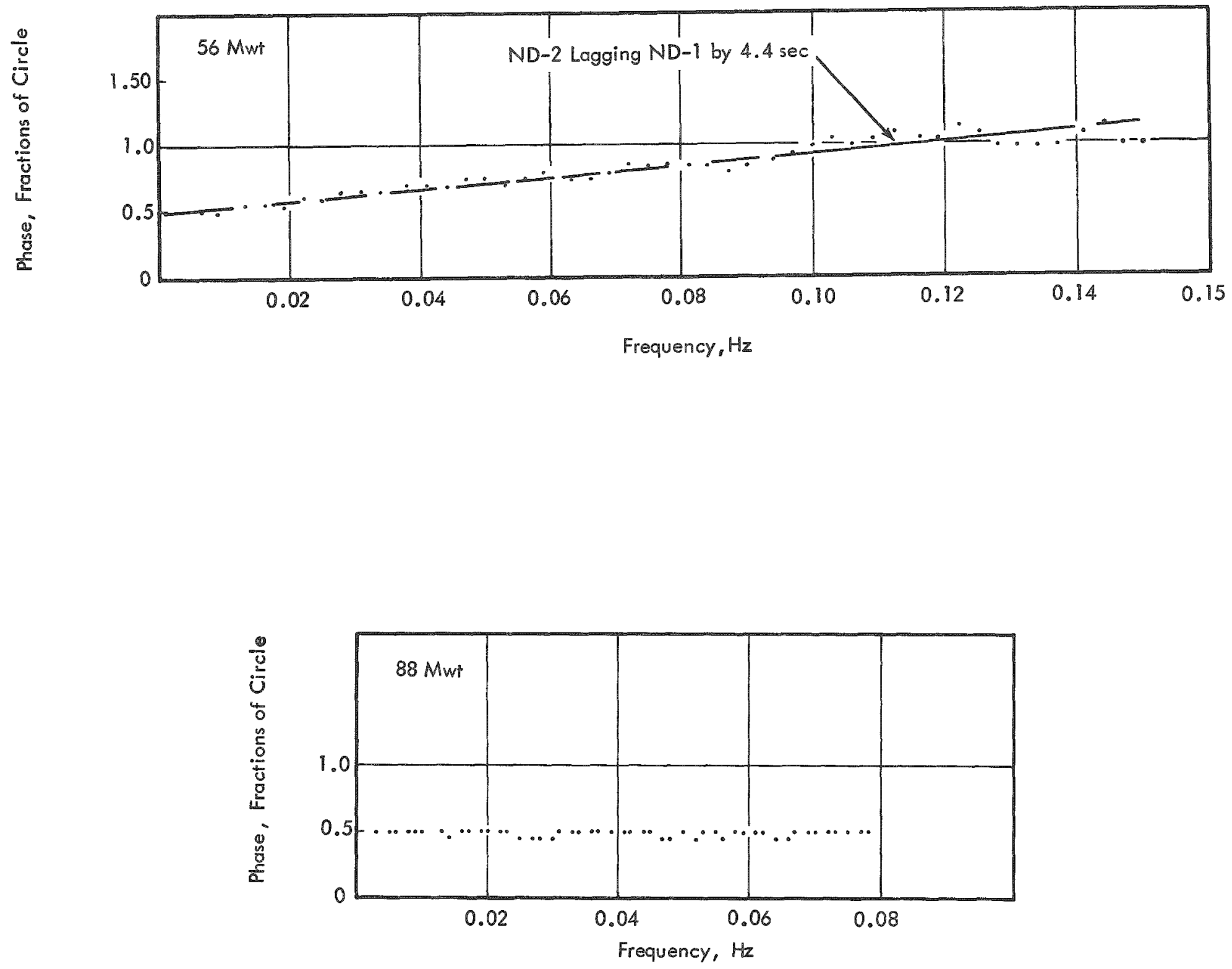

FIG. 5 PHASE BETWEEN ND-1 AND ND-2 


\section{RESULTS AND DEDUCTIONS}

The objective of noise analysis is to determine the system characteristics through parameter signal spectral distributions. The stability of a system is determined by examination of power spectral density and cross spectral density estimates taken at several power levels. The PSD and XSD functions also give information on the relative magnitude of noise levels; for data which is calibrated, the magnitude can be compared as a function of power level. The transfer functions and lags between parameters are determined from XSD and PSD of these parameters.

\section{A. SYSTEM STABILITY}

No indications of system instability are evident in the data. The data did indicate several small resonances, which are listed below:

1. At $0.05 \mathrm{Mwt}$, a resonance was measured between reactor flow and power at $0.1 \mathrm{~Hz}$ (see Fig. 6). This resonance does not appear in the XSD between inlet temperature and reactor power (Fig. 7), the PSD of the reactor flow (Fig. 8), or the PSD of the reactor inlet temperature (Fig. 9). These would indicate that a flow-induced variation is occurring at a frequency of $0.1 \mathrm{sec}^{-1}$. One possibility for this variation is a flow-induced motion of the control and/or safety rods or the oscillator rod.

2. At 56 Mwt (2-loop) operation, the region between 0.025 and 0.05 $\mathrm{Hz}$ shows a small resonance in several cross spectral density functions computed with flow, inlet temperature and power (see Figures $8,9,10,11,12,13$, and 14). The resonance is so small as to be the limit of detection; however, its presence in so many functions adds credence to the fact that it could be indicative of os cillatory flow patterns due to 2-loop operation.

3. No similar resonances were found at $88 \mathrm{Mwt}$ (see Figures 15, 16, and 17).

\section{B. POWER SPECTRAL DENSITY FUNCTIONS}

\section{Reactor Power PSD Function}

The spectral densities of most parameters are used primarily as indicators of system stability, as previously discussed, and as a factor in the calculation of transfer function, as discussed in the follow- 


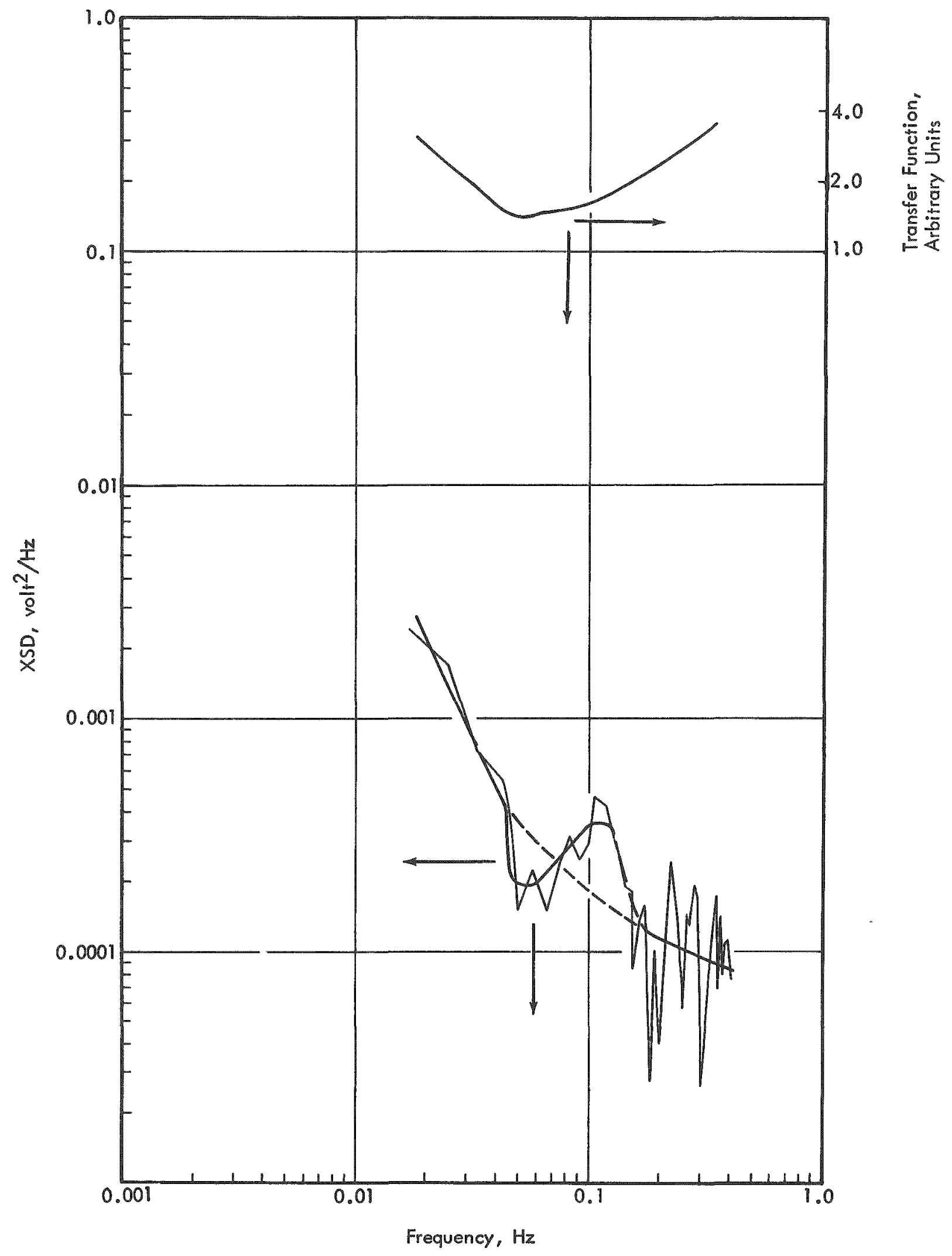

FIG. 6 CROSS SPECTRAL DENSITY AND TRANSFER FUNCTION FOR LOOP 3 SODIUM FLOW AND REACTOR POWER, 0.05 MW" 


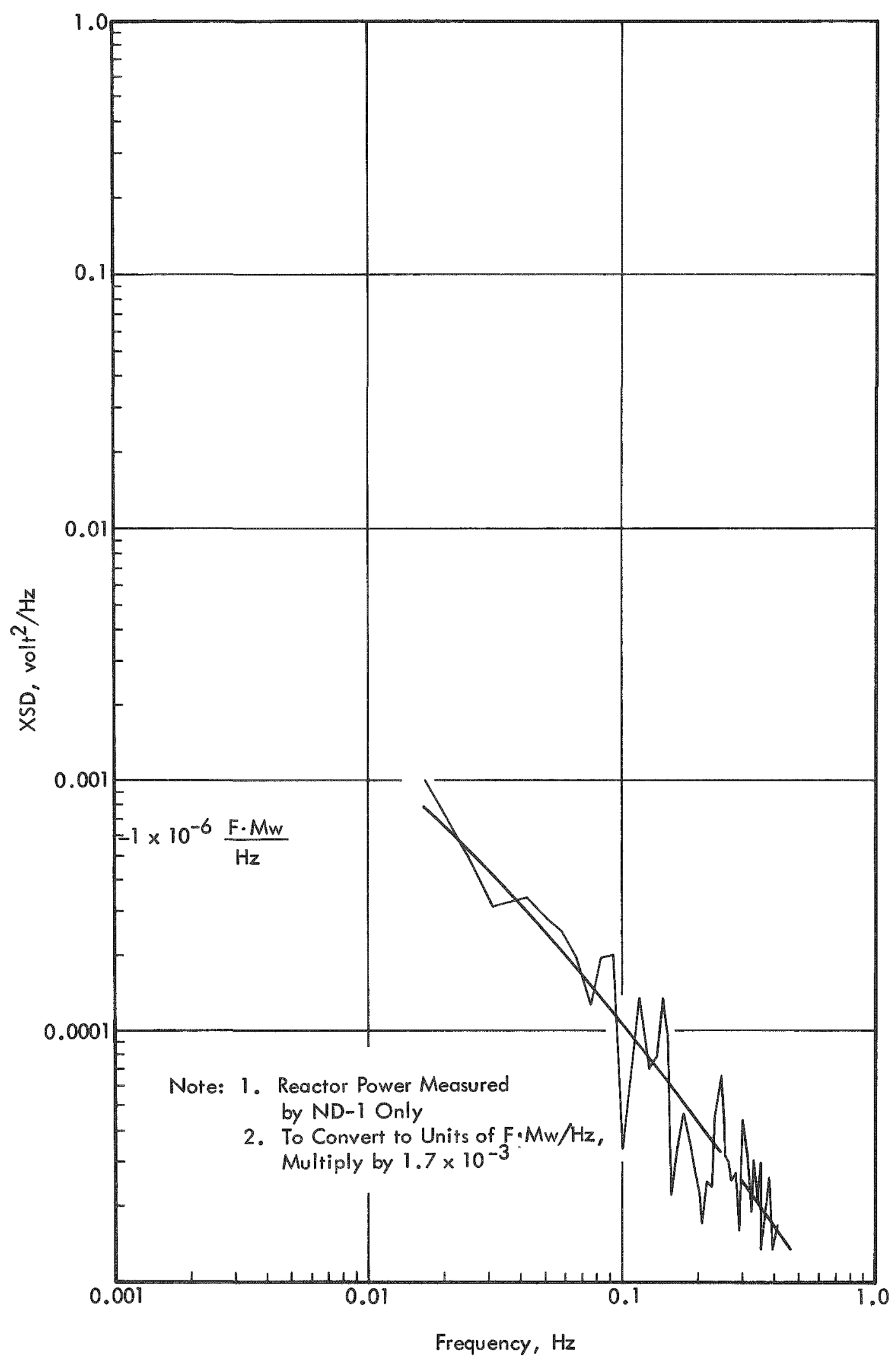

FIG. 7 CROSS SECTION DENSITY FOR REACTOR INLET TEMPERATURE AND REACTOR POWER, $0.05 \mathrm{MW}$ 


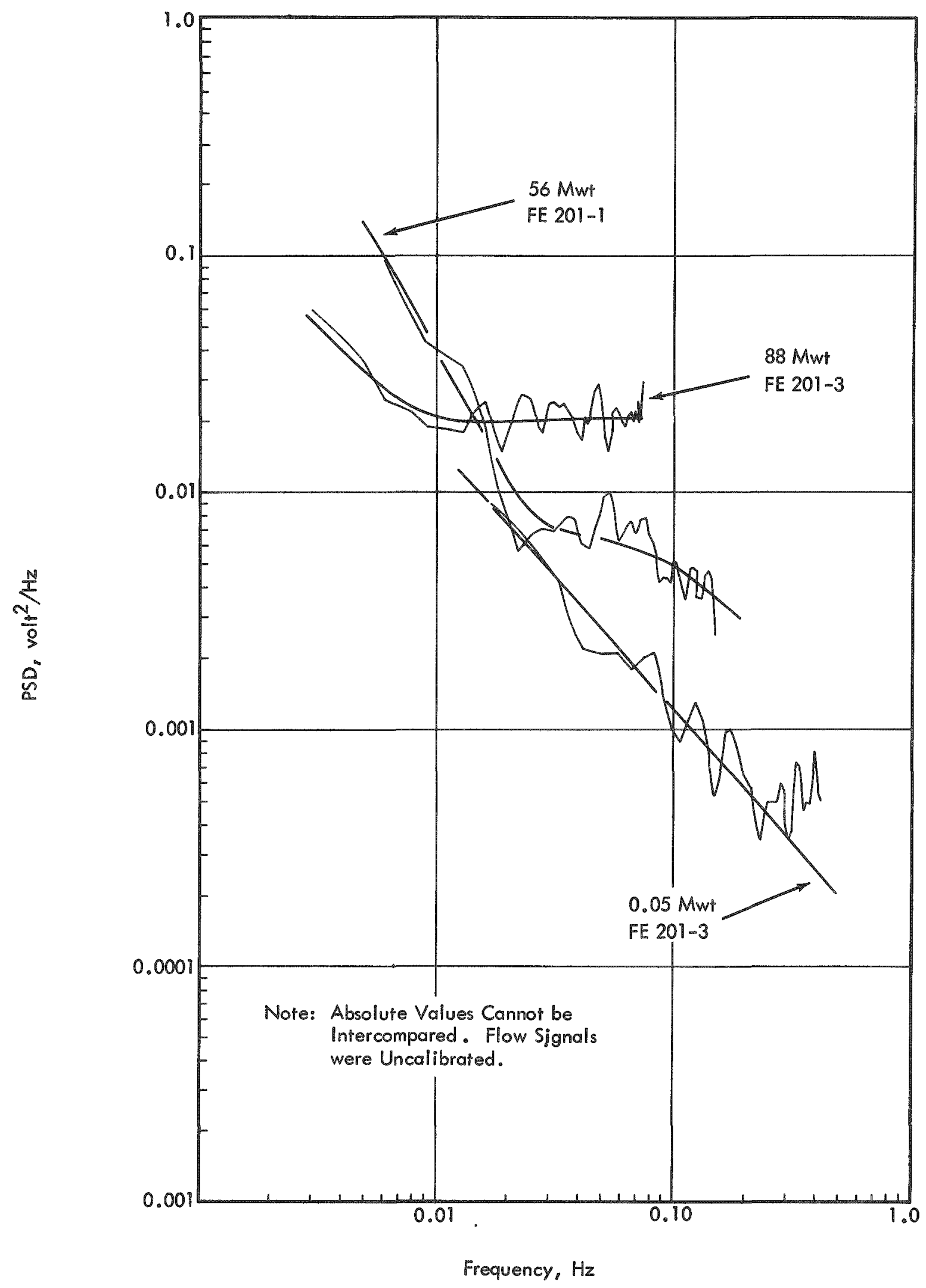

FIG. 8 POWER SPECTRAL DENSITY OF INLET SODIUM FLOW 


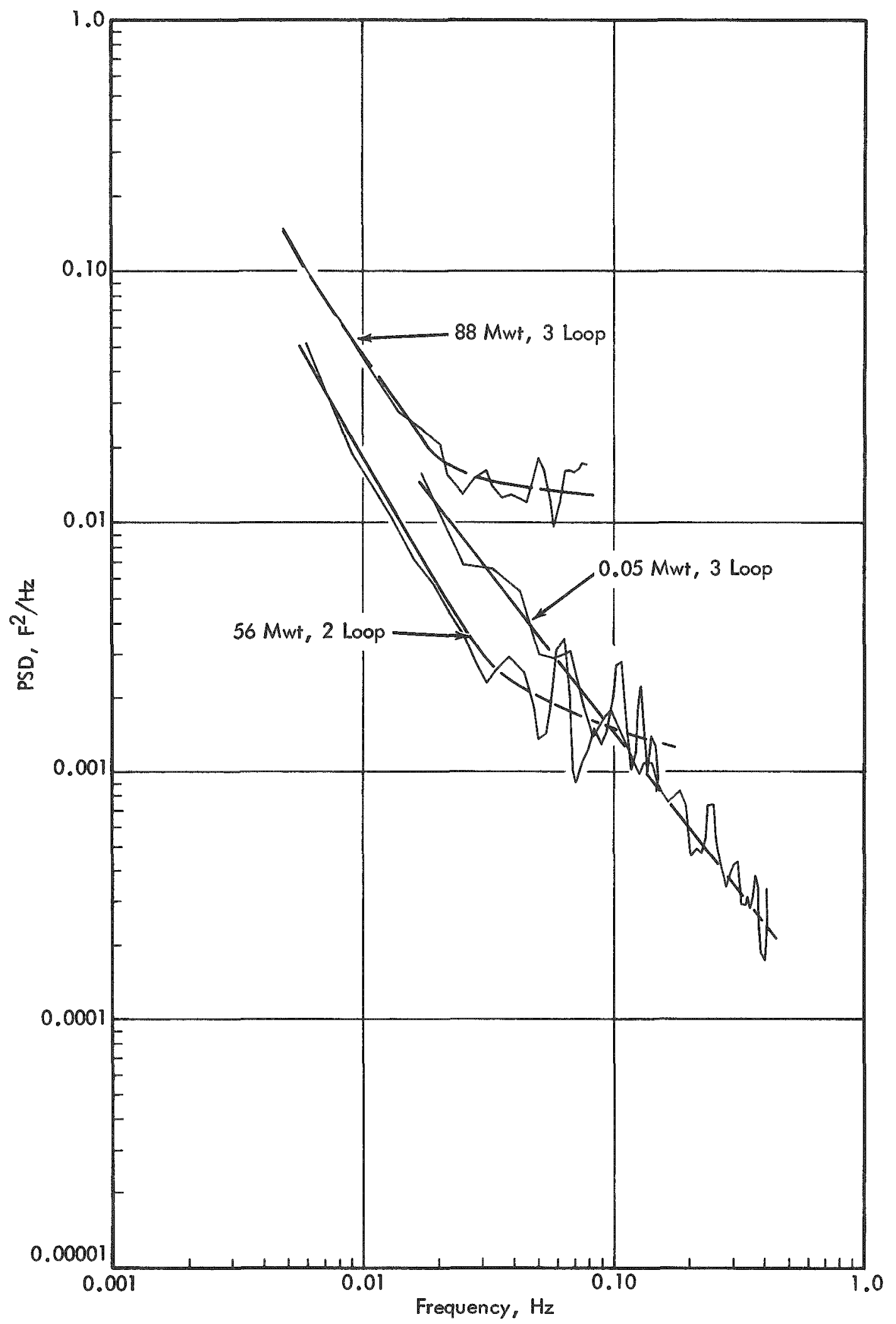

FIG. 9 POWER SPECTRAL DENSITY OF REACTOR INLET TEMPERATURE 


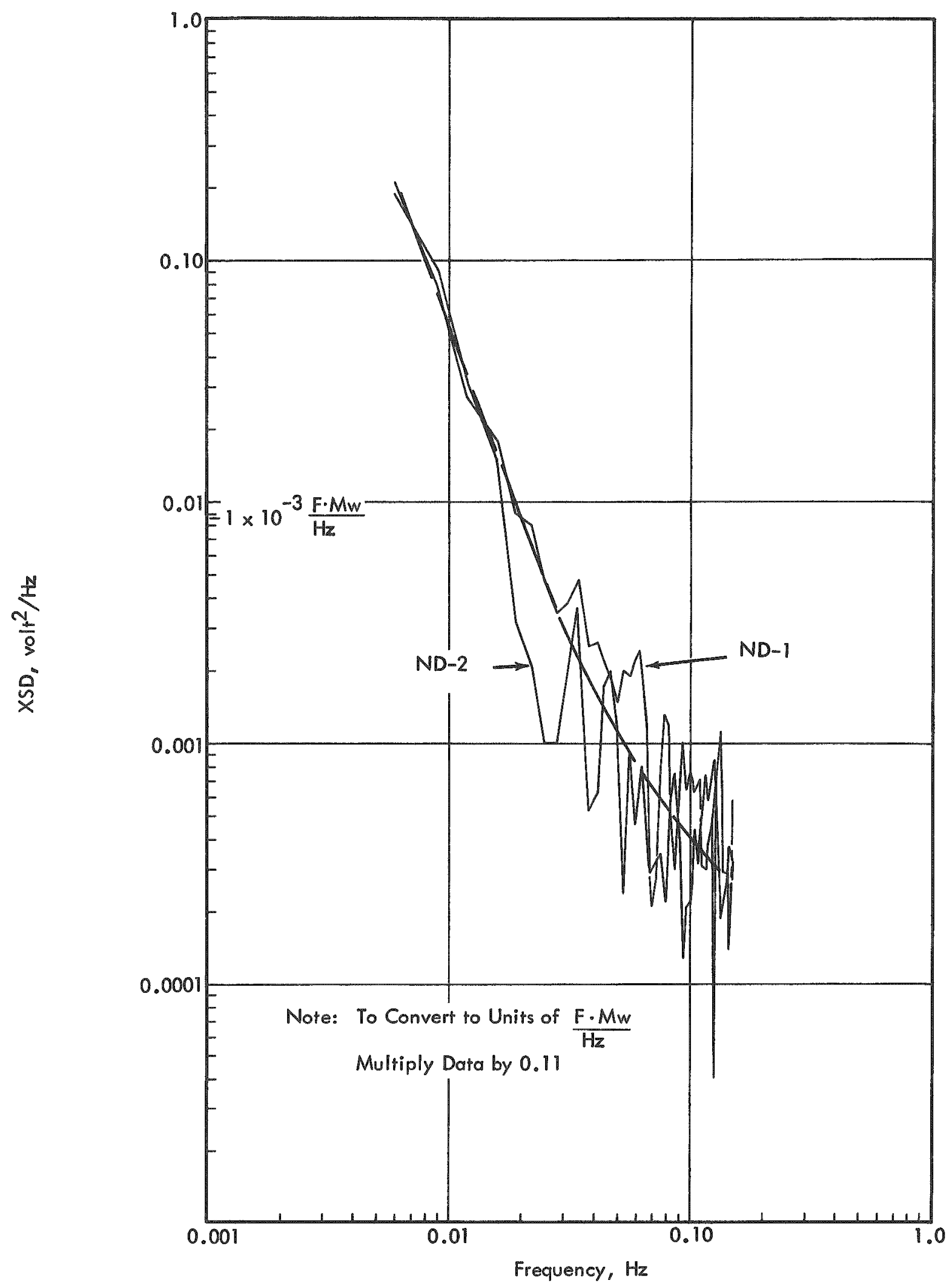

FIG. 10 CROSS SPECTRAL DENSITY FOR REACTOR INLET TEMPERATURE AND REACTOR POWER, 56 MWt 


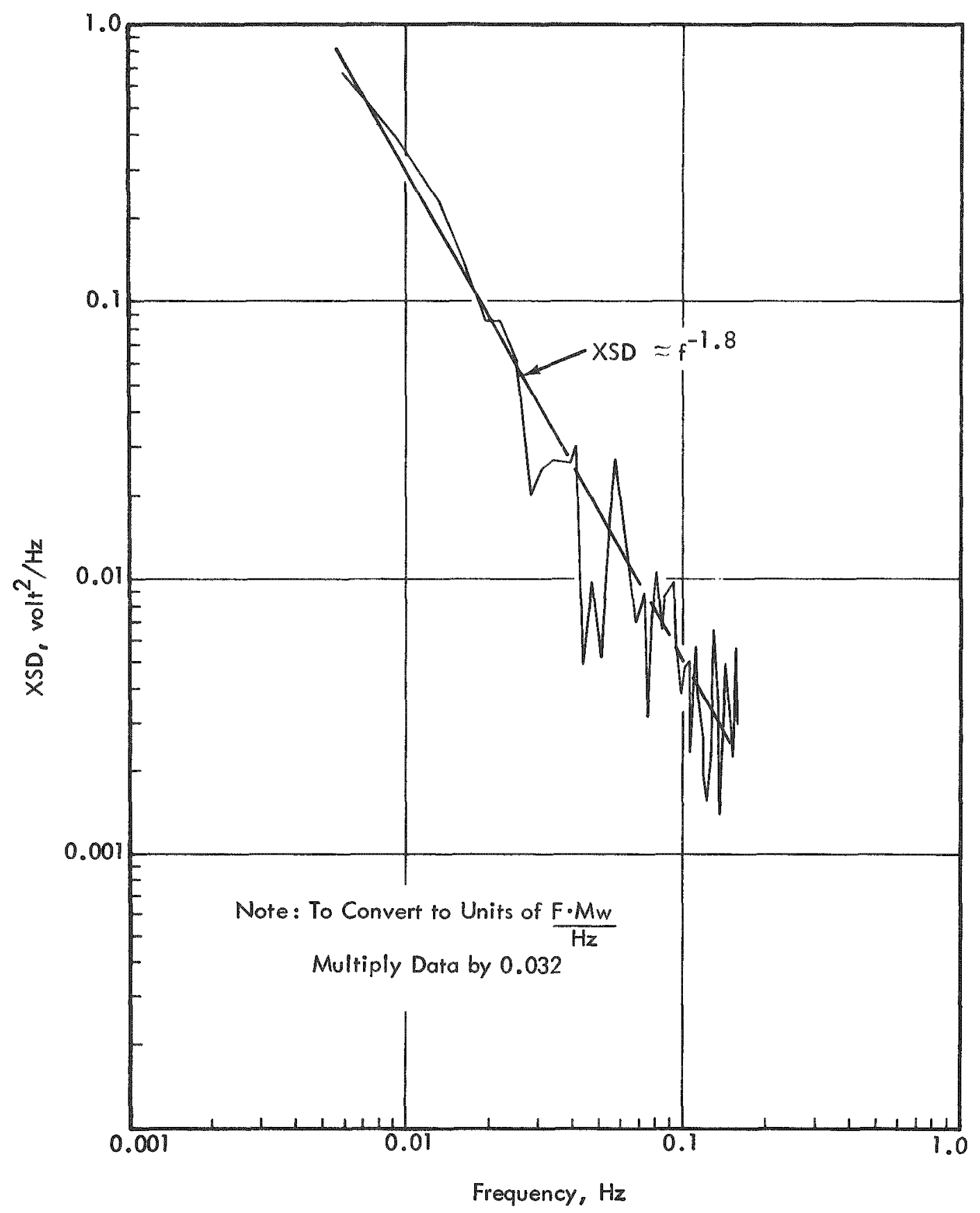

FIG. 11 CROSS SPECTRAL DENSITY FOR REACTOR OUTLET TEMPERATURE AND REACTOR POWER, 56 MW' 


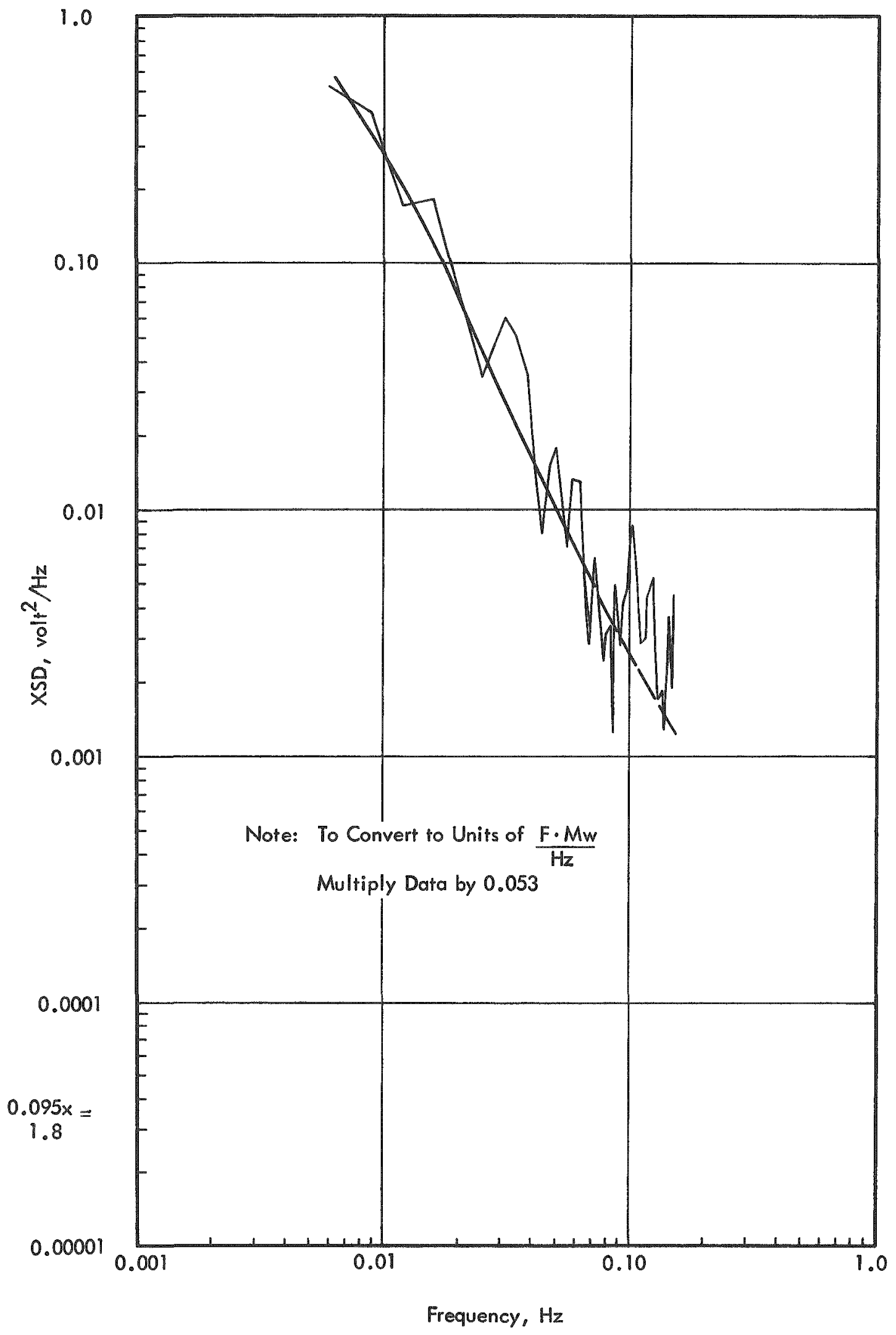

FIG. 12 CROSS SPECTRAL DENSITY FOR PLENUM OUTLET TEMPERATURE AND REACTOR POWER, 56 MW" 


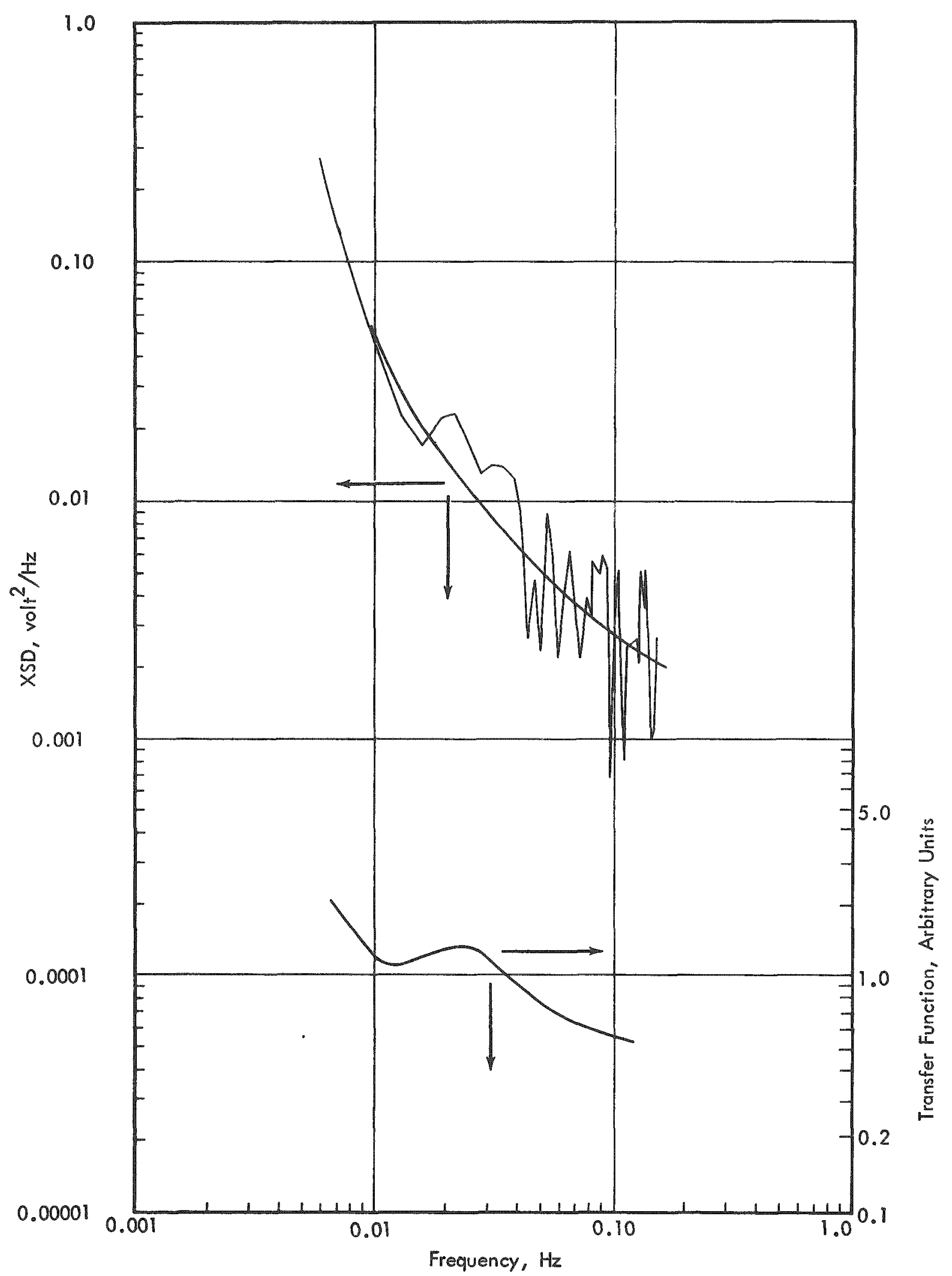

FIG. 13 CROSS SPECTRAL DENSITY AND TRANSFER FUNCTION FOR LOOP I SODIUM FLOW TO REACTOR OUTLET TEMPERATURE, 56 MW 


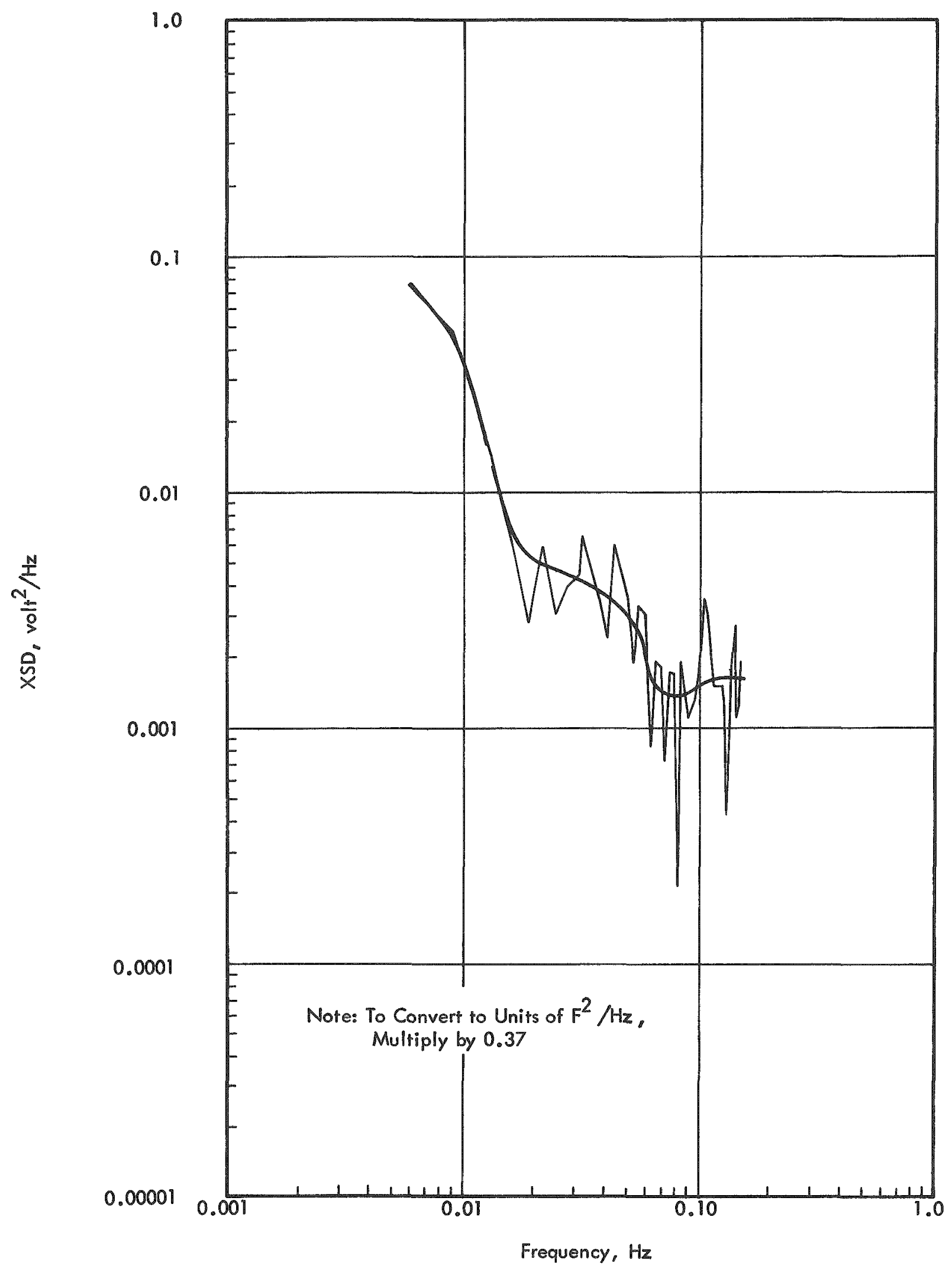

FIG. 14 CROSS SPECTRAL DENSITY FOR REACTOR INLET AND REACTOR OUTLET TEMPERATURE, 56 MWT 


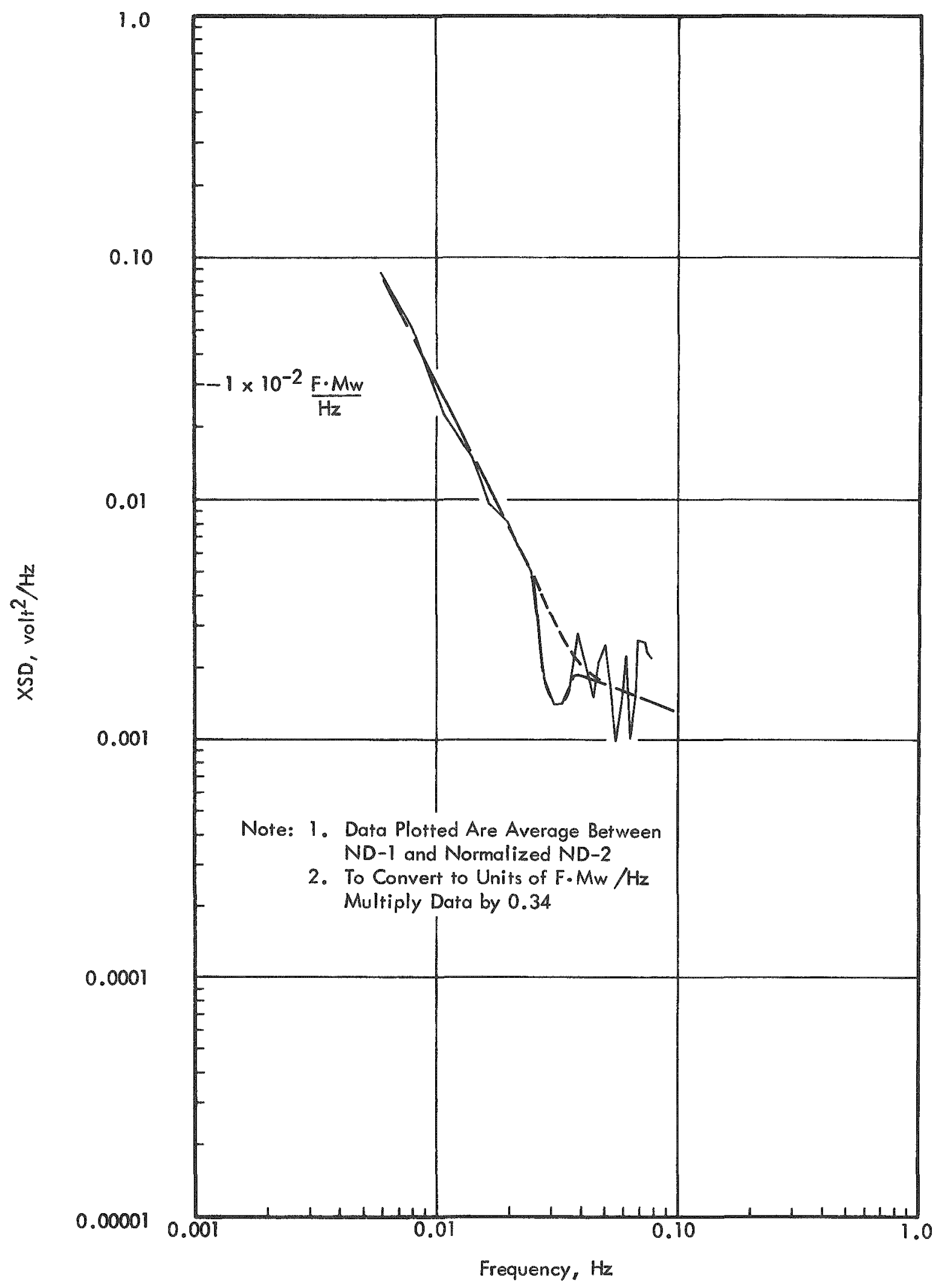

FIG. 15 CROSS SPECTRAL DENSITY FOR REACTOR INLET TEMPERATURE AND REACTOR POWER, 88 MW" 


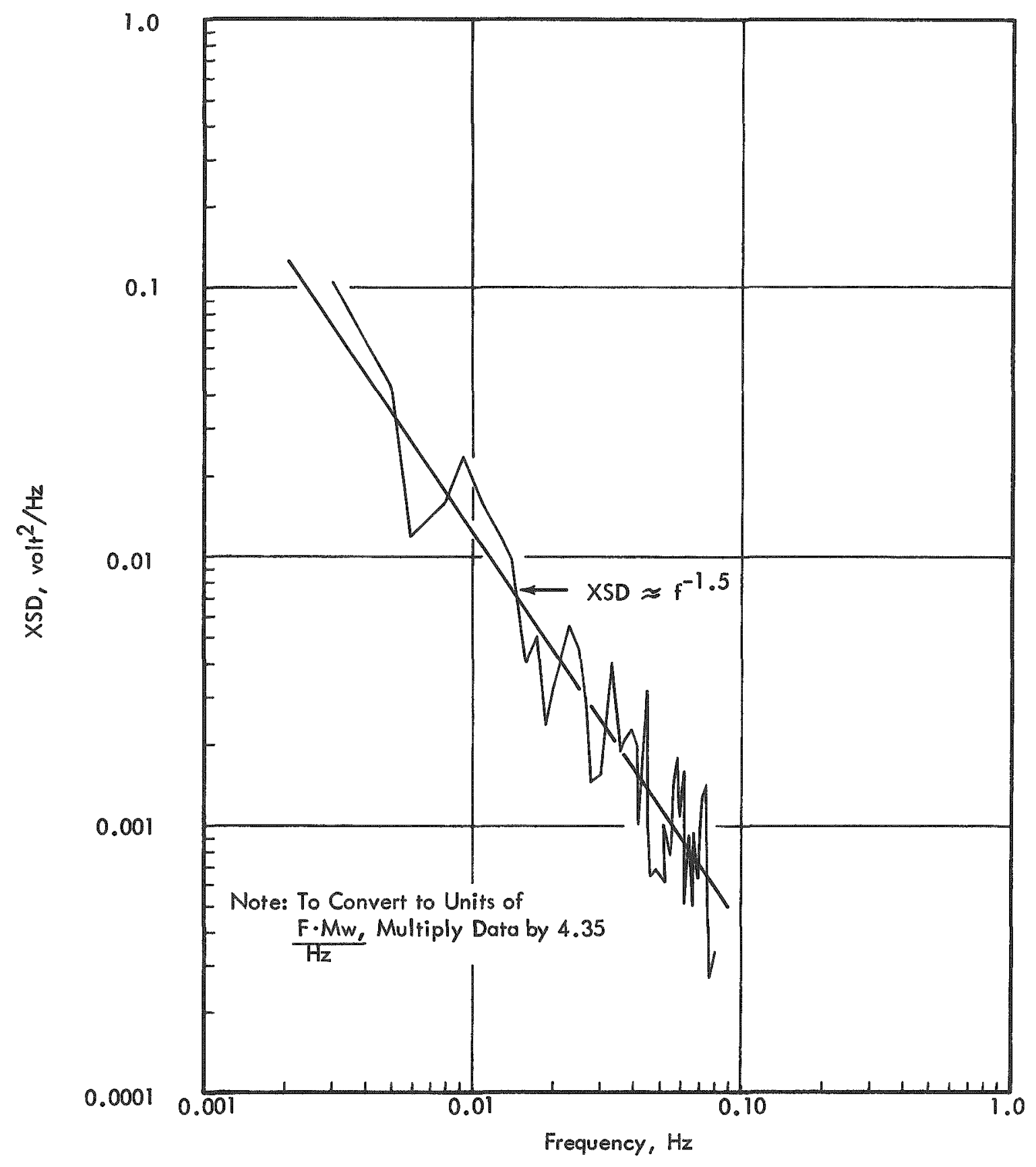

FIG. 16 CROSS SPECTRAL DENSITY FOR PLENUM OUTLET TEMPERATURE AND REACTOR POWER, 88 Mw 


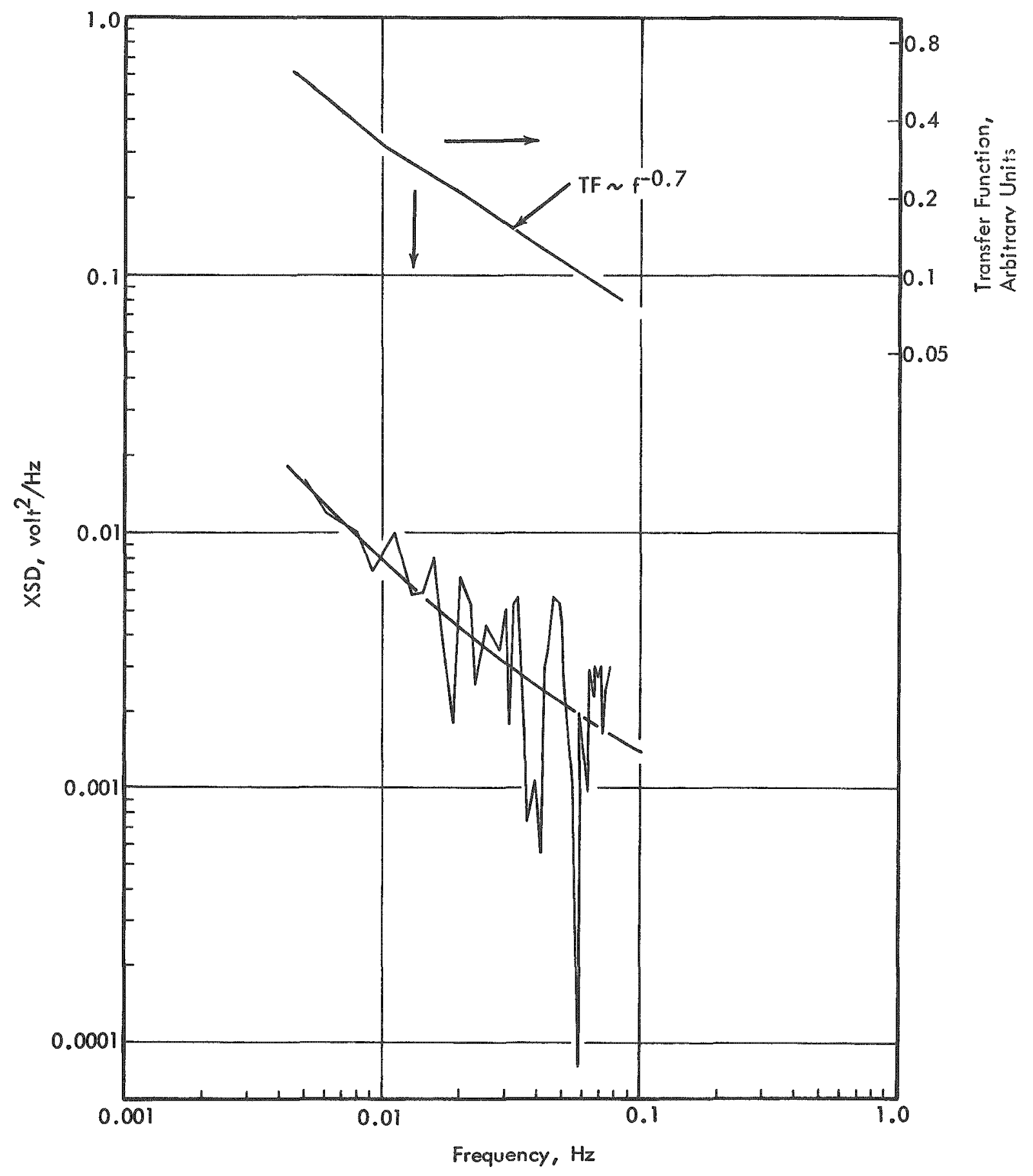

FIG. 17 CROSS SPECTRAL DENSITY AND TRANSFER FUNCTION FOR LOOP 3 SODIUM FLOW AND PLENUM OUTLET TEMPERATURE, 88 MW 
ing section. However, some system characteristics can be observed directly from the spectral distribution of reactor power.

Three items are the main contributors to the noise of reactor power, i.e.,

1. Variation of the number of neutrons given off per fission

2. Variation of inlet temperature

3. Variation of inlet flow.

The variation in the number of neutrons per fission is statistically random and is a classic example of what is known as "white noise". This component is prominant only at the very lowest power levels; for the work reported here, the second and third components are far more important. The variation of inlet temperature causes noise in reactor power due to the temperature coefficient of the core. Noise in reactor power is caused by variation of inlet flow during power operation through the interrelationship between flow and temperature.

The reactor power PSD functions for $56 \mathrm{Mwt}$ and $88 \mathrm{Mwt}$ are given in Figures 3 and 4. Direct comparison can be made between reactor power PSD functions by normalizing the calibrated functions by the square of the power level. When this is done, the 56 Mwt 2-loop PSD function is larger by $70 \%$ than the $88 \mathrm{Mwt} 3-100$ p function at low frequencies, with this difference decreasing as frequency increases. Since the flow spectrum is one of the important contributors to the reactor power spectrum, these data indicate flow noise is greater for 2 -loop than for 3-loop operation.

The reactor power PSD of $0.05 \mathrm{Mwt}$ is given in Figure 18. This PSD normalized by the square of power level gives very high values when compared to $56 \mathrm{Mwt}$ and $88 \mathrm{Mwt}$ measurements, an indication that the signal on ND-1 at this power level contains an appreciable extraneous noise term. The extraneous noise term is not necessarily electronic noise but could be noise due to the random nature of neutron travel to the detector, noise due to the small temperature variations of the sodium passing through the outer radial blanket, or noise due to the small resonance discussed in the preceding section.

\section{PSD Measurements of Outlet Temperature}

Reactor outlet temperature (TE 115-26) was measured at 0.05 Mwt and 56 Mwt. Upper plenum outlet temperature was measured at 56 Mwt and $88 \mathrm{Mwt}$, using TE 217-1 at 56 Mwt and TE 201-1 at $88 \mathrm{Mwt}$. The 0.05 Mwt data contained so little fluctuation that the computer was unable to analyze it. The $56 \mathrm{Mwt}$ and $88 \mathrm{Mwt}$ data have been converted to absolute units and are shown in Figure 19. The difference in magnitude between TE 115-26 and TE 217-1 PSD results indicates that the temperature fluctu- 


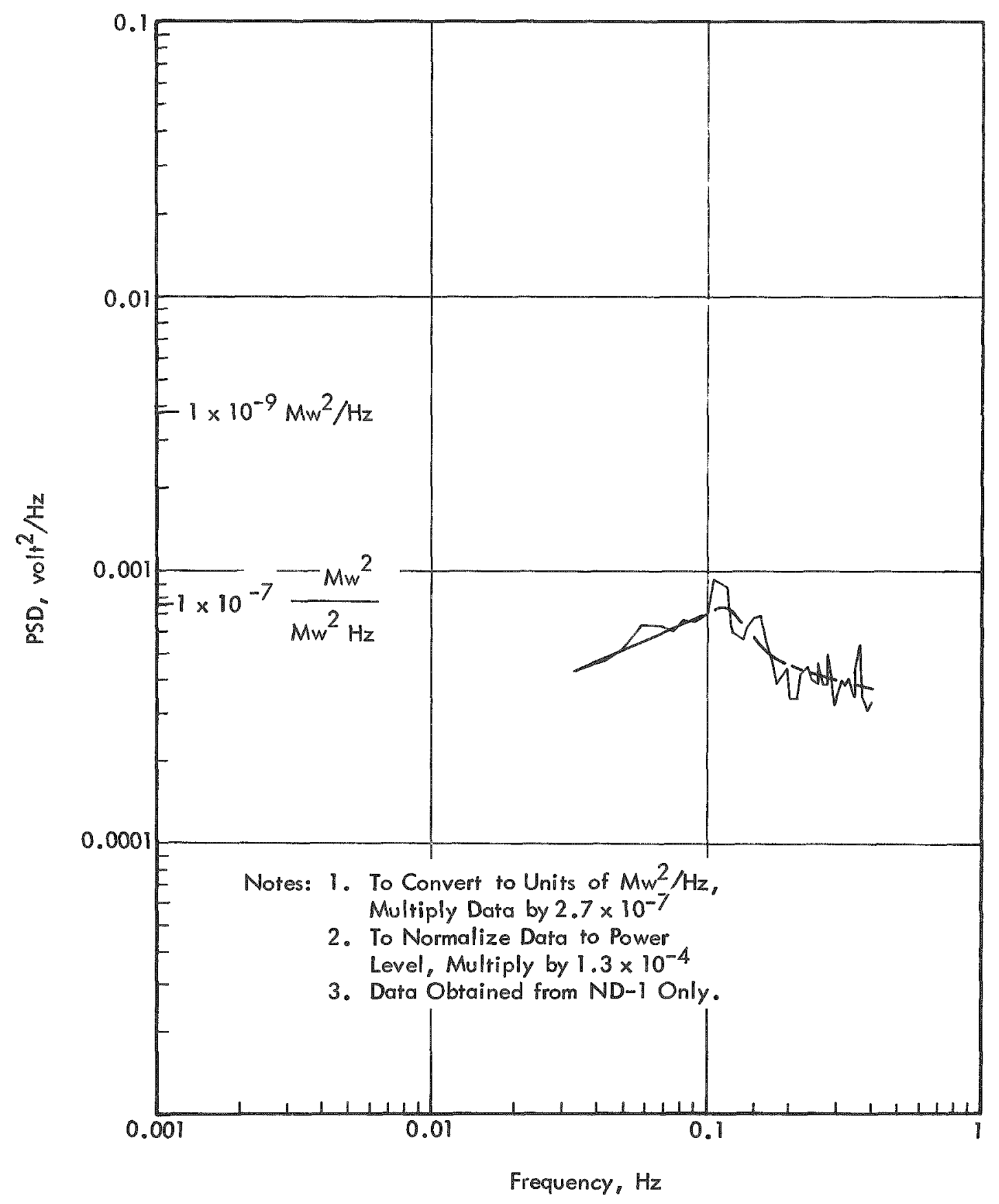

FIG. 18 POWER SPECTRAL DENSITY OF REACTOR POWER, 0.05 MW 


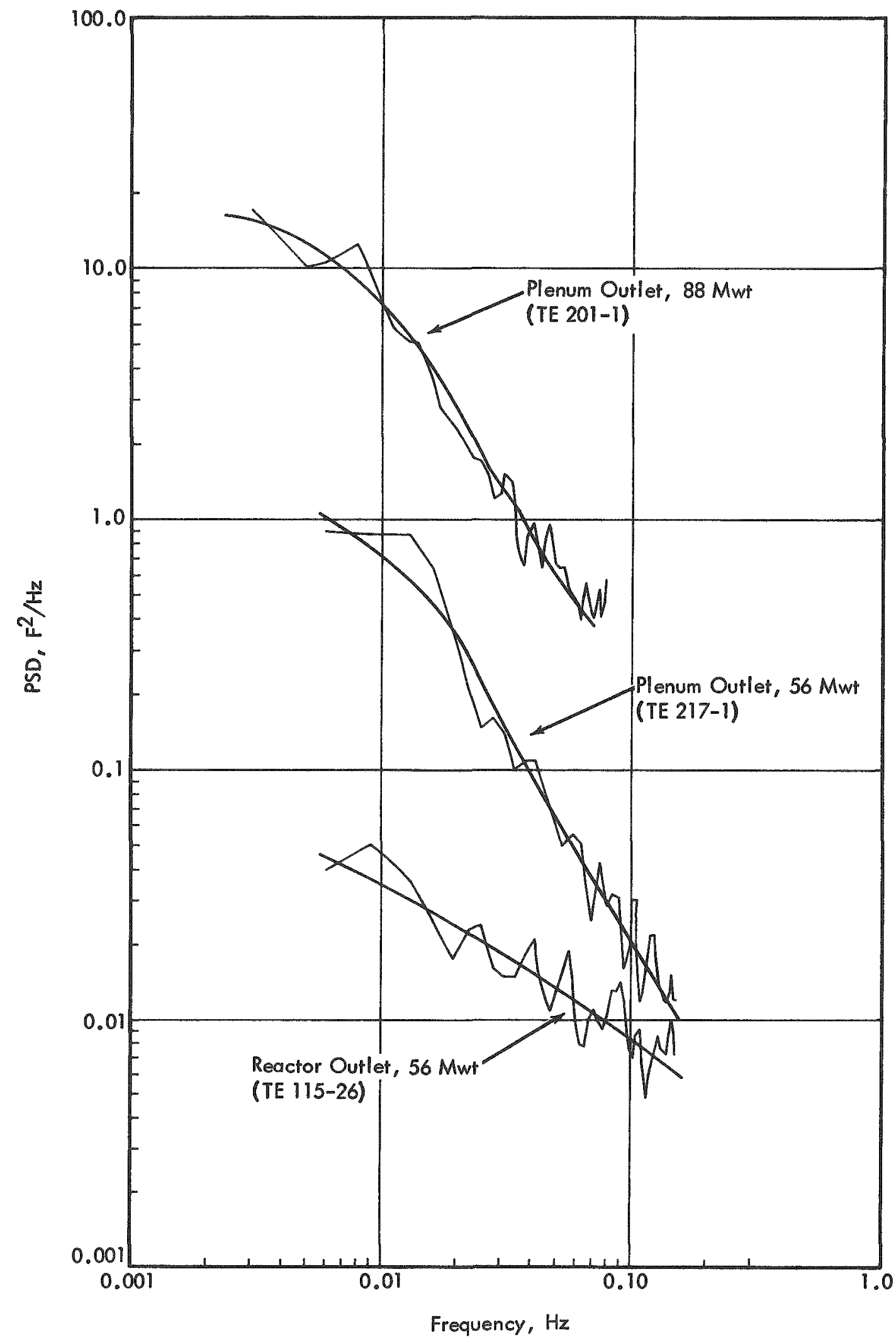

FIG. 19 POWER SPECTRAL DENSITY OF UPPER PLENUM TEMPERATURE 
ates much more at the plenum outlet than at the reactor outlet. This implies poor mixing in the upper plenum between core and blanket sodium.

Some increase would be expected in fluctuations of upper plenum outlet temperature as power level increases; but, for these data, it would be very difficult to estimate how much should be expected, since the flow was also increased. The measurement indicates a factor of 10 increase in the upper plenum outlet temperature PSD between these conditions.

\section{TRANSFER FUNCTIONS}

\section{Flow to Inlet Temperature}

As pointed out previously, flow and inlet temperature variations are the two most important sources of reactor noise. Before attempting to examine how these variations affect the system, however, it is necessary to determine if they are independent or coherent signals. The XSD measurements between flow and reactor inlet temperature were obtained in all three data sets and are shown in Figures 20, 21 and 22. The XSD from the 88 Mwt set is so rough that no attempt was made to obtain a transfer function; the XSD from the $56 \mathrm{Mwt}$ set was somewhat better; the $0.05 \mathrm{Mwt}$ set appeared least rough. This relationship between apparent quality of data and power level seems reasonable, in that the pump work is probably an increasingly important fraction of inlet temperature fluctuations as power decreases. The conclusion drawn is that these can be considered independent noise sources.

\section{Sodium Flow to Reactor Power}

When the reactor power level is sufficient that significant heat is given to the sodium as it passes through the core, variations in flow produce variations in the average coolant temperature and concomitant variation in power level. Since the sodium is flowing in a loop, it would be reasonable to expect the transfer function between these parameters to have a time constant equal to the loop time. However, the heat transfer around the entire loop is sufficiently complicated that a prediction of the flow-to-power transfer function would be a study in itself, and such a study is beyond the scope of this report.

Flow-to-power transfer functions were measured in all three data sets. Results are shown in Figures 6,23, and 24. These results do not have shapes indicative of simple time constants; consequently, no attempt has been made to draw conclusions from them. The transfer function from the $88 \mathrm{Mwt}$ data is similar in shape to that from the 56 Mwt data except that the time constants are a factor of four longer; the explanation for this factor of four is not known. 


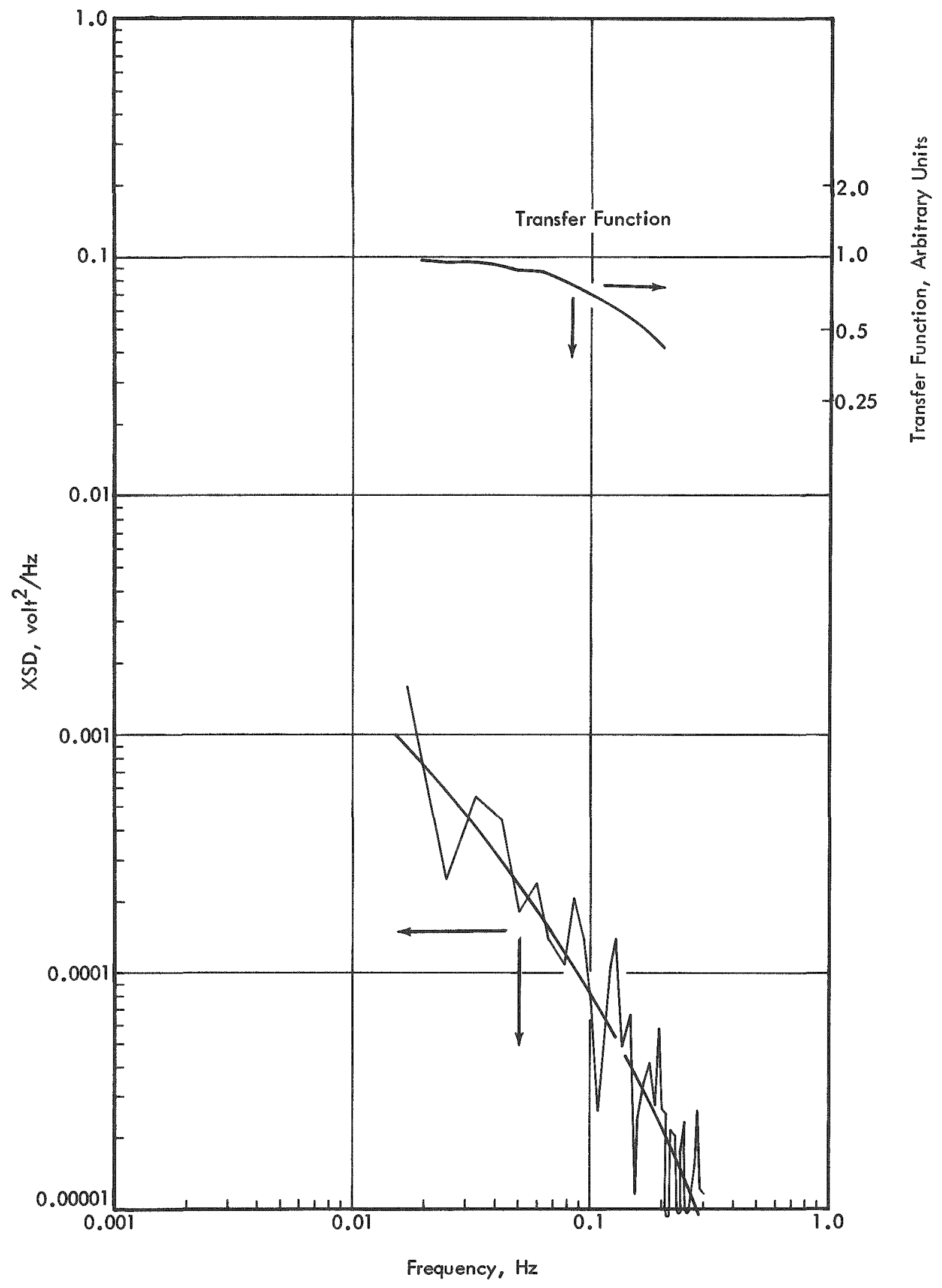

FIG. 20 CROSS SPECTRAL DENSITY AND TRANSFER FUNCTION FOR LOOP 3 SODIUM FLOW AND REACTOR INLET TEMPERATURE, 0.05 MW 


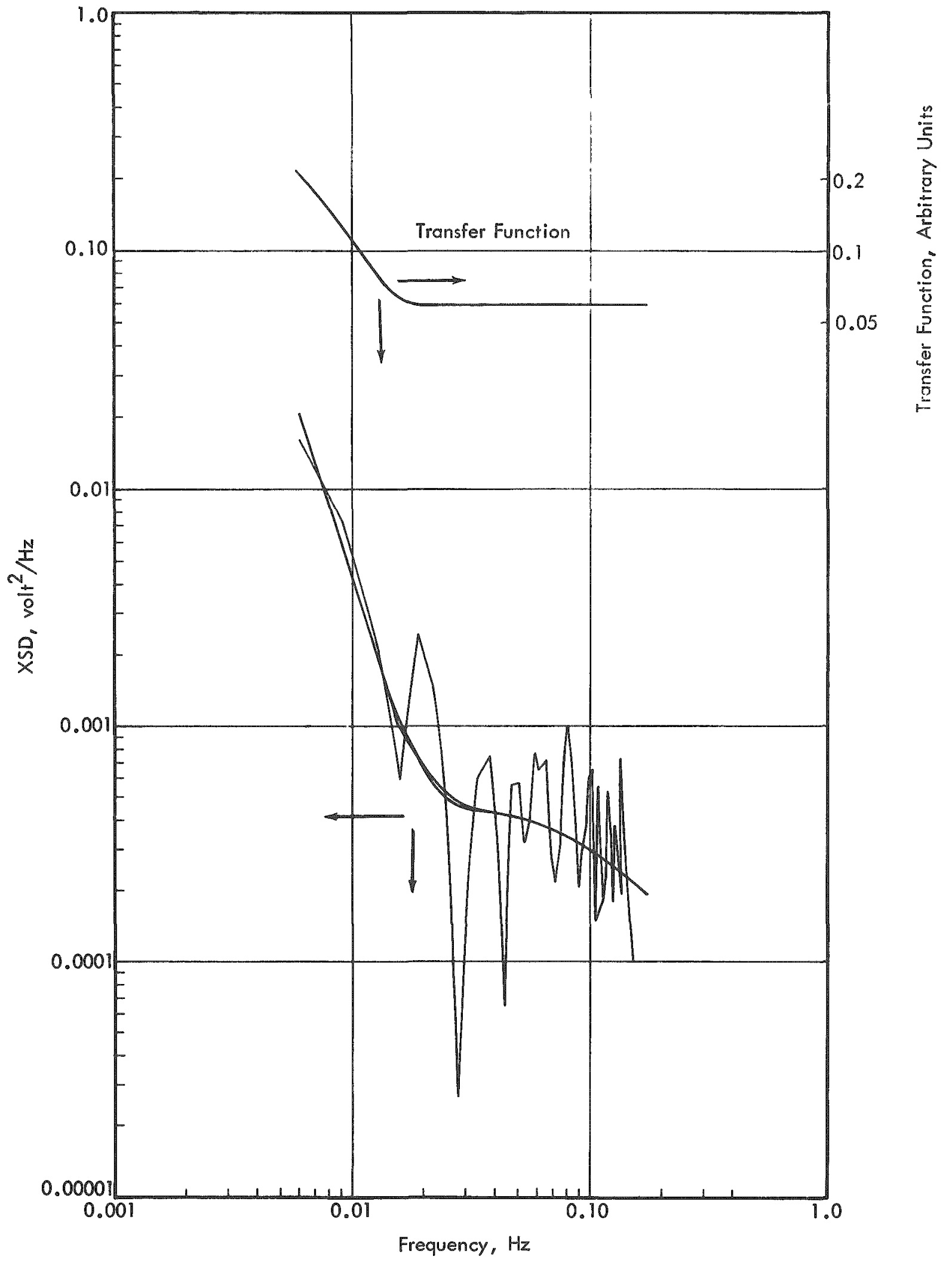

FIG. 21 CROSS SPECTRAL DENSITY AND TRANSFER FUNCTION FOR LOOP I SODIUM FLOW AND REACTOR INLET TEMPERATURE, 56 Mwt 


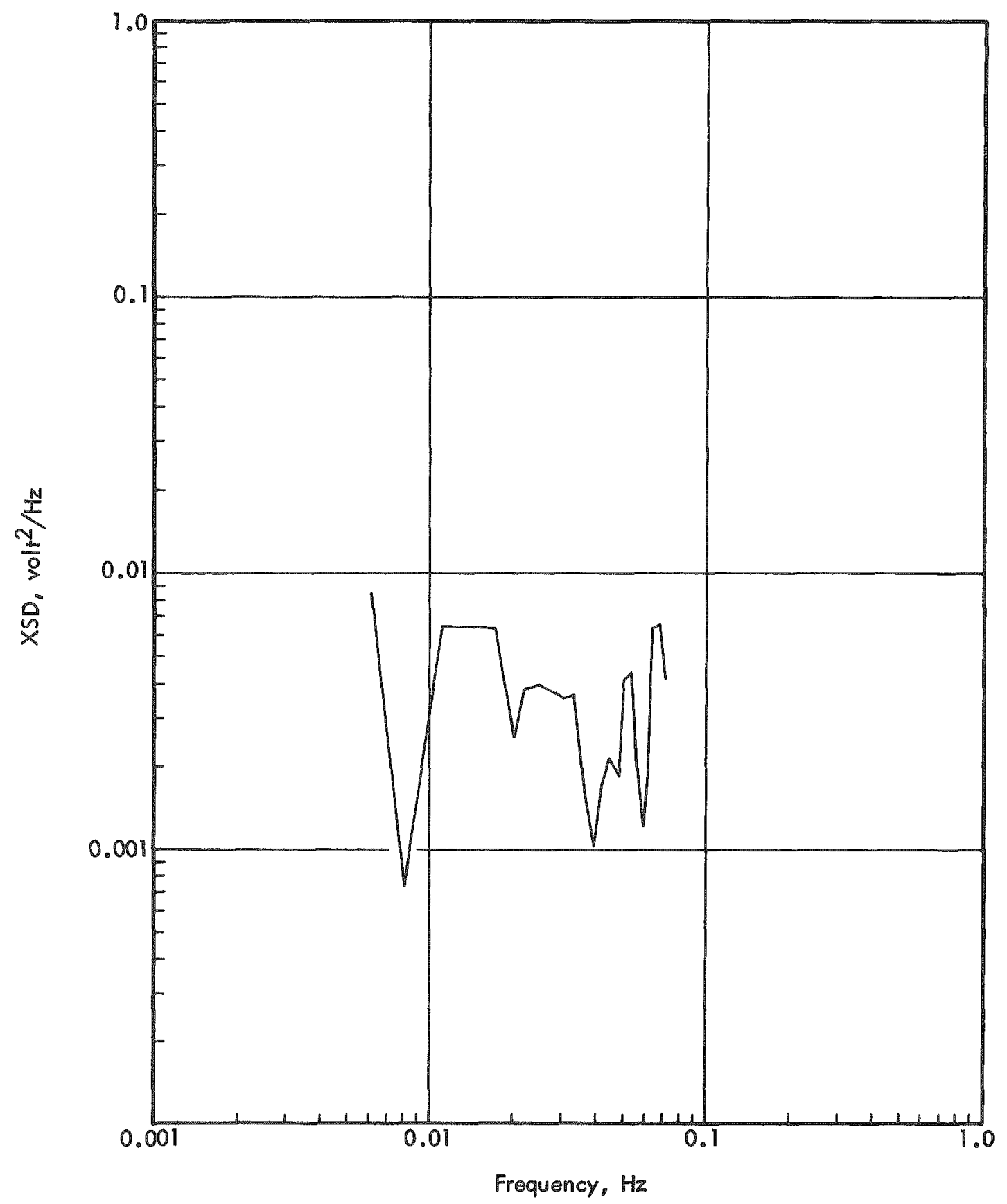

FIG. 22 CROSS SPECTRAL DENSITY FOR LOOP 3 SODIUM

FLOW AND REACTOR INLET TEMPERATURE, 88 MW" 


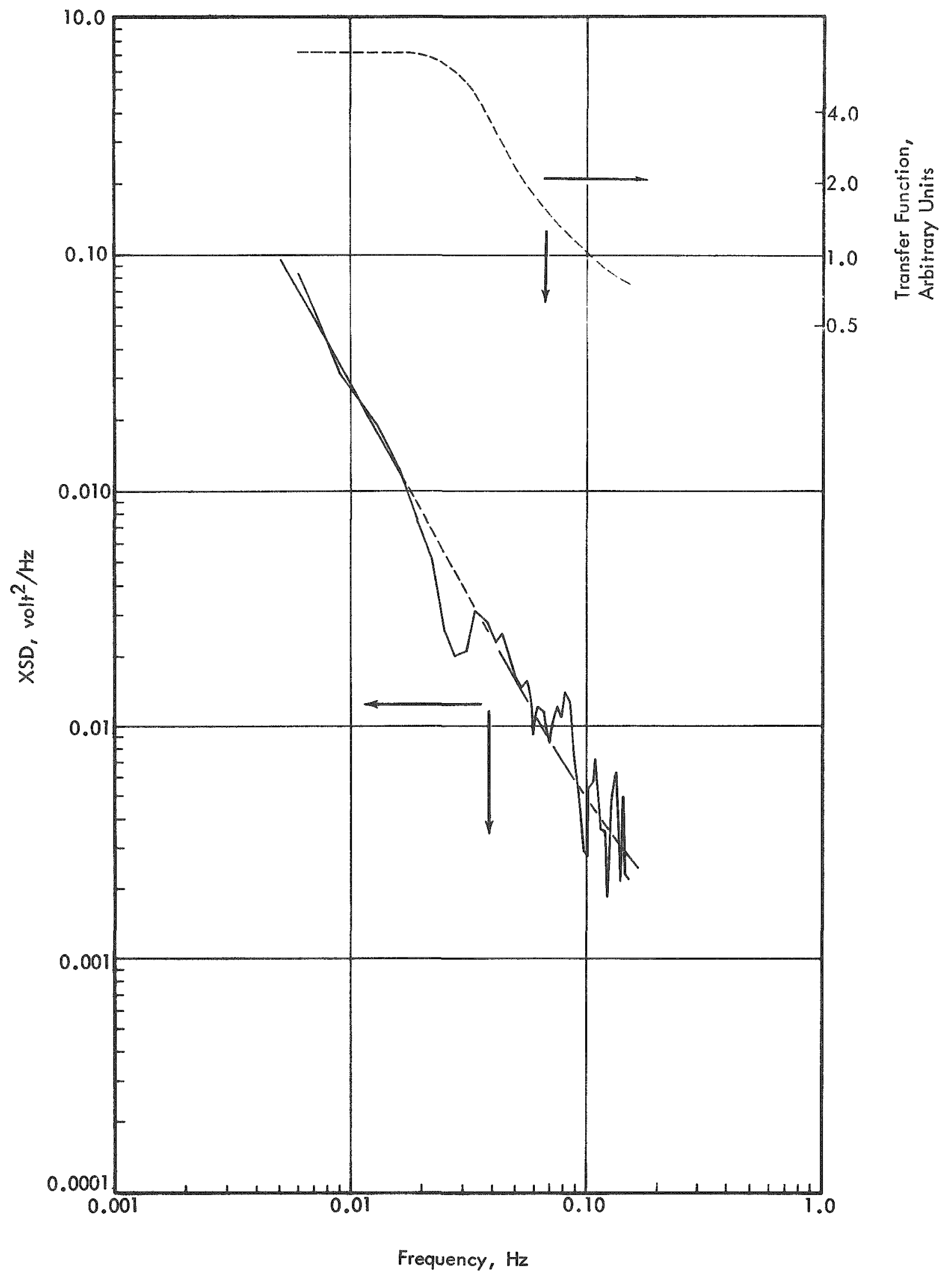

FIG. 23 CROSS SPECTRAL DENSITY AND TRANSFER FUNCTION FOR LOOP I SODIUM FLOW AND REACTOR POWER, 56 MW" 


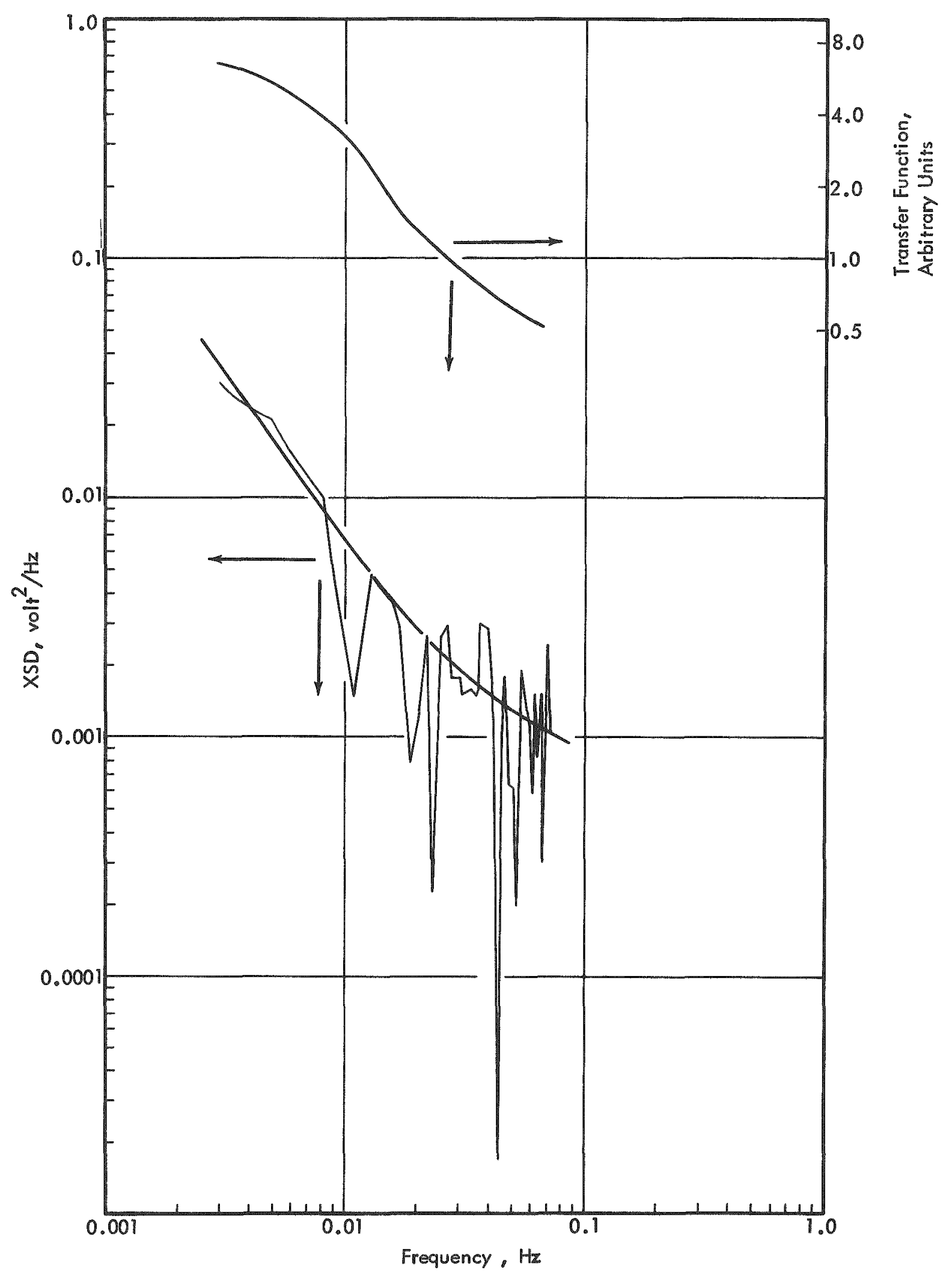

FIG. 24 CROSS SPECTRAL DENSITY AND TRANSFER FUNCTION FOR LOOP 3 SODIUM FLOW AND REACTOR POWER, 88 MW' 


\section{Inlet Temperature to Reactor Power}

At the start of the data analysis, it was believed that the transfer function between reactor inlet temperature and reactor power should have exactly the same shape as the reactivity transfer function measured by oscillator experiments 8 ; it was believed that the spectral distribution of inlet temperature would cause precisely the same spectral distribution of core reactivity. Figure 25 shows this not to be the case for any of the three data sets; the temperature transfer function falls much more rapidly than the reactivity transfer function. There are two possible explanations for this discrepancy: (1) the temperature coefficient is frequency-dependent, and, (2) TE $110-1$ is not measuring core inlet temperature. The first of these explanations is true at higher frequencies but not at the frequencies covered in these measurements.

Between the detector and the actual power-producing core are the lower axial blanket, flow nozzles, and support plates. It is felt that this mass of material has an appreciable effect on the temperature spectrum and that TE 110-1 is indeed not measuring the core inlet spectrum. Thus, the presence of the lower blanket has been used to explain the difference between the reactor inlet temperature to core power transfer function and the reactivity transfer function. The more basic finding, however, is that the spectrum of the inlet temperature cannot be used as a driving function for determining reactivity transfer functions.

\section{Core Outlet Temperature to Reactor Outlet Temperature}

\section{a. Computation of Core Outlet Temperature Spectrum}

The core outlet temperature is the most important component in the upper plenum temperatures. Unfortunately, it cannot be directly measured. A study which was undertaken to develop the core outlet temperature from the measured parameters is summarized in Appendix B. Basically, the study showed an effective transfer function from reactor power to core outlet temperature could be computed with the information at hand using a set of reasonable assumptions. This effective transfer function will be identified by P2T. Thus, transfer functions between core outlet temperature and other parameters can be computed by multiplying measured transfer functions between reactor power and these parameters by P2T. Computed values of P2T are included in Table VI.

\section{b. Core Outlet Temperature to Reactor Outlet Temperature}

The thermocouple included in these data which is most immediately affected by the core outlet temperature is the reactor outlet thermocouple TE 115-26. The transfer function between core outlet temperature 


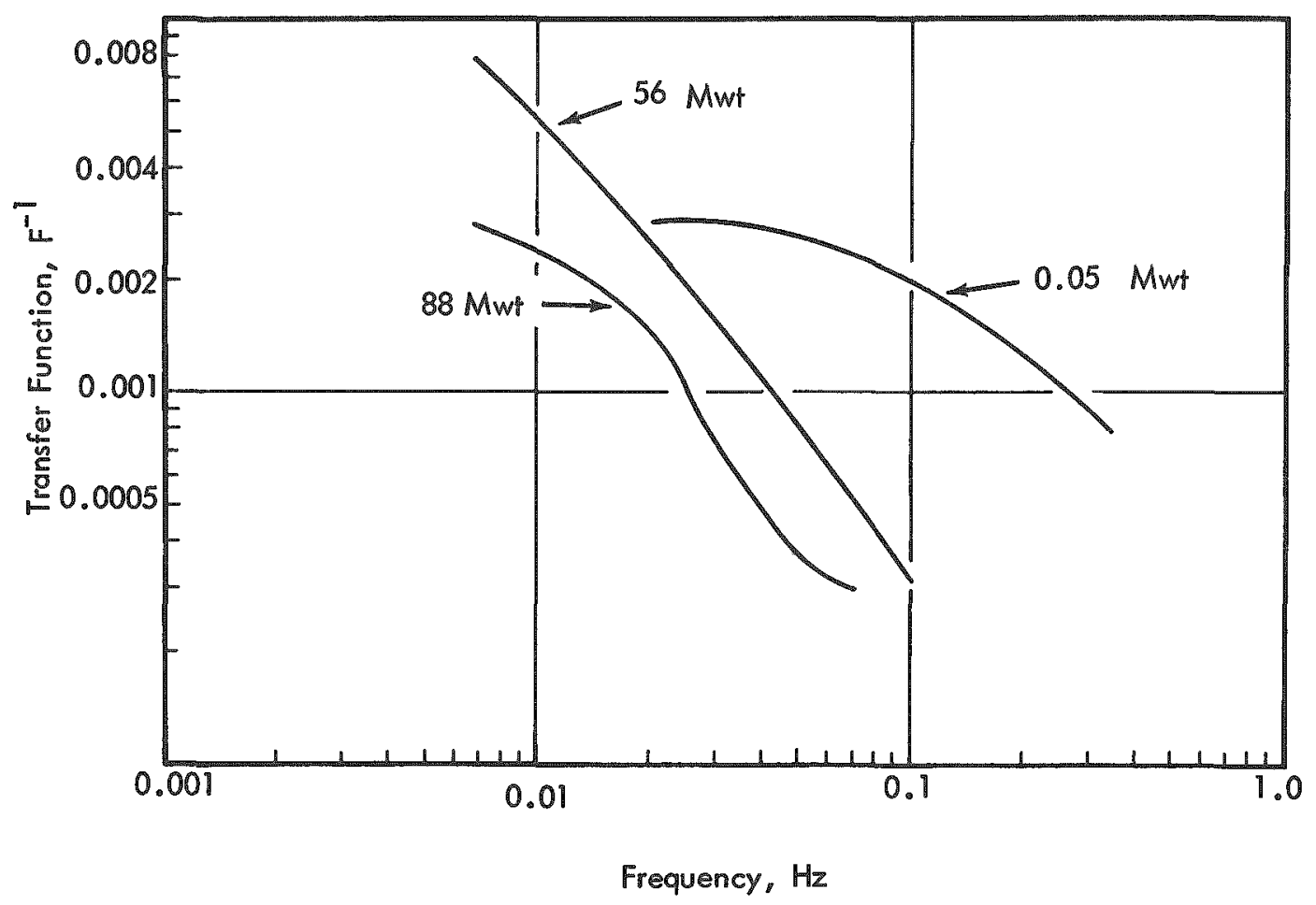

Note: Functions Have Been Divided by Reactor Power

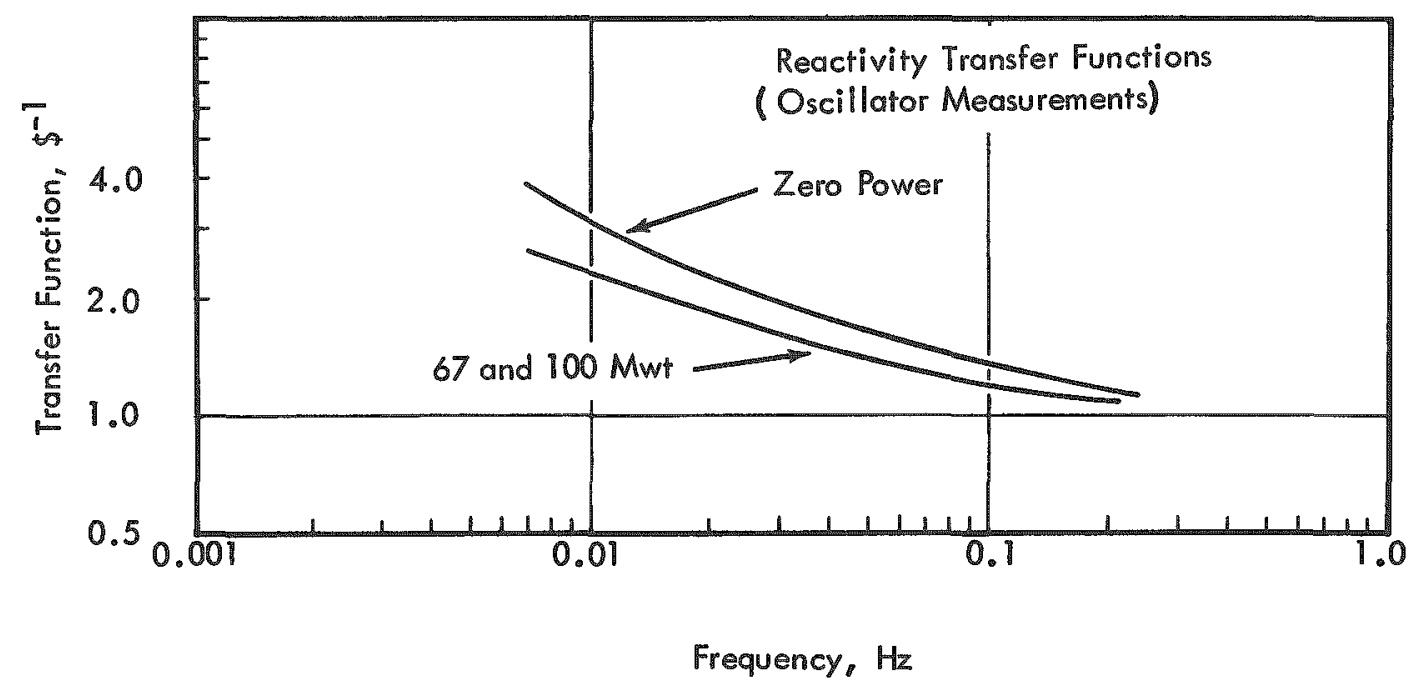

FIG. 25 TRANSFER FUNCTION FROM REACTOR INLET TEMPERATURE TO REACTOR POWER 
TABLE VI - SUMMARY OF TRAXSFER FLNCTIONS

Power Lewel

$0.05 \mathrm{Rw}$ 56 Mwt

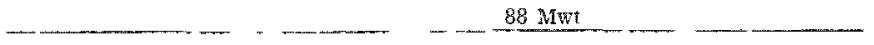

Reactivaty

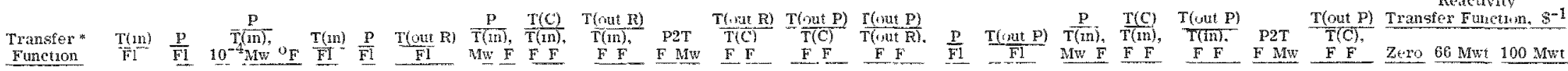

Frequency, Hz

0.005

0.01

0.02

0.03

\begin{tabular}{|c|c|c|c|c|c|c|c|}
\hline & & & 0.21 & 7.3 & 1.9 & 0.45 & 3.0 \\
\hline & & & 0.13 & 7.1 & 1.2 & 0.33 & 2.1 \\
\hline 0.97 & 0.29 & 1.5 & 0.07 & 6.8 & 1.3 & 0.17 & 1.2 \\
\hline 0.97 & 0.20 & 1.6 & 0.06 & 5.5 & 1.2 & 0.11 & 0.93 \\
\hline 0.90 & 0.14 & 1.6 & 0.06 & 2.8 & 0.75 & 0.060 & 0.75 \\
\hline 0.83 & 0.15 & 1.6 & 0.06 & 1.5 & 0.64 & 0.043 & 0.72 \\
\hline 0.70 & 0.16 & 1.5 & 0.06 & 1.0 & 0.58 & 0.029 & 0.62 \\
\hline 0.42 & 0.23 & 1.3 & & & & & \\
\hline & 0.33 & 1.2 & & & & & \\
\hline & Symben & & & & arameter & & \\
\hline & Fl & & Na flow in & 14-1n & a. lne & & \\
\hline & $T(\mathrm{in})$ & & Na temper & rature & entermy & reactor & \\
\hline & $\mathrm{p}$ & & Reactar po & rower $f$ & from nesu & trin dett & returs \\
\hline & $T(C)$ & & Computed & i gutlet & tempar & ature of & core \\
\hline & $T($ out $R)$ & & Na temper & rature & leavng & reuctor & \\
\hline & $T$ (out P) & & Na temper & & leavms & apper ple & \\
\hline
\end{tabular}

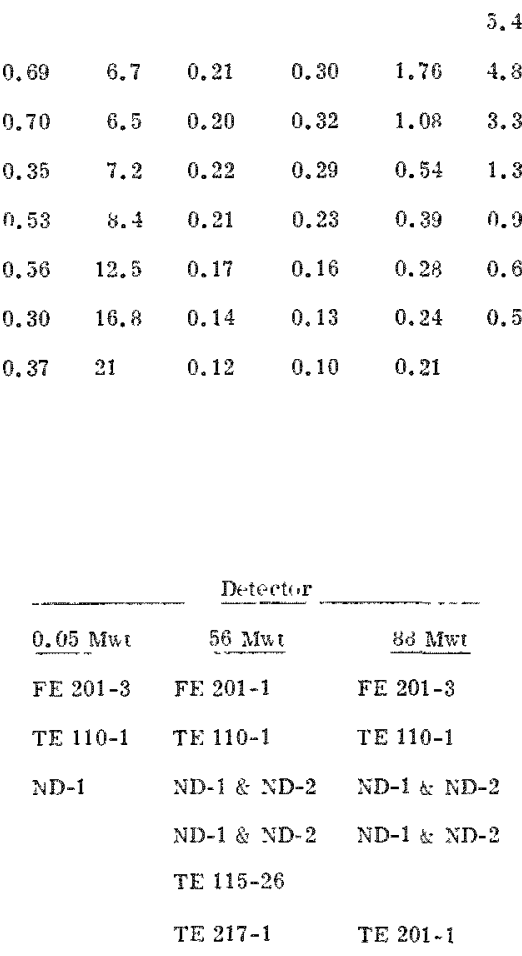

\begin{tabular}{|c|c|c|c|c|c|}
\hline & \multirow[b]{2}{*}{ Symibul } & \multirow[b]{2}{*}{ Parameter } & & & \\
\hline & & & $0.65 \mathrm{MW}$ & 56 Mut & $83 \mathrm{MWt}$ \\
\hline \multirow{6}{*}{ * Numenclature: } & FI & Na flow in $14-1 n_{0}$ lne & FE 201-3 & FE $201-1$ & FE 201-3 \\
\hline & $T(\mathrm{in})$ & Na temperature entermeg reactor & TE $110-1$ & TE $110-1$ & TE $110-1$ \\
\hline & $\mathrm{p}$ & Reactar power from neure in detecturs & $N D-1$ & NDD-1 \& ND-2 & NDD-1 $\&$ ND-2 \\
\hline & $T(C)$ & Computed outhet temprerature of core & & NDD-1 \& ND 2 & $N D-1$ a $X D-2$ \\
\hline & $T($ out $R)$ & Na temperature leaving reuctor & & TE $115-26$ & \\
\hline & $T($ out $P$ ) & Na temperature leavang upper plenum & & $\mathrm{TE} 217-1$ & $\mathrm{~T} E 201-1$ \\
\hline
\end{tabular}


and this thermocouple should have the form of a single time constant equal to the response time of the thermocouples $T$; i.e.,

$$
\mathrm{TF} \sim \frac{1}{1+i \omega \mathrm{T}}
$$

The response time for TE 115-26 measured in reactor pulse experiments (Reference 9) was 2.0 seconds. The response measured in Figure 26 from reactor power and TE 115-26 data using $\mathrm{P} 2 \mathrm{~T}$ is 2.5 seconds. (The response time was measured by overlaying on the data a function of the form $(1 / 1+i \omega)$ until the best agreement was achieved; the ratio of corresponding values of $w$ gives a value of the response time.) A 25\% error indicates the accuracy of P2T is not good; but in light of the many approximations involved in P2 T and the fact that $P 2 T$ varies by a factor of 7 over the frequency range of measurements, the error seems reasonable and the P2T transfer function development seems basically correct.

\section{Core Outlet Temperature to Plenum Outlet Temperature}

Transfer functions between plenum outlet and core outlet, shown in Figure 26, indicate a 5-second time constant for TE 217-1 and a 7-second time constant for TE 201-1. The response time of TE 201-1 has been measured as 6 seconds in a laboratory by plunging it into a hot, stagnant pool of sodium. 10 Thus the measured time constants are commensurate with the response times of the detectors.

However, if the time constant of the upper plenum was within the range of measurement, it should appear in this data as an additional roll-off. Since this is not the case, it must be concluded that the time constant of the upper plenum is less than 1 second. With complete mixing in the upper plenum, its time constant would be in the range of 30 seconds. The conclusion is drawn, therefore, that little or no mixing is occurring in the upper plenum.

6. Reactor Inlet To Core, Reactor, and Plenum Outlet Temperatures

The cross spectral density for the reactor inlet and plenum outlet temperatures at $88 \mathrm{Mwt}$ power is shown in Figure 27.

Figure 26 shows that the transfer functions from reactor inlet temperature, TE $110-1$, to temperatures at other points of the system are irregular and not indicative of any combination of two simple time constants (one time constant for each detector). The coherence functions (Sec V.E.) show low common signal level between TE 110-1 and upper plenum temperatures from which one would expect low accuracy, but the ir regularity of TE 110-1 to core outlet temperature is difficult to understand and has been 


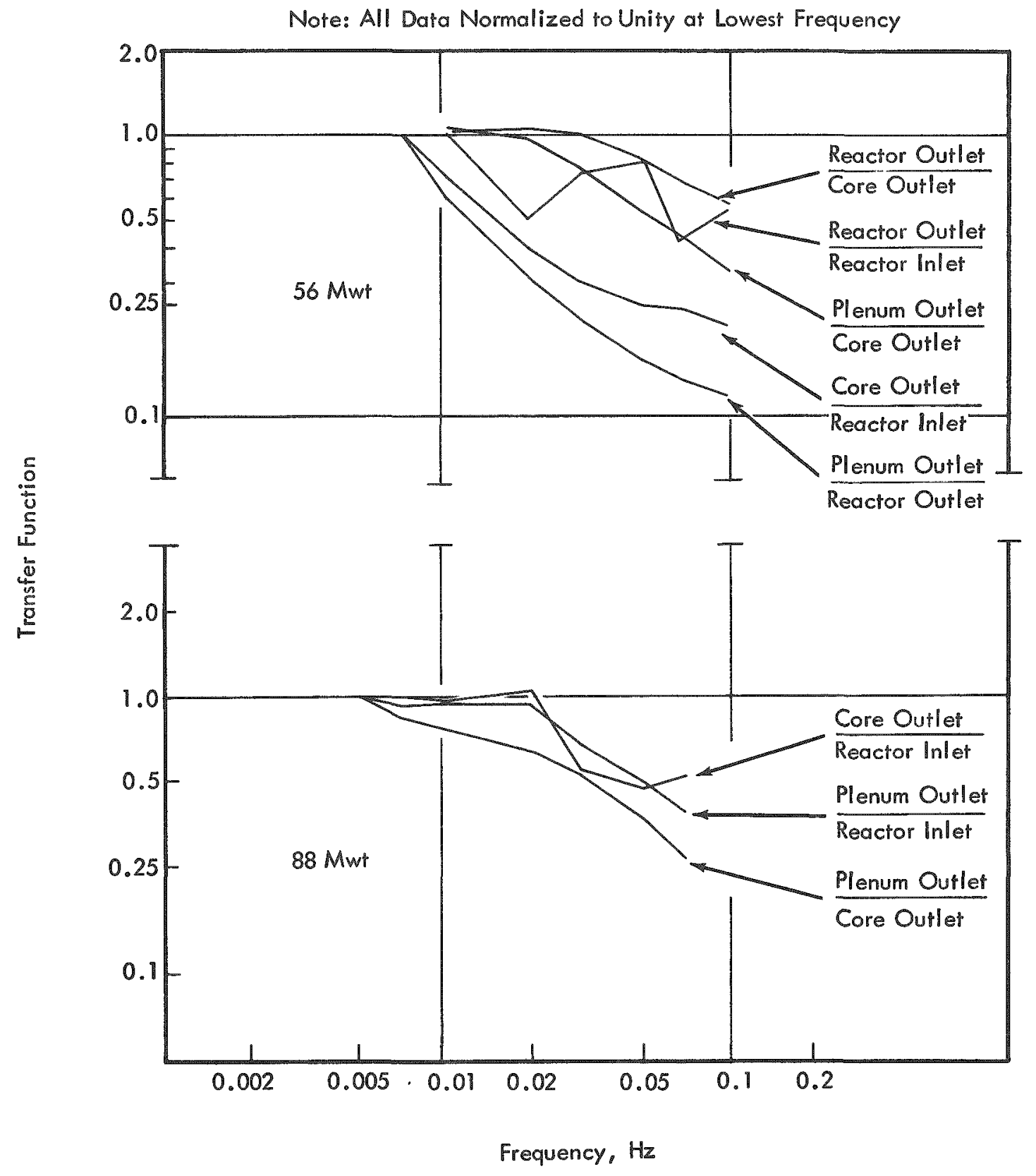

FIG. 26 TEMPERATURE TRANSFER FUNCTIONS 


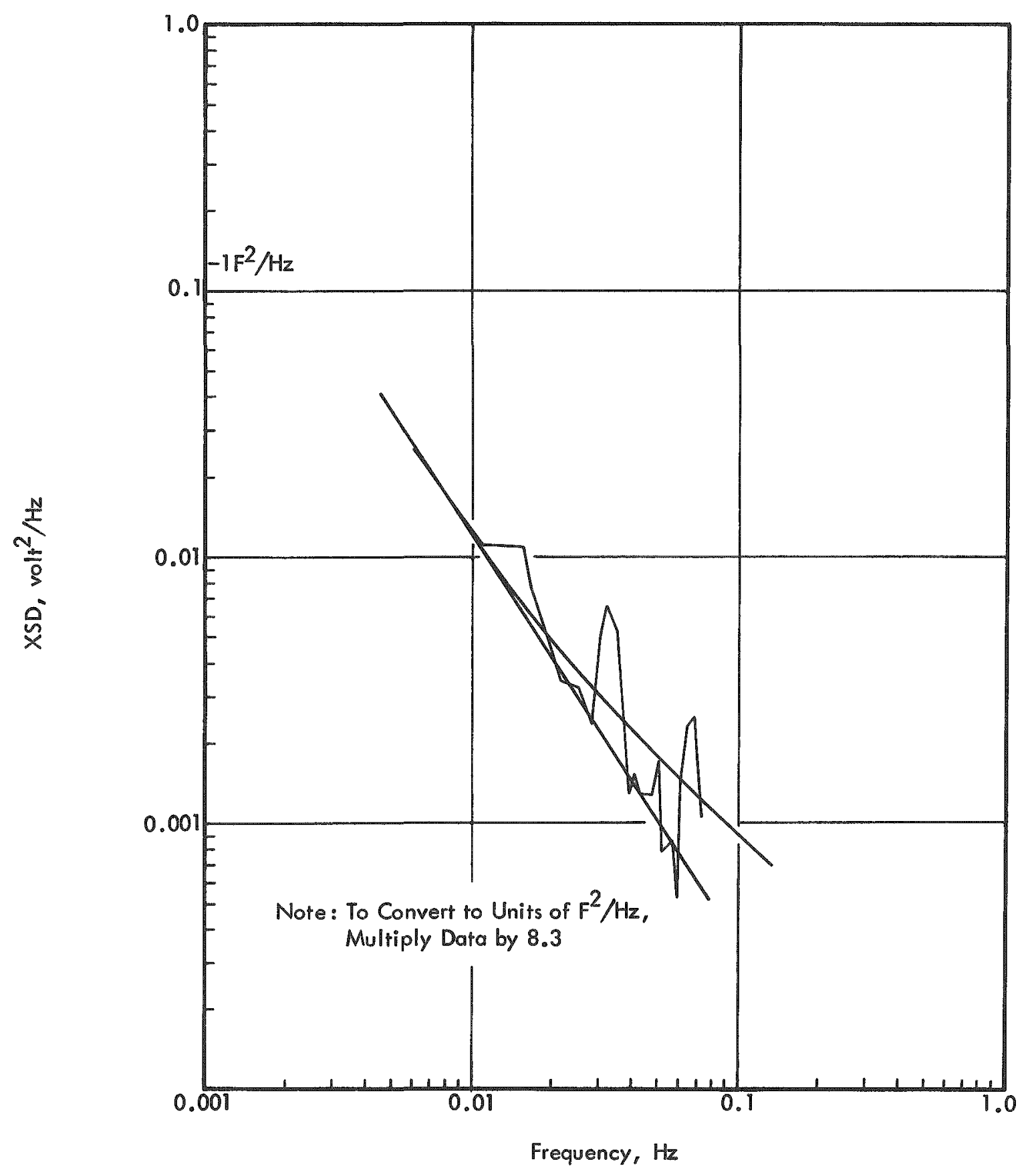

FIG. 27 CROSS SECTION DENSITY FOR REACTOR INLET AND PLENUM OUTLET TEMPERATURES, 88 MWI 
left as an unanswered question. Future work should investigate the response of TE 110-2 as well as TE 110-1, since TE 110-2 is in more direct contact with reactor inlet sodium.

\section{Reactor Outlet to Plenum Outlet Temperature}

The cross spectral density for reactor outlet and plenum outlet temperatures (measured only at $56 \mathrm{Mwt}$ power) is shown in Figure 28.

Figure 26 shows that the reactor outlet to plenum outlet temper ature transfer function falls by a factor of 10 from 0.07 to 0.1 Hertz. The shape of the transfer function is not consistent with either the other measured transfer functions or with the predicted transfer function, but is indicative of a large, random noise source (either real temperature variation or extraneous signal pickup) riding on the TE 115-26 signal. Coherence functions and error calculations support this theory.

\section{Low Frequency Asymptotic Value of Temperature Transfer Functions}

A transfer function of temperatures between one point of a system and another should approach unity as frequency goes to zero. Table VI, a summary of all measured transfer functions, shows the low frequency values varying between 0.2 and 3.0. Even though much accuracy of calibration was lost between original recording and digitizing, agreement should be better than shown. The situation would be much improved if the calibration of reactor power noise in the $56 \mathrm{Mwt}$ data set were in error by a factor of 2.2 or P2T for $56 \mathrm{Mwt}$ in error by a factor of 5 . It is difficult to find errors of this magnitude and the question raised by these low frequency values remains one to be answered by later work.

\section{DETERMINATION OF LAGS FROM PHASE CURVES}

The sodium flow is the main carrier of information around this system. Because of this flow, a time lag is expected between the various temperature detectors. As explained previously, the lag time between two signals manifests itself in their phase relationships; a single time lag introduces a linear trend which has a slope proportional to the lag time. The phase curves, plotted on linear scales, are presented in Figures 29, 30, and 31 for $0.05 \mathrm{Mwt}, 56 \mathrm{Mwt}$, and $88 \mathrm{Mwt}$ data set, respectively. The phase curves from all correlation functions were examined for lag indications. The results are shown diagrammatically in Table VII.

Time lags between points not including the plenum outlet were not seen for 3-loop operation (0.05 Mwt and $88 \mathrm{Mwt}$ ). The 56 Mwt2-loop data does indicate measurable lags up to 6 seconds between flow and reactor outlet temperature. The meaning of these lags is not understood. (Some of the 


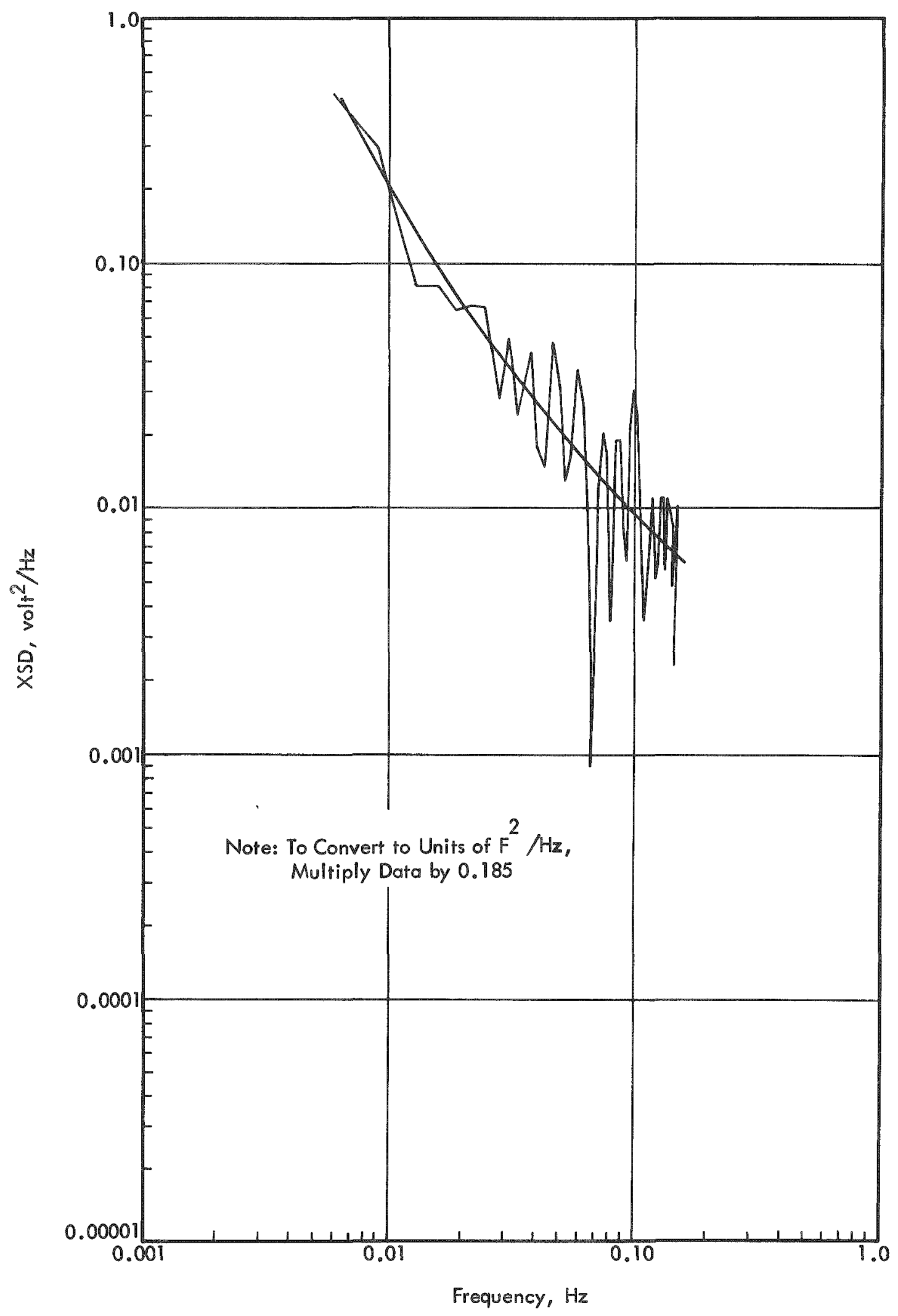

FIG. 28 CROSS SECTION DENSITY FOR REACTOR OUTLET AND PLENUM OUTLET TEMPERATURE, 56 MWH 


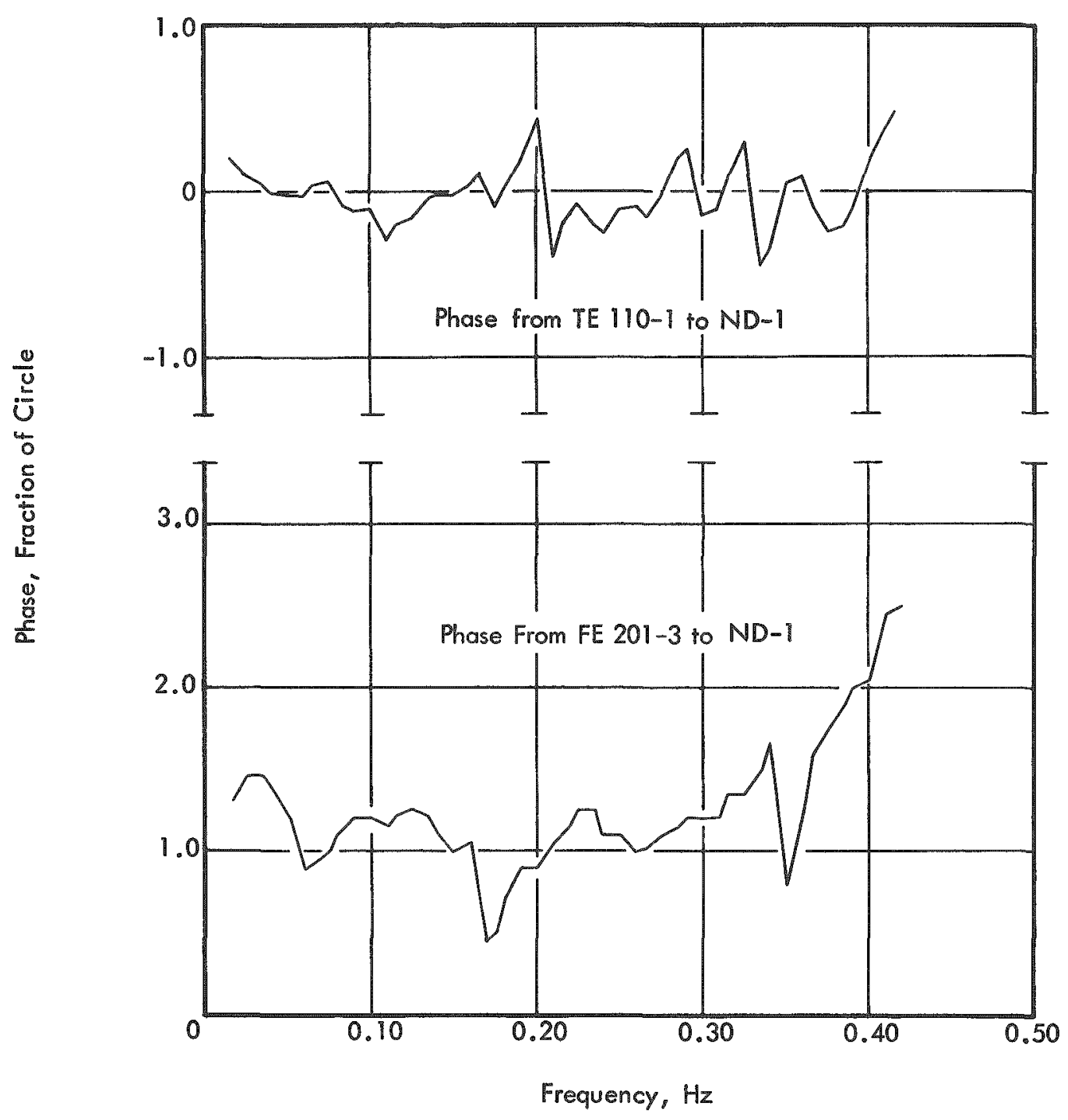

FIG. 29 PHASE CURVES FROM 0.05 Mwt CROSS SPECTRAL DENSITY CALCULATIONS 


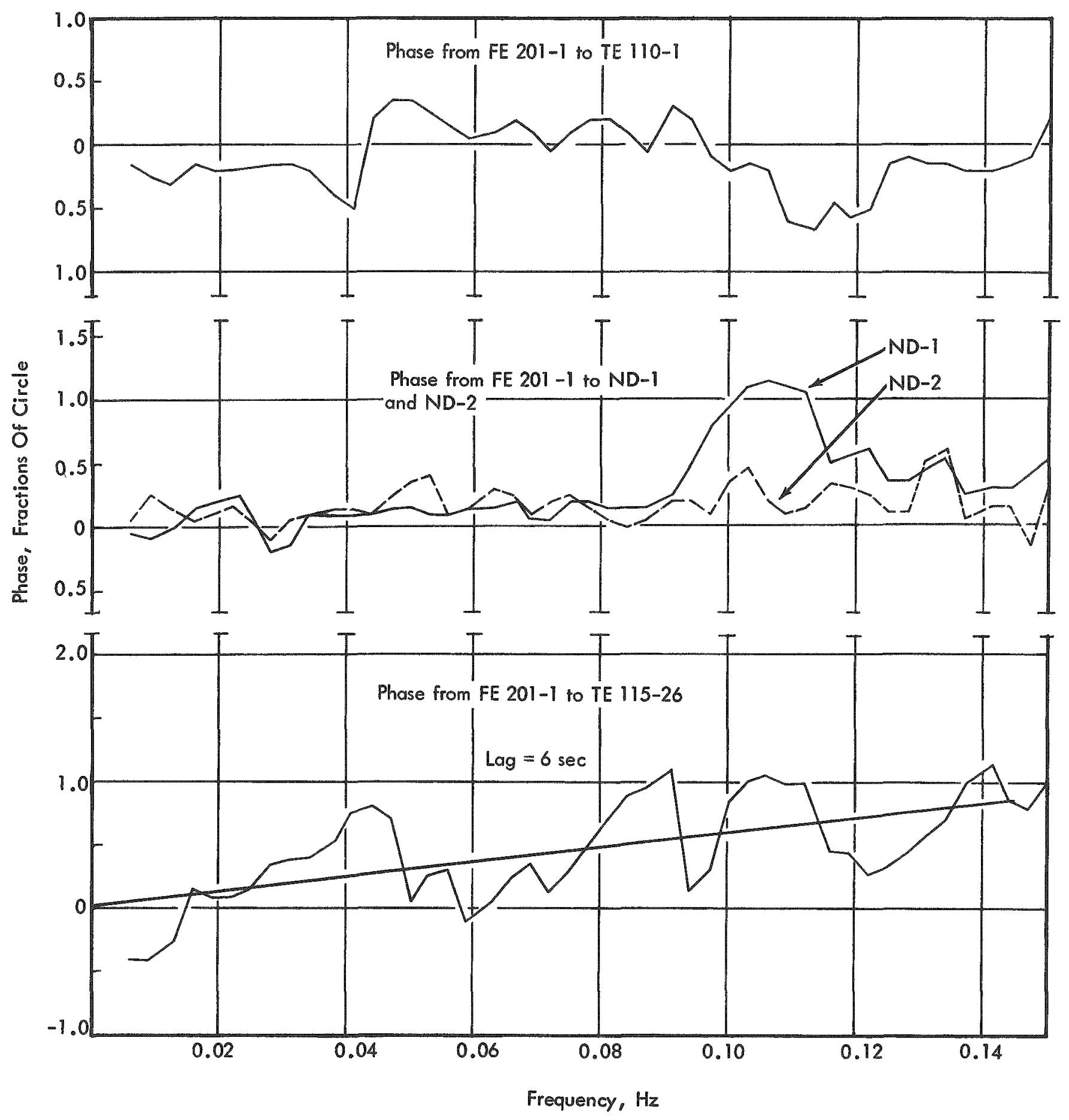

FIG. 30a PHASE CURVES FROM 56 MWT CROSS SPECTRAL DENSITY CALCULATIONS 

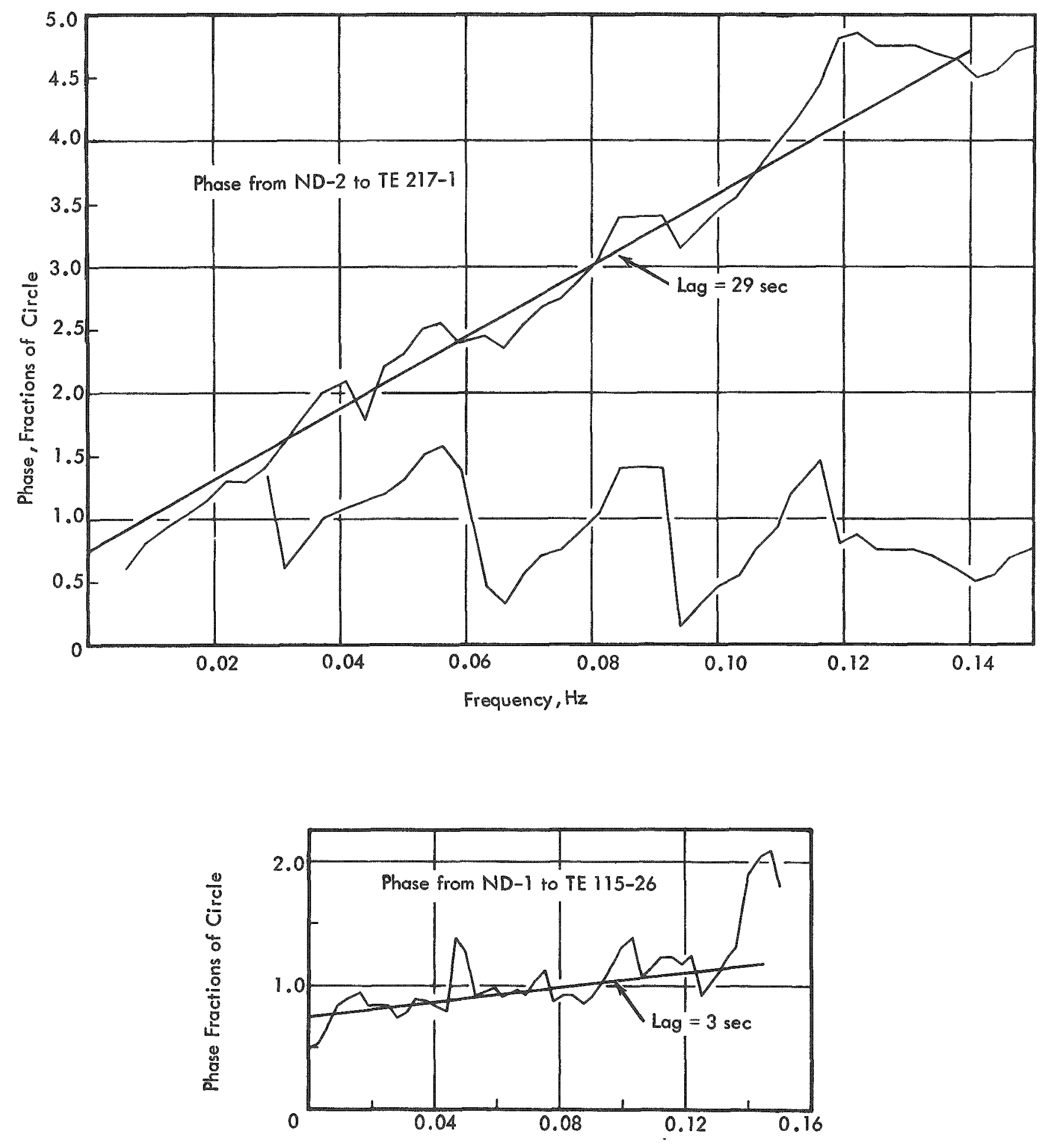

Frequency, $\mathrm{Hz}$ 


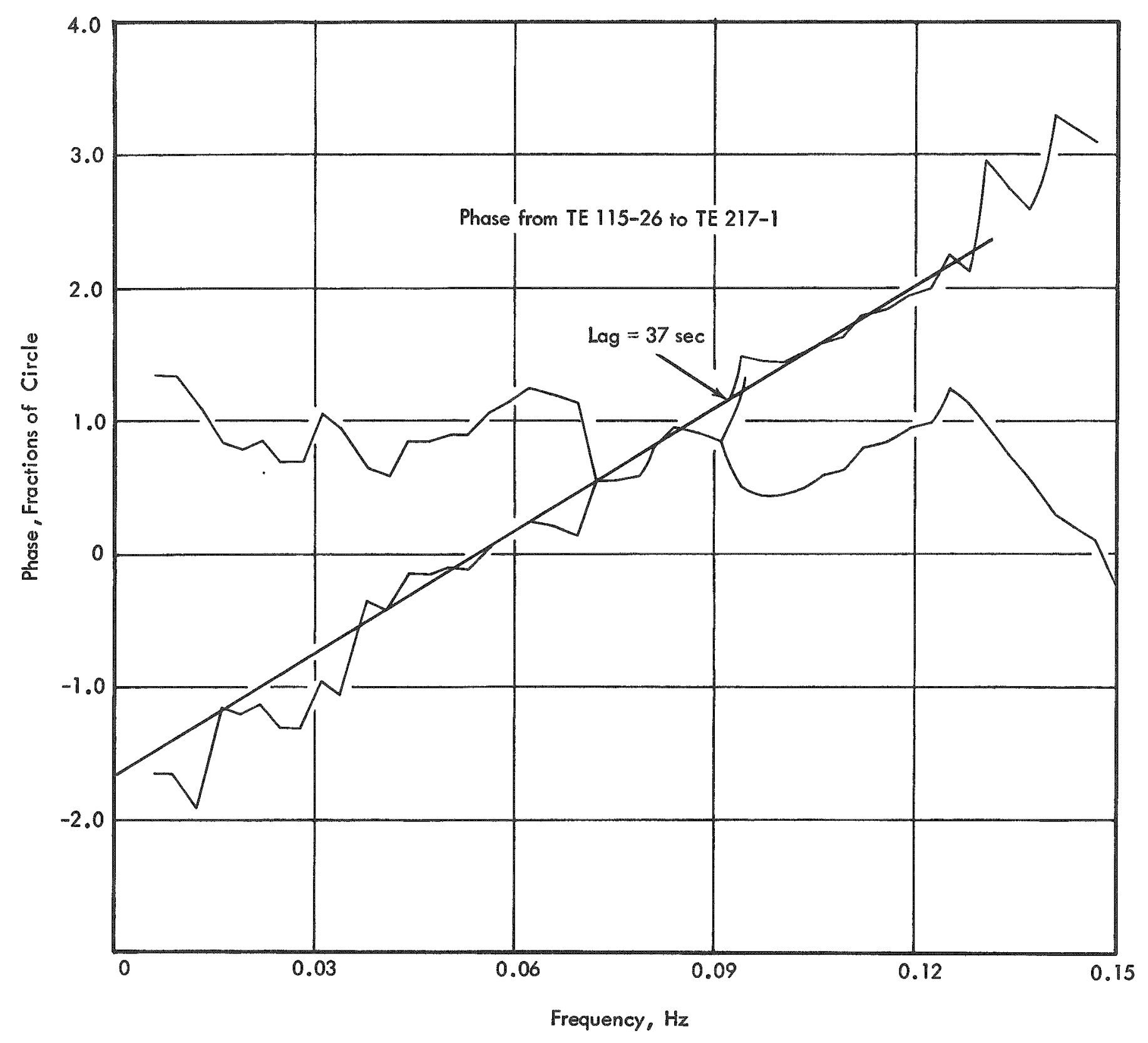

FIG. 30c PHASE CURVES FROM 56 Mwt CROSS SPECTRAL DENSITY CALCULATIONS 


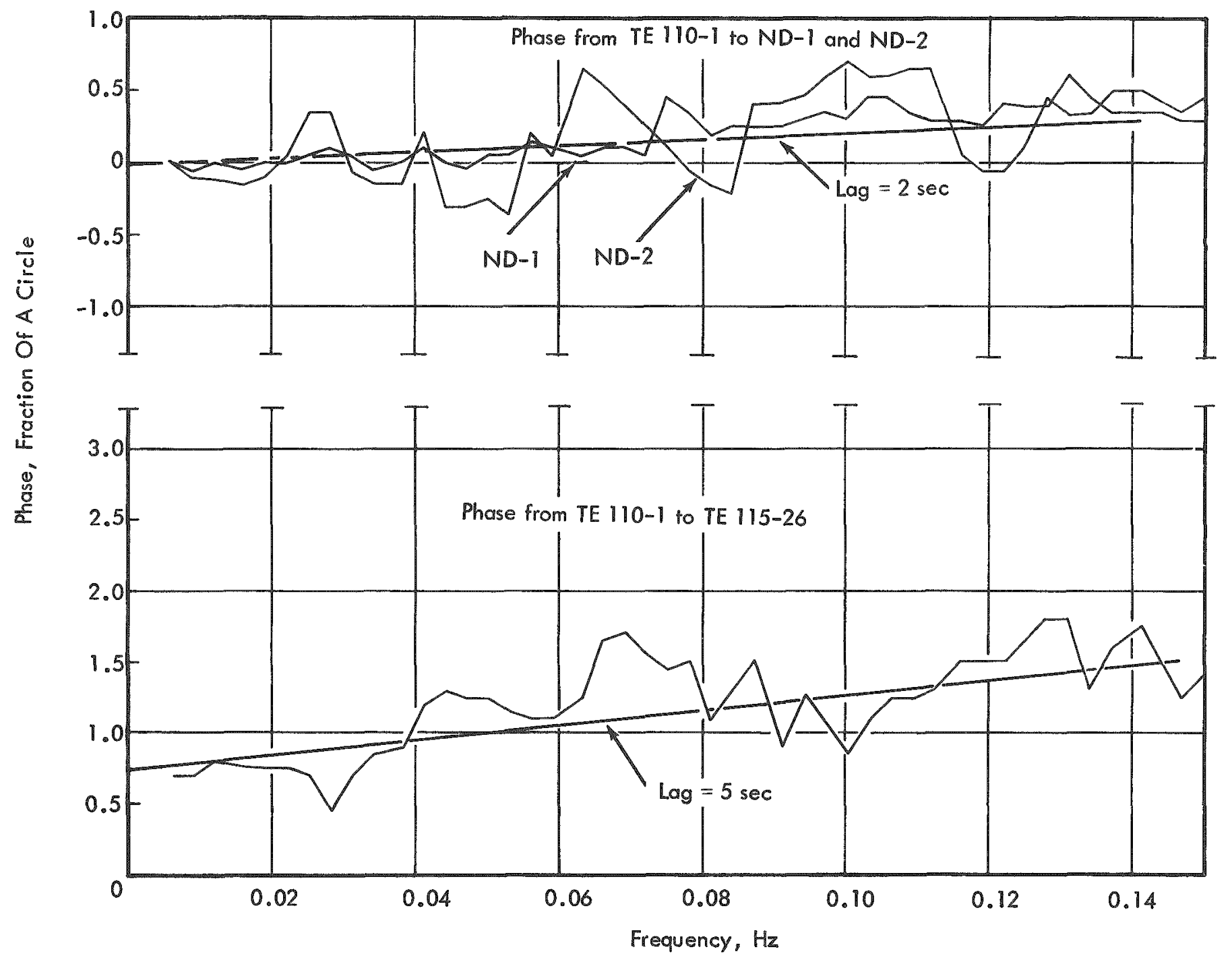

FIG. 30d PHASE CURVES FROM 56 MWI CROSS SPECTRAL DENSITY CALCULATIONS 


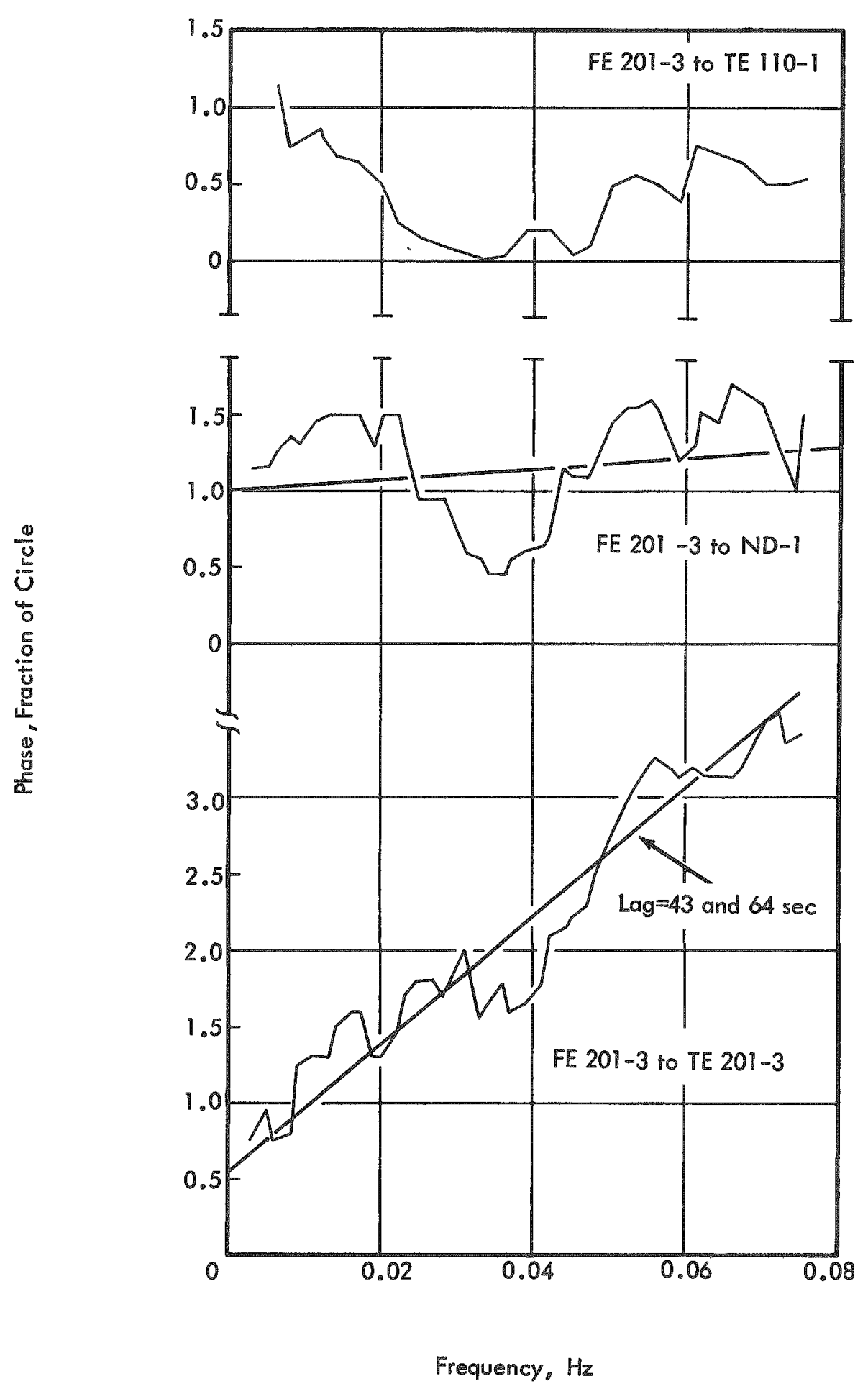

FIG. 31a PHASE CURVES FROM 88 Mw CROSS SPECTRAL DENSITY CALCULATIONS 

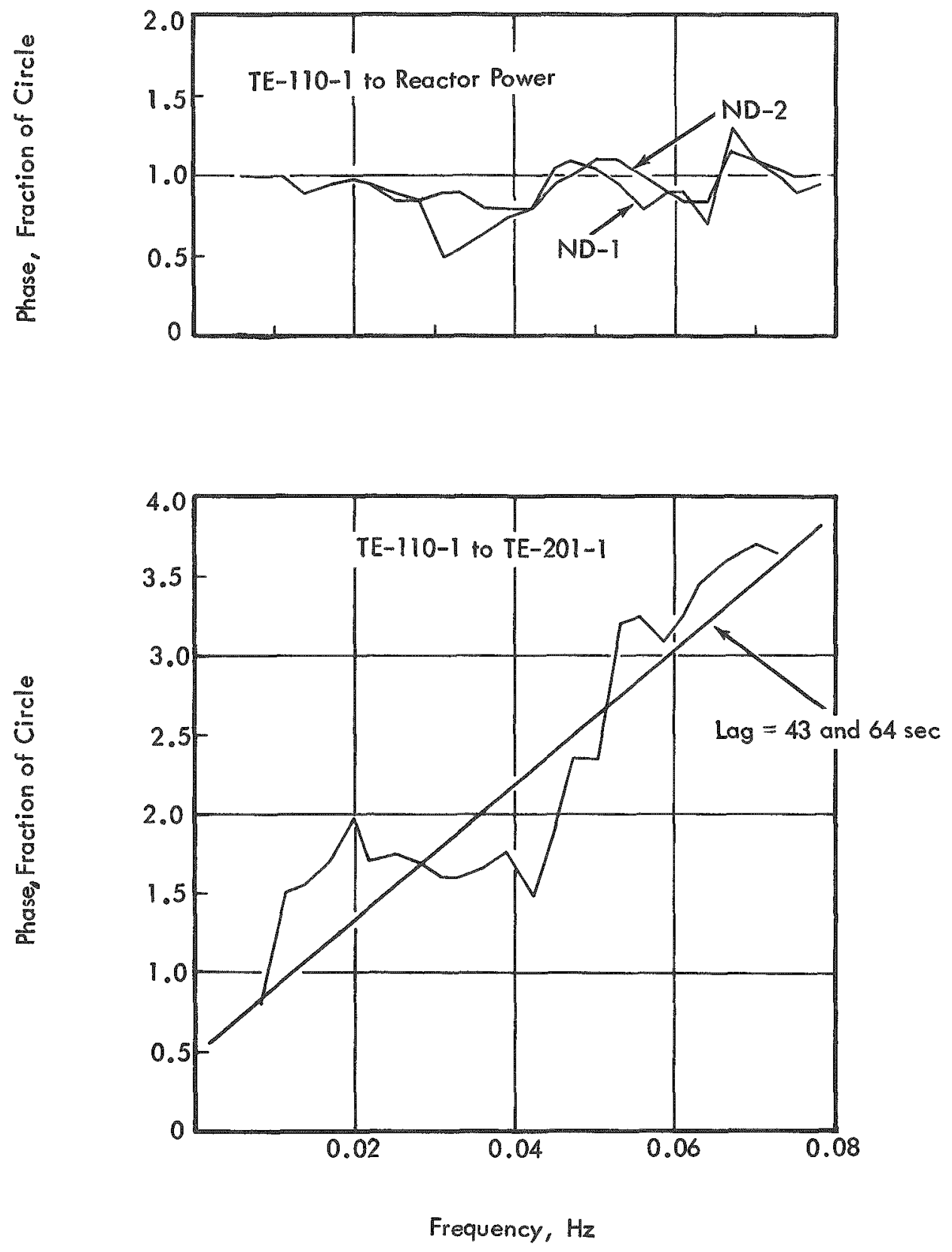

FIG. 316 PHASE CURVES FROM 88 Mwt CROSS SPECTRAL DENSITY CALCULATIONS 


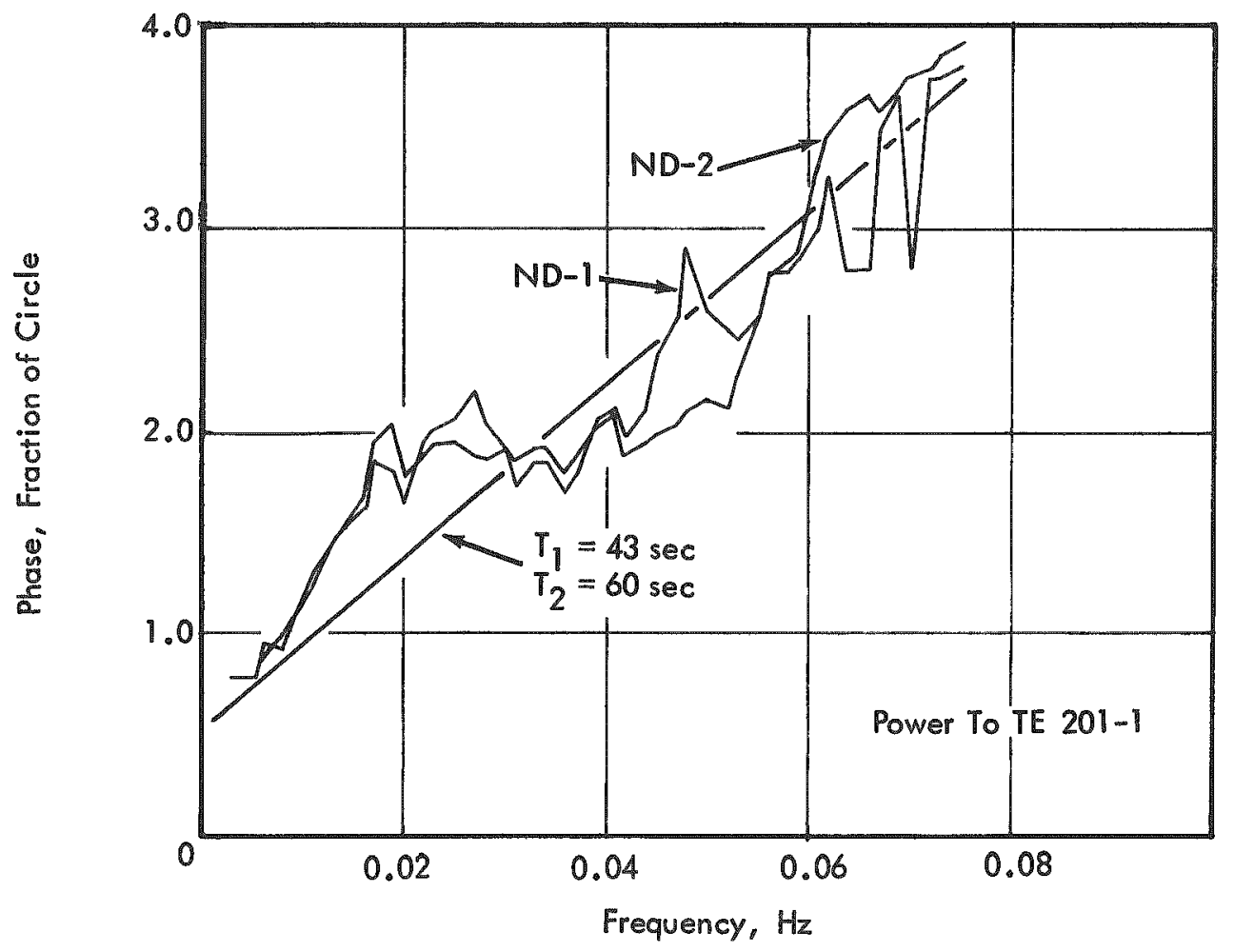

FIG. 31c PHASE CURVES FROM 88 MW CROSS SPECTRAL DENSITY CALCULATIONS 
TABLE VII - MEASURED TIME LAGS BETWEEN PARAMETERS

Lag Time, sec

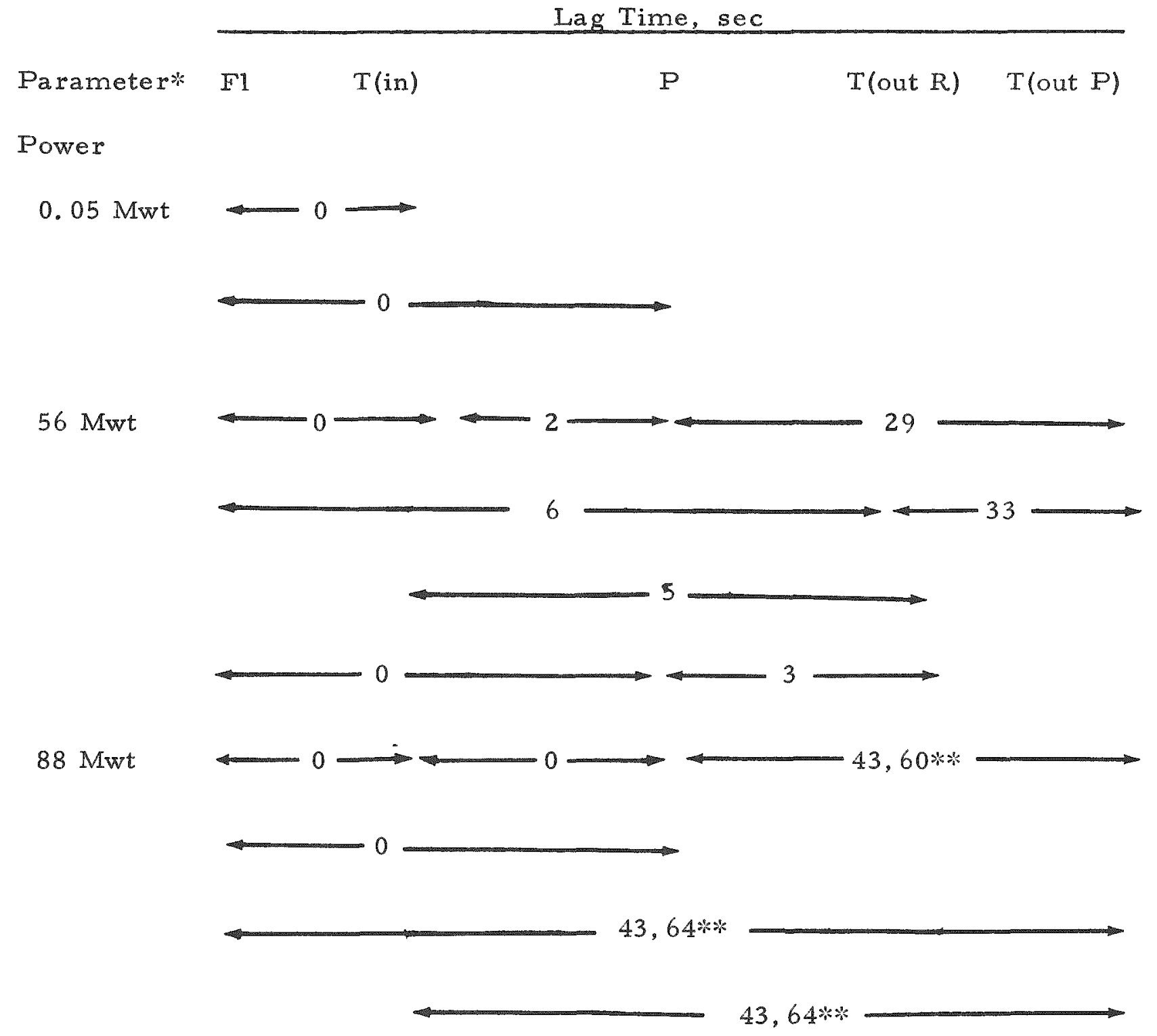

* See Table VI for definition of nomenclature.

** From the shape of phase curves, a two-time-constant model was considered to be most reasonable. 
measured lag could be due to digitizer start, which is no better than one sample time, or 3.2 seconds for these data.)

Time lags between various points and the upper plenum outlet are very long: on the order of 30 seconds for the $56 \mathrm{Mwt} 2-100$ p data and on the order of 40 seconds for the $88 \mathrm{Mwt} 3-100$ data. If there were complete mixing in the upper plenum, these time lags would be zero. If there were no mixing and no channeling, the time lags would be the quotient of the total plenum volume (1143 $\mathrm{ft}^{3}$ ) and the total sodium flow (Ref. 11, p. 280). These maximum lags are 47 seconds for the $56 \mathrm{Mwt}$ xun and 33 seconds for the $88 \mathrm{Mwt}$ run. The conclusions are (1) that very little mixing is occurring in the upper plenum, (2) that under 3-loop operation, little or no channeling is present, and (3) that under 2-loop operation, some channeling does occur.

The oscillatory nature of the 88 Mwtphase curves has been taken to be an indication of a second lag time of 60 seconds. The meaning of such a lag is not known. It could be the total loop time; however, since it appears only in data using TE 201-1 and only in the $88 \mathrm{Mwt}$ set, it could also be a nonstationary occurrence and not truly indicative of average characteristics.

Reference 12 uses calculated and measured values for lag times at various points in the loop. This reference lists the measured time lag for a temperature transient to reach TE 201-1 after a scram as 10 seconds for 2 -loop operation. Heuristically, this value seems more reasonable than the 30 seconds indicated by noise measurements. The total loop time calculated in this reference using the measured 10-second lag for the upper plenum is 34 seconds. This suggests the possibility that the lag measured is really the total loop time rather than upper plenum lag time; however, pulse experiments 13 under 3-loop conditions measured a lag between power and TE 201-1 of 30 seconds which supports the noise analysis results. Thus, we have an inconsistancy between measurements which will probably require additional data to resolve.

\section{E. COHERENCE FUNCTIONS}

Coherence functions are a measure of the amount of extraneous signal present while determining the transfer function of a parameter through a system. As such, they are a measure of the signal-to-noise ratio and are an indication of the quality of the data; however, they arealso a measure of relative importance of various inputs on an output.

The coherence functions averaged over broad frequency regions are listed in Table VIII for all computed cross correlations. The results are listed in order of decreasing coherence of the low frequency regions. It is interesting to note the relative position of some of these functions. 
TABLE VIII - COHERENCE FUNCTIONS

$\underline{\text { Rank }}$

1. Power of $0.05 \mathrm{Mwt}$

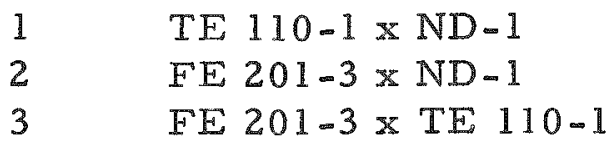

2. Power of $56 \mathrm{Mwt}$

\begin{tabular}{|c|c|}
\hline 1 & $N D-1 \times N D-2$ \\
\hline 2 & ND-1 $\times$ TE $115-26$ \\
\hline 3 & $\mathrm{TE} 110-1 \times \mathrm{ND}-1$ \\
\hline 4 & FE 201-1 $x$ TE 115-26 \\
\hline 5 & TE $110-1 \times$ ND-2 \\
\hline 6 & TE $110-1 \times$ TE $115-26$ \\
\hline 7 & $\mathrm{FE} 201-1 \times \mathrm{ND}-1$ \\
\hline 8 & FE 201-1 $\times$ ND-2 \\
\hline 9 & ND-2 $x$ TE 217-1 \\
\hline 10 & $N D-1 \times$ TE $217-1$ \\
\hline 11 & TE 115-26 x TE 217-1 \\
\hline 12 & FE 201-1 x TE $110-1$ \\
\hline
\end{tabular}

0.006 to $0.0344 \mathrm{~Hz} \quad 0.041$ to $0.131 \mathrm{~Hz}$
0.761
0.393
0.218
0.065
0.197
0.057
0.193
0.032
0.151
0.044
0.114
0.040
0.099
0.052
0.080
0.059
0.072
0.039
0.065
0.053
0.046
0.031
0.046
0.030

3. Power of $88 \mathrm{Mwt}$

\begin{tabular}{|c|c|}
\hline 1 & $\mathrm{ND}-1 \times \mathrm{ND}-2$ \\
\hline 2 & TE $110-1 \times N D-1$ \\
\hline 3 & TE $110-1 \times N D-2$ \\
\hline 4 & ND-1 x TE 201-1 \\
\hline 5 & FE 201-3 X TE 201-1 \\
\hline 6 & FE 201-3 x ND-1 \\
\hline 7 & $N D-2 \times T E 201-1$ \\
\hline 8 & TE 110-1 x TE 201-1 \\
\hline 9 & FE 201-3 x TE 110-1 \\
\hline
\end{tabular}

0.003 to $0.017 \mathrm{~Hz} \quad 0.020$ to $0.066 \mathrm{~Hz}$
0.844
0.495
0.185
0.082
0.137
0.038
0.055
0.046
0.055
0.045
0.047
0.027
0.044
0.047
0.040
0.041
0.034
0.034 
The greatest coherence is between the two neutron detectors, as would be expected. In all three data sets, the flow-inlet temperature coherence functions are at the bottom of the list. This is quite encouraging, in that it indicates that the two major sources of reactor noise are nearly independent, which simplifies analysis and improves accuracy of results.

The lists show that inlet temperature influences reactor power more than flow but that flow influences reactor outlet temperature more than inlet temperature. (It should be remembered that this is the flow in one loop only; if the total flow had been recorded, the rank of some of these parameters probably would be changed.)

The only real surprise in the lists is the very low rank of the outlet temperatures of the reactor outlet plenum (eleventh in the $56 \mathrm{Mwt}$ data set), but this is in agreement with the conclusion drawn during the discussion of their transfer function - that TE $115-26$ must contain a large extraneous noise component.

\section{F. ESTIMA TION OF ERRORS ON XSD FUNCTIONS}

Section III. E. 3 gave equations for computation of errors of PSD and XSD functions. The PSD functions in this report were all computed from 1000 data points with a maximum lag of 50 points. Using the given equation, the error on PSD estimates is $5 \%$. The error on PSD is not a function of irequency.

The errors of XSD functions have been computed for a number of cases and are tabulated in Table IX. Since the error in XSD is frequency dependent, the average error was computed over two broad frequency bands for each case.

The errors on the transfer functions will be less than the $20 \%$ indicated by the XSD errors, since the transfer functions are calculated from smoothed data. Since the smoothing operation is not a precise mathematical procedure, no precise value can be placed on the transfer function error. Intrinsically, the error is estimated to be around $10 \%$ on the magnitude and at least 20 degrees on phase. 
TABLE IX - ESTIMATION OF ERRORS ON XSD FUNCTIONS

Estimated Errors

\section{Power Cross Spectral Density}

$0.05 \mathrm{Mwt}$

TE $110-1$ to $\mathrm{ND}-1$

FE 201-3 to ND-1

$56 \mathrm{Mwt}$

$$
\begin{aligned}
& \text { ND-1 to ND-2 } \\
& \text { ND- } 1 \text { to TE } 115-26 \\
& \text { TE } 110-1 \text { to } N D-1
\end{aligned}
$$

FE 201-1 to TE 115-26

TE 110-1 to TE 115-26

FE 201-1 to ND-1

FE 115-26 to TE 217-1

$88 \mathrm{Mwt}$

TE 110-1 to ND-1

ND-1 to TE 201-1

FE 201-3 to ND-1
0.006 to $0.0344 \mathrm{~Hz}$

4
15
21

35

43

55

50

0.003 to $0.017 \mathrm{~Hz}$

8

30

27

2

21

9

18
0.041 to $0.131 \mathrm{~Hz}$

$\begin{array}{rr}15 & 7 \\ 100 & 17 \\ 90 & 20\end{array}$

$64 \quad 23$

$60 \quad 25$

100

7

$8 \quad 80 \quad 9$
0.020 to $0.066 \mathrm{~Hz}$

50

14

32

18

54

25 
.

0 


\section{CONCLUSIONS}

Before summarizing the findings, it should be re-emphasized that specific results reported here are based upon a single data set taken from each of three power levels; many of the findings may be unique to that data set, and not illustrative of the general situation. The basic objective of this work was exploratory in nature; however, the real purpose of the undertaking was to demonstrate the potential of a detailed study on the noise in the Enrico Fermi reactor system.

This work indicates that through noise analysis the stability of a system can be ascertained and basic phenomena of the plant measured, including type of flow in the plenum, lag times, in situ response characteristics of instrumentation, extraneous noise levels in instrumentation, and relative importance of components affecting a system.

The results of upper plenum temperature transfer functions point out that the first step for performing a detailed study of the upper plenum must be improvement in the determination of the temperature spectrum of sodium leaving the core. Recordings should be made of total flow and TE 110-2. In the work reported here, TE $115-26$ appeared to have an extraneous noise source. To improve the reliability of reactor outlet data, several reactor outlet thermocouples will have to be electronically combined to improve the signal-to-noise ratio.

The failure of temperature transfer functions to approach unity at low frequencies should be investigated in future work. The first step must be improved initial calibration procedures and more careful maintainance of calibration as data are transferred to computer input media.

The apparent success of the lag measurements using phase calculations points out an independent method for determining sodium flow rates, provided that appropriate thermocouples can be found.

The specific results from these measurements are

1. A small resonance is present around $0.035 \mathrm{~Hz}$ under $56 \mathrm{Mwt} 2$ loop operation. Since this did not appear in either 3-loop data sets, it is a possible indication of a flow or mechanical resonance under 2 -loop operation

2. The reactivity transfer function cannot be measured through fluctuations of reactor inlet temperature, probably due to change 
of temperature spectrum as sodium flows through lower axial blanket

3. The computation of core outlet temperature spectrum from core power spectrum indicates flow noise is the major contributor to power noise

4. Thermocouples appeared to have response times near their rated values

5. The spectral density of core power indicates flow noise is decreased going from 2-loop to 3-loop operation

6. The very long time lags and small time constants between reactor parameters and upper plenum outlet temperature indicate a nonmixing flow in the upper plenum with some channeling at 2-loop operation but no channeling at 3-loop operation. 


\section{REFERENCES}

1. "Enrico Fermi Hazards Summary Report and Technical Information," Volumes 1-7, as revised, Power Reactor Development Company, 1964.

2. Thie, J. A., Reactor Noise, p. 65, Rowman and Littlefield, New York, New York, 1963.

3. Bendat, J. S., and Pierson, A. G., Measurement and Analysis of Random Data, p. 208, John Wiley and Sons, New York, New York, 1966.

4. Ibid., p. 203.

5. Ibid., Section 5.7.5.

6. Thie, J. A., op. cit., p. 173.

7. BMD, Biomedical Computer Program, Health Physics Computing Facility, Department of Preventive Medicine and Public Health, School of Medicine, University of California, Los Angeles, edited by W. J. Dixon, revised September 1, 1965.

8. Klickman, A. E., Horne, R. E., and Wilber, H. A., "Oscillator Tests in the Enrico Fermi Reactor," APDA-NTS-11, August, 1967.

9. Ibid.

10. Herd, G. F., "Time Response Tests for an $L$ \& $N$ Resistance Thermometer," APDA-TM-8, November 4, 1959.

11. Schultz, M. A., Control of Nuclear Reactors and Power Plants, McGraw-Hill, New York, 1961 .

12. Peters, N. T., "Delayed Neutron Failed Fuel Detector," APDA Internal Memorandum S-67-305, September 6, 1967.

13. Batch, M. L., and Klickman, A. E., "Transfer Function from Reactivity Pulses Generated by the Regulating Rod - Enrico Fermi Reactor,", APDA-NTS-14, December 1967. 
. 
APPENDIX A: DERIVATION OF EQUATIONS OF PHASE SHIFTS DUE TO TIME DISPLACEMENT BETWEEN PARAMETERS

\section{A. INTRODUCTION}

The transport of temperature information around a system causes a time displacement or time lag from one point to another. This time lag manifests itself as additional terms in the phase relationship between the two points.

Equations have been developed for these additional terms for cases of a single time lag and of two time lags.

B. SINGLE TIME LAG

Consider a "black box" which has a transfer function. If the input contains a term $I(f) \sin 2 \pi f t$, the output will contain a term $O(f) \sin (2 \pi f t+$ $\phi(f))$ where $\phi(f)$ is the phase shift. Now, if in addition we add a delay in the box such that the output information does not appear until a time $T$ later, the output becomes

$$
a 0(f) \sin (2 \pi f(t+T)+\phi(f)) \text {. }
$$

The phase shift measured in transfer functions is the difference between the arguments of the sine term. In the first case this difference is $-\phi(f)$; in the second case, the difference is $-(2 \pi f T+\phi(f))$. Thus a time lag $T$ between two signals introduces an additional term $2 \pi f T$ in their phase relationship.

\section{DOUBLE TIME LAG}

For the double time lag, the input is assumed to split into two streams of unequal length such that the output from the first stream is a $0(f) \sin \left(2 \pi f\left(t+T_{1}\right)+\phi(f)\right)$ and the output of the second stream is b0 (f) $\sin \left(2 \pi f\left(t+T_{2}\right)+\phi(f)\right)$. The net output of the system, $0(f)$, is the vector sum of these components. The development of the equation for the net phase is an exercise in trigonometry. Figure Al illustrates how the vector components were combined to yield the following equation:

$$
\text { Phase }=-\left(\phi(f)+2 \pi f T_{1}+\arctan \frac{\sin 2 \pi f\left(T_{2}-T_{1}\right)}{a / b+\cos 2 \pi f\left(T_{2}-T_{1}\right)}\right)
$$




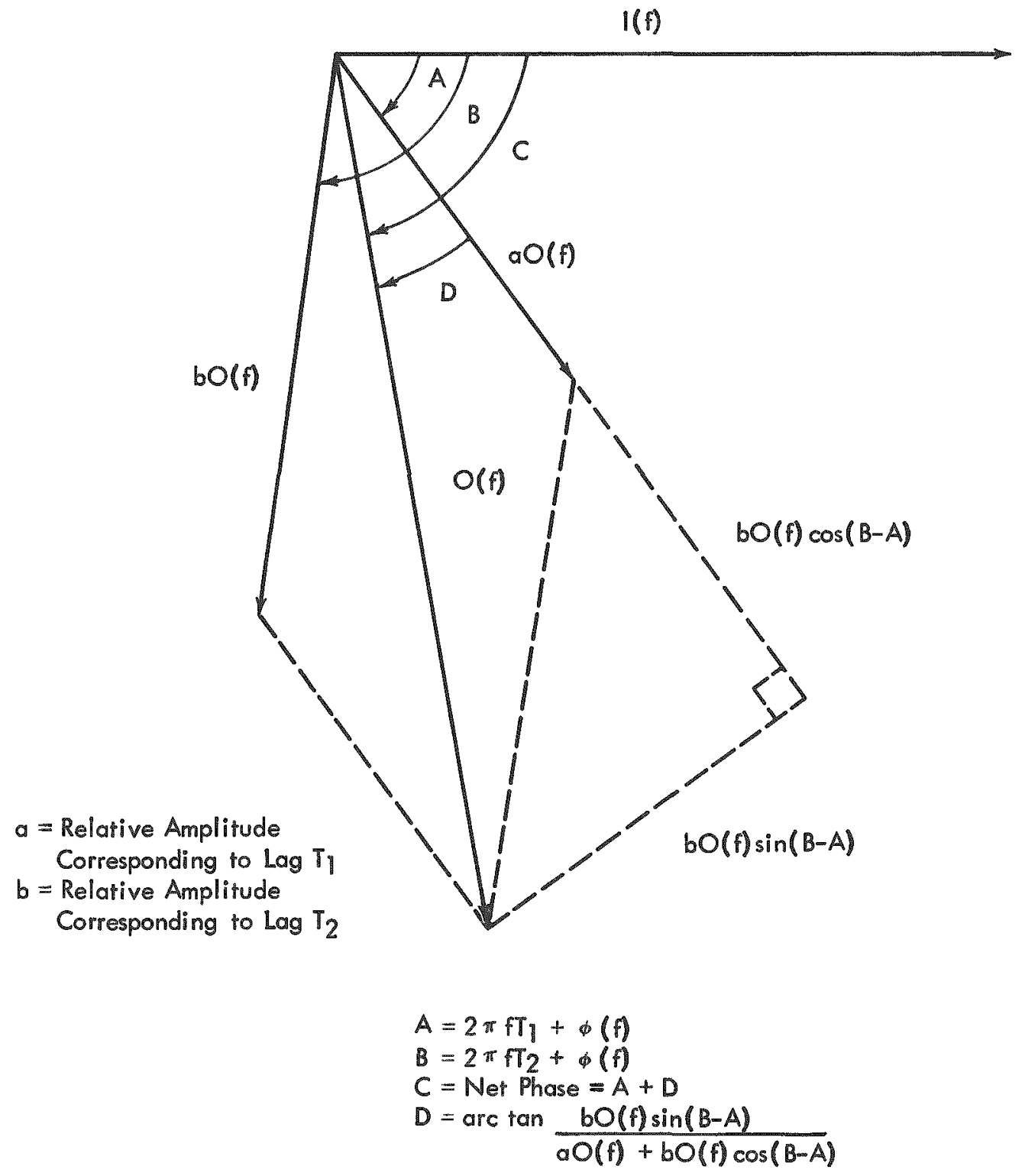

Net Phase $=\phi(f)+2 \pi f T_{1}+\arctan \sin 2 \pi f\left(T_{2}-T_{1}\right)$

$\frac{\sin 2 \pi f\left(T_{2}-1\right)}{\operatorname{dos} 2 \pi f\left(T_{2}-T_{1}\right)}$

FIG. A.1 DEVELOPMENT OF NET PHASE SHIFT FOR TWO,TRANSPORT LAGS 
Thus, the second lag adds a third term to the phase equation. A brief study of this equation was undertaken with $\phi(f)$ equal to zero and is illustrated in Figure A.2. The study shows the phase curve will have a general slope of $2 \pi f T_{1}$ where $T_{1}$ is the lag with the larger amplitude. About this linear slope, the function oscillates. The amplitude of the oscillation is a function of the relative magnitude of the second lag. The period of this oscillation $f_{p}$ is the reciprocal of the absolute difference between the two lag times. If the first half-cycle of the oscillation is positive, $T_{2}$ exceeds $T_{1}$ by the difference; if negative, $T_{2}$ is less than $\mathrm{T}_{1}$ by the difference. 


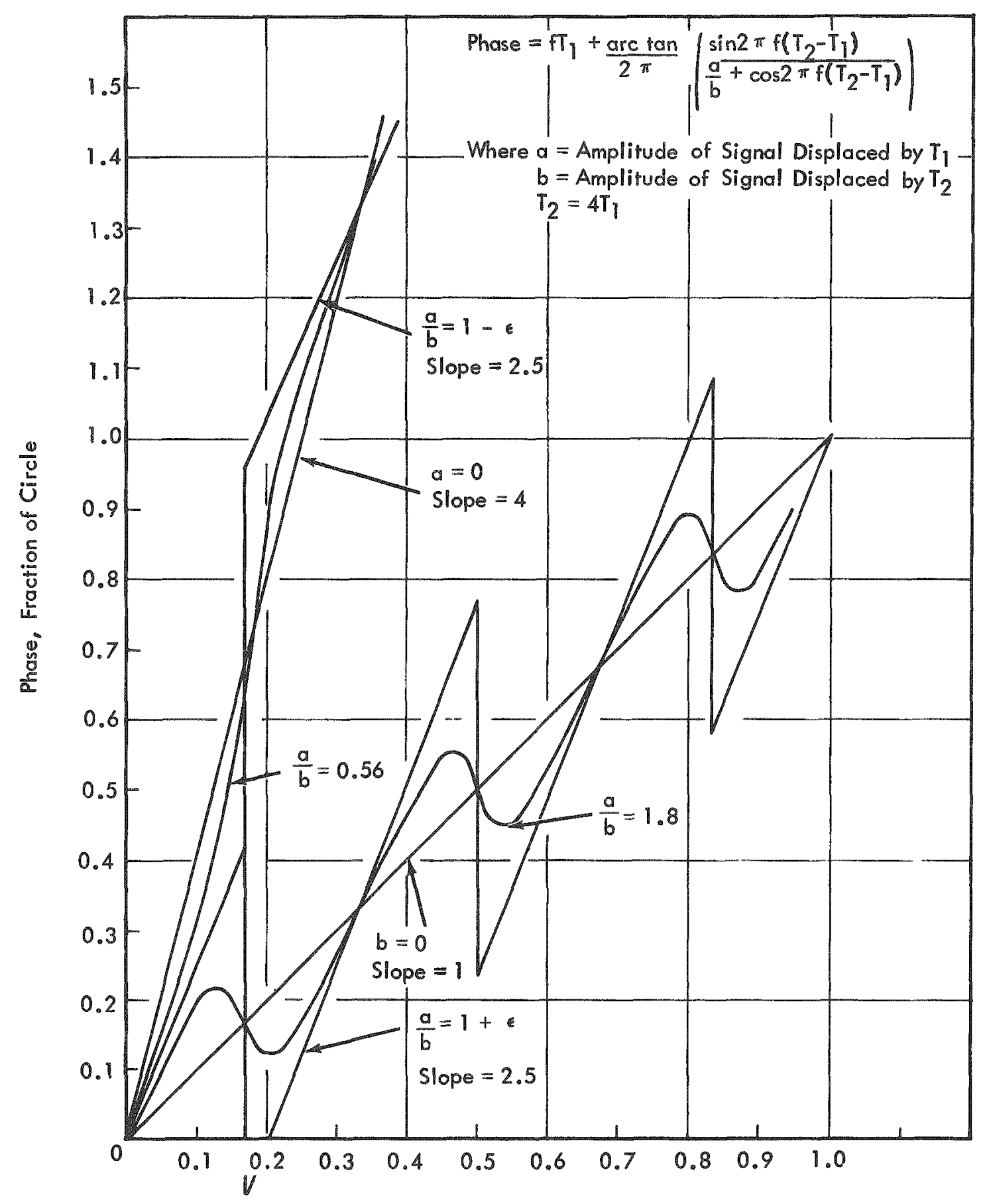

$\mathrm{fT}_{1}$

FIG. A.2 STUDY OF PHASE FUNCTION WITH TWO TRANSPORT LAGS 


\section{APPENDIX B: DETERMINATION OF CORE OUTLET TEMPERATURE SPECTRUM}

The parameter most strongly affecting upper plenum temperatures is the temperature of coolant leaving the core. (The reader is reminded of the difference in this report between the terms "core" and "reactor".) Therefore, to understand the upper plenum behavior, it is essential to know the spectrum of temperature of the coolant leaving the core. Since this is not measured directly, an attempt was made to establish this spectrum by using the measured reactor power spectrum, the reactivity transfer function and certain physical constants of sodium.

The development of core outlet temperature spectrum from the power spectrum requires the following assumptions:

- The value of the temperature coefficient is independent of frequency

- The thermal time constant of the core is less than the shortest period included in spectrum measurements

- The reactivity of the core is a function only of its average coolant temperature.

Note that these need be reasonable only over the frequency range of meas urement: 0.006 to 0.15 Hertz.

The power spectral density of core outlet temperature is considered as made up of two terms - (1) the PSD of inlet temperature, and (2) the PSD of the sodium increase in temperature as it passes through the core:

$$
\operatorname{PSD}_{f}\left(T_{\text {out }}\right)=\operatorname{PSD}_{f}\left(T_{\text {in }}\right)+\operatorname{PSD}_{f}(\Delta T)
$$

The PSD of core $\triangle T$ can be obtained directly from the PSD of core power $P$ and the PSD of flow $W$ :

$$
\operatorname{PSD}_{f}(\Delta T)=\operatorname{PSD}_{f}(P)\left(\frac{\partial \Delta T}{\partial P}\right)^{2}+\operatorname{PSD}_{f}(W)\left(\frac{\partial \Delta T}{\partial W}\right)^{2}
$$

The two partial derivatives are readily evaluated from

$$
\Delta T=P / W H
$$


where $H$ is the specific heat of sodium in units of $\mathrm{Mw} \mathrm{hr/lb} \mathrm{F}$. Equation (B. I) thus becomes

$$
\operatorname{PSD}_{f}(\Delta T)=\frac{\operatorname{PSD}_{f}(\mathrm{P})}{W^{2} H^{2}}+\frac{\operatorname{PSD}_{f}(W) P^{2}}{W^{4} H^{2}}
$$

The PSD of core inlet temperature will be derived from the PSD of core power and the PSD of core $\triangle T$. The development is built around computing the PSD of average core temperature by two methods and algebraically combining these to attain the PSD of core inlet temperature. The first method states that the PSD of average core coolant temperature is the sum of the PSD of core inlet temperature and one fourth (one half squared) the PSD of core $\triangle T$ :

$$
\operatorname{PSD}_{\mathrm{f}}(\overline{\mathrm{T}})=\operatorname{PSD}_{\mathfrak{f}}\left(\mathrm{T}_{\mathrm{in}}\right)+1 / 4 \operatorname{PSD}_{\mathrm{f}}(\Delta \mathrm{T})
$$

The $\operatorname{PSD}_{f}(\Delta T)$ is derived above. The second method computes $\operatorname{PSD}_{f}(\bar{T})$ directly from the $\mathrm{PSD}_{\mathrm{f}}(\mathrm{P})$ through the three approximations stated above by

$$
\operatorname{PSD}_{f}(\bar{T})=\frac{\operatorname{PSD}_{f}(P)}{P^{2} \times\left(\rho T F_{f}\right)^{-2} \times(T C)^{-2}}
$$

where $\rho T F_{f}=$ reactivity transfer function at frequency $f$ measured by oscillator techniques

$\mathrm{TC}=$ temperature coefficient

The equations combine to give

$$
\operatorname{PSD}\left(T_{\text {out }}\right)=\operatorname{PSD}(\mathrm{P})\left(\frac{0.75}{W^{2} \mathrm{H}^{2}}+\frac{(\rho \mathrm{TF})^{2}(\mathrm{TC})^{2}}{\mathrm{P}^{2}}\right)+\frac{0.75 \mathrm{PSD}_{\mathrm{f}}(\mathrm{W}) \mathrm{P}^{2}}{W^{4} \mathrm{H}^{2}}
$$

Rewriting in a slightly different form

$$
\operatorname{PSD}\left(T_{\text {out }}\right)=\operatorname{PSD}(P)\left(\frac{0.75}{W^{2} H^{2}}+\frac{(P T F)^{2}(T C)^{2}}{P^{2}}+\frac{0.75 P^{2}}{W^{4} H^{2}} \cdot \frac{\operatorname{PSD}_{f}(W)}{\operatorname{PSD}_{f}(P)}\right)(B .2)
$$

Note that the third term is scaler and the entixe factor in brackets can be considered a frequency-dependent gain factor. This equation is analogous to a system which has reactor power as the input and reactor outlet temper ature as the output; the bracket is the square of the system transfer function. Thus, transfer functions measured between reactor power and other parameters can be converted to core outlet temperature and these parameters by applying the square root of the bracketed factor. For convenience, the symbol P2T will be used for the square root of the bracketed factor. 
To calculate P2T, each of its terms must be in the same units of course. To achieve this in the third term, an attempt must be made to calibrate $\mathrm{PSD}_{\mathfrak{f}}(W)$, even though the signal was recorded with no calibration. The integral of $\operatorname{PSD}_{f}(W)$ over frequency is the total noise; this integral was computed for the data and set equal to the true amplitude of the total noise which can be estimated from observations on recorders. (This noise is approximately $4.5 \%$ of the loop-3 flow and $1.5 \%$ of the loop-1 and $100 \mathrm{p}-2$ flows.) These combine to give a flow noise of $2 \%$ of the total flow for the $88 \mathrm{Mwt} \mathrm{3-loop} \mathrm{run} \mathrm{and} 1.5 \%$ of the total flow for the $56 \mathrm{Mwt} 2$-loop (No. 1 and 2) run. This calculation gives $1.46 \times 10^{10}$ for the $88 \mathrm{Mwt}$ run and $1.1 \times 10^{10}$ for the $56 \mathrm{Mwt}$ run as the factors to be applied on $\operatorname{PSD}_{\mathrm{f}}(W)$ for calibration in units of $(\mathrm{lb} / \mathrm{hr})^{2} / \mathrm{Hz}$.

Values for P2T were calculated for seven frequencies from both the $88 \mathrm{Mwt}$ and $56 \mathrm{Mwt}$ data sets and are tabulated in Table VI.

The first two terms in brackets of Equation (B.2) are functions of the reactor power spectrum and the third term is a function of coolant flow spectrum. The third term varies from 1.2 times (at $0.005 \mathrm{~Hz}$ ) to 15 times (at $0.07 \mathrm{~Hz}$ ) greater than the sum of the first two. From this, it can be concluded that the most important parameter affecting the noise level of coolant temperature leaving the core is coolant flow variation.

The above conclusions also indicate that to obtain better information on the behavior of the upper plenum, data should be recorded of the total flow noise, i.e., the sum of the three flow meters. 